\title{
The prescription drug history in pharmacoepidemiology
}

Citation for published version (APA):

Petri, J. L. (1992). The prescription drug history in pharmacoepidemiology. [Doctoral Thesis, Maastricht University]. Datawyse / Universitaire Pers Maastricht. https://doi.org/10.26481/dis.19920611.jp

Document status and date:

Published: 01/01/1992

DOI:

10.26481/dis.19920611.jp

Document Version:

Publisher's PDF, also known as Version of record

\section{Please check the document version of this publication:}

- A submitted manuscript is the version of the article upon submission and before peer-review. There can be important differences between the submitted version and the official published version of record.

People interested in the research are advised to contact the author for the final version of the publication, or visit the DOI to the publisher's website.

- The final author version and the galley proof are versions of the publication after peer review.

- The final published version features the final layout of the paper including the volume, issue and page numbers.

Link to publication

\footnotetext{
General rights rights.

- You may freely distribute the URL identifying the publication in the public portal. please follow below link for the End User Agreement:

www.umlib.nl/taverne-license

Take down policy

If you believe that this document breaches copyright please contact us at:

repository@maastrichtuniversity.nl

providing details and we will investigate your claim.
}

Copyright and moral rights for the publications made accessible in the public portal are retained by the authors and/or other copyright owners and it is a condition of accessing publications that users recognise and abide by the legal requirements associated with these

- Users may download and print one copy of any publication from the public portal for the purpose of private study or research.

- You may not further distribute the material or use it for any profit-making activity or commercial gain

If the publication is distributed under the terms of Article $25 \mathrm{fa}$ of the Dutch Copyright Act, indicated by the "Taverne" license above, 
THE PRESCRIPTION DRUG HISTORY

IN PHARMACOEPIDEMIOLOGY 



\section{THE PRESCRIPTION DRUG HISTORY}

\section{IN PHARMACOEPIDEMIOLOGY}

\section{PROEFSCHRIFT}

ter verkrijging van de graad van doctor

aan de Rijksuniversiteit Limburg te Maastricht, op gezag van de Rector Magnificus, Prof. Mr. M.J. Cohen, volgens het besluit van het College van Dekanen, in het openbaar te verdedigen op donderdag, 11 juni 1992 om 16.00 uur

door

Johannes Laurens Petrì 
Promotores:

Beoordelingscommissie:
Prof. ar. F. Sturmans

Prof. dr. I. Urquhart

Prof. dr. H.A.J. Struijker Boudier, RL (voorzitter)

Prof. dr. A. Bakker, RU Utrecht

Prof. dr, ir. A. Hasman, RL

Prof. dr. J.A. Knotmenus, RL

Dr. B.H.Ch. Stricker, Ministerie WVC

CIPGEGEVENS KONINKLIME BMBLOTHEEK. DEN HAAG

Pettri, Johanancs Laurens

The prescriplion angy history in phimatopldemiology/

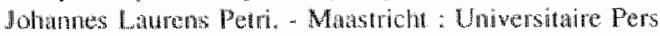

Mandriohl. - Hi!.

Thesis Magstricht. - With ref. - With sumbarty in Dutch.

$15 B N 30-5278-017-X$

NUG176/3:

Subject hendings: drug utiliation ; eptadenology /

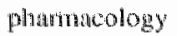

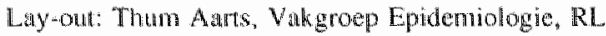

Produktie: Dutawyse Mastricht

In de drukkosten van dit proesschrift is bijgedragen door de firma ${ }^{2} \mathrm{~S}$ Janssen, Duphar, Boehringer Ingetheim, Pfizer on Hoechst in Nederland. 


\section{CONTENTS}

1. Introduction; structure of this thesis i

2. Epidemiology and drugs: background of the work 3

3. Pharmacy data in the estimation of drug use in populations 11

4a. Prescription sequence analysis: a new and fast method to ascertain adverse reactions to prescription drugs in large populations

4b. Rapid method for estimating the risk of acutely controversial side effects of prescription drugs

5. Markers of adverse drug reactions in medication histories: an analysis of inhaled steroid utilization

6. Channeling bias in the interpretation of drug effects

7. Characteristics of patients prescribed three different inhalational beta- 2 agonists: an example of the channeling phenomenon

8. Channeling of specific antidepressant drugs to patients with cardiovascular conditions

9. Do patients' prescribed drugs always follow them to hospital?

10. Comparison of questionnaire information and pharmacy data on drug use

11. Epilogue

Summary

Samenvatting

Publications

Dankwoord 
$\ldots$ 


\section{ABBREVATIONS}

ACE angiotensin-converting emzyme

ATC anatomic-therapeutic-chemical

$\mathrm{ADR}$ adverse drug reaction

CI confidence interval

DDD defined daily dose

MAO monoamine-oxidase

MEMS medical event monitoring system

NZAMS New Zealand Asthma Mortality Study

OTC over-the counter

PSA prescription sequence analysis

TCA tricyclic antidepressant

WHO World Health Organization 



\section{Chapter 1}

\section{INTRODUCTION}

After introduction of a new drug for general medical use it is often not well known how the drug is used, by whom, and what its effects are in the group of users. Development and registration of a new drug occurs in a more or less standardized stepwise process, but what happens after market introduction is often known only in a fragmentary way. Questions remain about the reasons the drug is actually used for, what kind of people get the drug and what are the benefits and hazards of using the drug for these patients.

Pharmacoepidemiology seeks to answer these questions. Knowledge in this field has implications for pharmacotherapy in individual patients: expected benefits from use of a drug should be set against potential side-effects. Knowledge of these intended and unintended effects in the heterogeneous group of users in the population at large can only come from observational studies.

The adoption of a new medicine by prescribing physicians and its use in specific groups of patients depend on the perceived characteristics of the drug, marketing forces, and the availability of other drugs with a similar therapeutic indication. Effects of drugs can be expected to vary between groups of users with different age distribution, disease stage, or co-morbidity. Without specifically directed research, little is known about these differences. Also, the use of a drug has a time component: it is initiated and stopped at a certain time and may be followed by other therapy. These consumption patterns are usually not known at population level. Recognizing that the prescription drug history is an essential tool in pharmacoepidemiology we focussed out work on developing methods to collect, analyze and interpret such drug histories.

\section{STRUCTURE OF THIS THESIS}

The studies presented have a specific source of information on drug consumption in common: automated records in Dutch community pharmacies. An introductory chapter gives an overview of approaches in epidemiology to study drug use and drug effects, as far as they are relevant for this thesis (Chapter 2); the text is partly based on two earlier publications. ${ }^{1,2}$ Chapter 3 describes the various ways with which data on drug use can be collected, with emphasis on automated records in Dutch pharmacies. The main purpose of this thesis is to show three ways in which such records are useful in pharmacoepidemiology:

1) The analysis of collections of drug histories to look for patierns of dispensing that are suggestive of prescribing to counter side effects of another drug. (Prescription Sequence Analysis).

The approach is intended as a fast screening method when there is an urgent need for more information about the reality of possible side-effects after case reports; the approach is restricted to the subgroup of adverse reactions for which a specific medical therapy exists. Analyses are presented of drug histories of persons who received the anti-vertigo/anti-migraine drug flunarizine (chapter 4 ) and inhalational anti-asthmatic steroids (chapter 5).

2) The detection of differences of recipients of pharmacologically closely related drugs (channeling).

Concomitantly prescribed medication can point to differences in disease severity. Higher dosages of treatment and drugs intended for more severe stages of a disease are especially suggestive of such differences. More severe medical problems can be expected to be seen in patients with markers of more severe or difficult-to-treat disease. 
This "channeling" can occur as selective prescribing due to differences in drug labelling, but also as a consequence of less obvious factors, such as time of market introduction, the availability of other drugs, and promotional activities. Channeling and its consequences are discussed in chapter 6 . A comparison of users of three pharmacologically related asthma drugs for markers of disease severity is presented in chapter 7 . In chapter 8 , users of ten antidepressant drugs are compared for differences in prevalence of cardiovascular conditions.

3) The study of drug use before and after hospital admission.

Cessation of therapy at hospital admission may or may be not have been purposeful. The juxtaposition of drug histories from community and hospital pharmacies reveals such cessations of therapy. Chapter 9 presents the results of such a comparison. The comparison is completed with a study of medical files in the hospital to assess whether the stopping was inadvertent or purposeful.

In order to assess the quality of drug histories from pharmacy data bases we compared results from a patient questionnaire with pharmacy data on drug use. In chapter 10 the results of this comparison are presented.

An epilogue, chapter 11, gives an overview of the work and the ideas presented in thesis, with some of their implications. Also, suggestions for work in the future are made.

There is some repetition in the description of methods in chapters 4-10, due to the fact that the material has been published in the form of articles. An advantage should be that these chapters can be read separately.

\section{References}

1. Petri $H_{3}$ Sturmans $F$. Data linkage and intervention" a perspective. In: Muller NF, Hekster YA. (cds.) Progress in clinical pharmacy: rational use of drugs. Noordwijk: Amsterdam Medical Press,
1989

2. Petri H, de Vet HCW, Sturmans F. Farmaco-epideniologie: een retrospechieve bijdrage an valigheid? [Pharmacoepidemiology: a retrospective contribution to safety?] Pharm Weekbl 1987 .
122 : 14.5.149 


\section{Chapter 2}

\section{EPIDEMIOLOGY AND DRUGS: BACKGROUND OF THE WORK}

Before a drug is registered for general use, its benefits and degree of safety must be shown in one or more controlled clinical trials. Clinical trials to test for therapeutic. effect of a drug rarely cower more than 3000 patients. Yet, severe adverse reactions with a low incidence, between 1 in 5000 and 1 in 30,000 users, have forced withdrawal of drugs. Detection of a much more common adverse reaction needs a large clinical trial if the condition has a sizeable background incidence (table 1). Apart from being very costly and impractical, studies to determine the incidence of serious adverse reactions would take a prohibitively long time to perform. Thus, one can say that methods other than controlled clinical trials are needed for the assessment of rare adverse drug reactions.

Also, controlled trials often include a rather limited diversity of patients. After introduction for general use, the drug may be prescribed for a more vulnerable group of patients with other concomitant conditions and other medication. Also, the indications for prescribing the drug may change in time, in the direction to conditions not included in premarket studies. Further, groups of patients kept out of trials because of exclusion criteria, e.g. pregnancy, may become exposed to the drug after market introduction. Thus, while homogeneity of a trial population makes the interpretation of the results of a study more straightforward, it may flaw the relevance of the trial for the more heterogeneous population of actual users of the drug.

Complementary to controlled clinical trials are studies in existing populations of users of drugs. In population-based studies of drug use and drug effects, epidemiological methods have an obvious place. Epidemiology is mainly concerned with such factors as the determinants, occurrence, and prognosis of disease in different groups of people. Drug use, both as a consequence and a determinant of disease, thus is a valid subject for population-directed study methods. Pharmacology and epidemiology also are linked by subjects other than rare adverse reactions, e.g. the study of initially unrecognized beneficial effects, many of which are recognized only after years of general use. $1-3$.

The approaches to study an adverse reaction to a specific drug depend on both frequency of use of the drug concerned and the incidence of the ADR in a group of users (tables 2 and 3 ). In a methodological sense table 2 gives a hierarchy of the strength of evidence that can be prowided by the different approaches, with the controlled clinical trial at top and case reports on the bottom. The choice of the approach to study a specific problem is a trade-off beween feasibility and the strength of evidence that can be achieved.

\section{Case reports}

First reports of adverse reactions are often published in medical journals as case reports or case series. Case reports have proven their value especially in the early recognition of possible adverse reactions; historically, initial alerting has almost always occurred by publication of case reports. . $^{4-7}$

In a more systematic way, case reports are collected and analyzed in a regional ${ }^{89}$ or nationa 7.10 setting. The approach was initiated in Britain after the thalidomide catastrophe in the early 1960s. In this approach, physicians are encouraged to report on a standard form the adverse reactions they recognized. The background idea is that a set of reports of a suspected adverse reaction, submitted independently by many physicians, are stronger evidence than isolated reports. The quality and plausibility of the reports are assessed by the staff of the centers. If questions arise, contact is sought 
with the reporting physician. Reports are mostly based on the relative frequency of reports on a problem with one drug as compared with other dnus with a similar indication. Publication often occurs in a collaboration of several national monitoring. centers, sometimes with data of an international registry under the aegis of the W. H.O. 10,11

Table 1 . Size of clinical trial needed to detect an adverse drugy reaction (ADR)*

Rate of ADR

in control group

$\begin{array}{ll}\mathbb{N}^{* *} & N^{* *} \\ \text { control group } & \text { exposed group }\end{array}$

3,000

16,000

3,000

16,000

1: 100

$1: 500$

* based on a significance level a of .05 , a power of .90 and a relative risk of 2 .

* number of persons needed

Table 2. Approaches to study adverse drug reactions

\section{Controlled clinical trial}

- Cohort study

- Case-conirol study

- Case series

- Case reports

Table 3. Preference of approach for the stwly of adverse drug reactions

$\begin{array}{lll}\text { Use of drugg: } & \text { Adwerse reaction } & \text { frequent } \\ \text { rare } & \text { case reports } & \text { colhort study } \\ \text { frequent } & \begin{array}{l}\text { case-control } \\ \text { study }\end{array} & \begin{array}{l}\text { cohort-or case- } \\ \text { control study }\end{array}\end{array}$

\section{Case-control and cohort studies}

Compared to the collection of case reports, case-control and cohort studies provide a stronger kind of evidence on the relation between drug use and outcomes. 
In pharmacoepidemiology, cohort studies generally are more drug-oriented than case-control studies. In a cohort study, a group of persons that uses a certain drug is followed and the subsequent occurrence of conditions is monitored. Thus, the cohort is defined on basis of exposure to the drug under investigation. The outcome is compared with that of a reference group not using the drug.

An example of a large cohort study from the past is the study of consequences of use of oral contraceptives by the British Royal College of General Practitioners. ${ }^{12}$ Typically for cohort studies, it was initiated after the publication of case reports and case-control studies ${ }^{13,14}$ that suggested the existence of detrimental effects from this class of drugs.

A specific type of cohort study in the field of pharmacoepidemiology is Prescription Event Monitoring. ${ }^{15,16}$ In this monitoring system, copies of prescriptions for specific drugs are collected via the prescription pricing authority in Britain. Prescribers thus identified are asked to provide information on all medical events before, during, and after use of the drug by the patient for whom the drug under investigation was prescribed. Up to 40,000 users of a drug are covered in this way, ${ }^{17}$ i.e. much more than in clinical trials.

In a case-control study, the primary selection criterion is the presence of a specific condition. Drug use and other determinants are ascertained after selection of the case and control groups. If several other determinants, in addition to a specific drug are thought to be relevant for the disease, this approach will be more efficient than a cohort study. The case-control approach has been used on a relatively large scale in studies on adverse drug effects. Sometimes case-control studies have been definitive, even when they were rather small. The classic study on the relation of adenocarcinoma of the vagina with exposure in utero to diethylstilbestrol consisted of 8 cases and 40 controls. While the case-control studies generally take less time and effort to conduct than cohort studies they are more subject to biases, as will be discussed in the second half of this chapter.

Finally the "nested case-control" approach tries to combine the strength of cohort approach with the efficiency of case-control studies. In a defined population with registered exposure, controls are sampled at random. The control patients thus are sampled in the population from which the cases originated. Automated databases, with a limited array of information but covering defined large groups of patients, may be the framework to do more of such studies in the future.

\section{Choice of approach}

Frequent side-effects of drugs generally will by detected by pre-registration clinical trials. However, they may be overlooked when the symptoms are common in the general population. In order to detect an increased incidence of these common symptoms, questionnaires may be used in the different treatment groups. Clinical trials are not suitable to study more rare drug reactions, as the numbers needed would be too large. Table 1 shows that a very large trial would be needed if a reaction also occurs in the control group of persons who do not use the drug under investigation; the example is for an adverse reaction that is not rare ( 1 in 500 users). Apart of logistical constraints, ethical considerations may preclude trials where safety of the drug is a serious issue.

The case-control and cohort approaches each have their advantages and drawbacks for studies on drugs. Case-control studies need usually less time than cohort studies. This is especially true if one wants to study long-term effects of drugs. Further, 
a cohort study generally needs a larger study population, especially in the case of relatively rare adverse reactions (table 3). However, if the drug under investigation is prescribed relatively infrequently, a cohort approach can be more efficient if the adverse reaction has a high incidence; in this case, adverse reactions are more readily detected within the group of users of the drug that is identified in advance. If use of the drug and the occurrence of the adverse reaction with the users are common, both the case-reference and the cohort approach are practical. If one wants to investigate a specific suspected adverse drug reaction, the case-control approach has the advantage that one knows which patients have to be selected. To study a rare reaction to a commonly used drug, the case-control approach is also more efficient than a cohort study. Case-control studies generally are completed in a shorter time than cohort studies. A drawback is caused by the interpretation problems that the results of many case-control studies on drugs have generated; we will discuss this issue later in this chapter.

If both the use of the drug and the adverse reaction are rare, the association generally has to be uncovered by case reports. A very large study population would be needed to show such a relationship with a more formal approach. Thus, the detection of these rare reactions will remain dependent on the individual observant physician. This detection and reporting, however, can be promoted by a national or regional institute that monitors drug safety.

\section{Problems of interpretation in observational studies on drug effects}

Historically, case recognition and observational studies have been the means to detect adverse drug reactions in the general population. As in all observational studies drug. monitoring is subject to several types of bias. We will discuss here the three main forms of bias and subsequently will show examples in the field of drug studies:

Selection bias occurs when the persons selected for a study differ in a systematic way from those who were eligible but not selected. Selection bias can take many forms, common is that the persons who are included in a study differ from those who are not with respect to the relation between exposure and disease.

Observarional bias occurs when there are flaws in the measurement of exposure or outcome in the groups to be compared. In studies on possible adverse drug reactions the problem frequently occurs in the form of a higher likelihood of detection of use of the imputed drug in the case group than in a control group.

Confounding bias is present when the apparent effect of an exposure is an artifact caused by the association of both the exposure parameter and outcome to a third, extraneous, factor. In pharmacoepidemiology problems associated with use of a drug have been confounded with the disease that was the reason for the therapy.

Observational studies on drug effects are perhaps.even more susceptible to these forms of bias than other subjects in epidemiology: use of a drug is likely to be associated with use of other drugs, other morbidity, and specific, not well recognized, behaviora] covariates. Compared to a field such as occupational health, pharmacoepidemiological studies generally will cover populations which are older and which have a more diverse
and complex morbidity. 


\section{Biases in the different types of study}

Case recognition, with spontaneous reporting, or in the more organized form of a national monitoring scheme, will not reveal the actual frequency of an adverse reaction, as only a minority of the problems are recognized to be drug-related, and only a minority of those recognized problems will be reported. Observational bias is likely to occur if a drug had some publicity about a purported adverse reaction: the drug will get more attention and the reported association between the drug and a problem is seen and reported more frequently. ${ }^{19} 20$ Comparison of the frequency of teports in a national monitoring scheme of two drugs is often hindered by lack of knowledge of the numbers of patients treated with the drugs. Thus, both the numerator (number of ADRs) and the denominator (number of users) required to establish a useful frequency parameter is not known. Even if the size of the treated population is known, a comparison is dubious, for the drugs may be used by patients with different health status, which may happen even with drugs in one therapeutic class. The weaknesses of the case approach are obvious; however, it should be recognized that case reports have often brought to attention previously unrecognized problems, initiating more formal studies. As we pointed out earlier in this chapter, some types of ADRs can only come to light when recognized and reported by an individual perceptive physician.

Case-control studies have been performed on a considerable scale in pharmacoepidemiology. Often the studies were initiated after the publication of a series of case reports. While relatively easy to perform, the results of case-control studies often have lead to considerable interpretation problems. Several times carefully designed case-controll studies, partly very large and expensive resulted in controversy about the interpretation of results. ${ }^{21-28}$

An example of the interpretative problems of a case-control study is the New Zealand asthma mortality study (NZAMS). ${ }^{29}$ This study stimulated us to study characteristics of users of some asthma drugs in the Netherlands (Chapter 7).

As discussed by Miettinen, ${ }^{30}$ basically a control group should come from the same source population as the cases; thus if cases have an asthma history controls should have one too. In the NZAMS indeed a group of asthmatics was chosen as controls, patients with a hospital discharge diagnosis of asthma. The association with mortality was ascertained for the different asthma drugs, both for pooled data and in subgroups defined by markers of asthma severity. The overall relative risk of asthma death in patients prescribed fenoterol by metered dose inhaler was 1.55 (95\% confidence interval 1.04-2.33). The risk was higher in subgroups with a marker of more severe asthma. This elevated risk was not found for inhaled salbutamol, with fenoterol the only drug of the beta agonist class in New Zealand.

The relationship is especially difficult to study because an effect of the drug can easily be confounded with an effect of the disease. In this case, the purported fatal adverse reaction may be a consequence of asthma, the reason for therapy. Further, as in most other case-control studies, the choice of a reference group is not easy. In the NZAMS the reference group consisted of people admitted to hospital with the primary diagnosis of asthma. In order to compare the association of mortality to the use of different drugs, the degree of severity of asthma in the treatment groups should be similar. Obviously, degree of severity is hard to assess after the moment a patient was admitted to hospital or died. Also, the drug use before admission or death has to be 
established. A small bias could result in the modestly elevated relative risk that was found in the NZAMS for patients prescribed fenoterol.

The collection of data on both disease severity and drug use is subject to observational bias: the different outcome may influence the quality of the data about the past of the patient. Information on drug use concerned the regularly prescribed medication and medication newly prescribed during the final attack. The NZAMS was criticized for not taking into account whether the imputed drugs were used in the hours preceding a fatal attack, 31 this criticism does not seem reasonable as this information generally is not available. Retrospective studies on causes of mortality have their limitations, but there hardly seems any alternative in the case of asthma mortality in younger persons, an uncommon event even in groups of patients with more severe stages of the disease.

The recent introduction of accessible databases in health care makes case-control and historic cohort studies more convenient to perform. Databases can be linked to each other to provide the information about both exposure to drugs and disease in large numbers of patients. ${ }^{32-35}$ While the new information technology has promise for studies on larger groups of patients, caution is indicated with the use of these databases. Most databases were collected to accomplish billing and to have some information on drug consumption and use of medical services of individual patients. Procedures, interventions and other cost-linked aspects are better recorded than diagnoses. ${ }^{36-37}$ The present databases are largely hospital-bound, missing large parts of morbidity and giving little insight into the long-term changing condition of the patient.

Cohor studies are less susceptible to bias than case-control studies, but mostly impractical when the adverse reaction is rather rare. The selection of a suitable reference group is essential but is generally less difficult than the selection of a reference group in case-control studies. Unlike blinded clinical trials, exposure to drugs is known by the patients in cohort studies, a fact which may lead to observational bias. The baseline condition of patients in cohort studies remains crucial for the outcome of whatever exposure. An example where baseline condition clearly had a big role was the big mortality difference between two concomitantly run studies in the U.K. on users of enalapril. ${ }^{38.40}$ The mortality was $8 \%$ for a group of users of enalapril in Inman's Prescription Event Monitoring Study. ${ }^{38-39}$ In the other study ${ }^{40}$ fewer than $0.5 \%$ of the users of enalapril died. "The latter study excluded patients with congestive cardiac failure, renovascular disease, or other complications of hypertension. This study essentially included the relatively healthy persons, leaving Inman*s study with many patients with a poor prognosis.

The last example shows how differences in patient characteristics can confound the comparison of outcome in therapy between treated groups. This common problem in pharmacoepidemiology made us to look for ways to characterize larger populations for
the presence and severity of certain conditions.

Much of the work which will be presented in this thesis is focussed on the drug history as a marker of morbidity. Another impetus for us to focus on the drug history is that both case-control and historic cohort studies are vulnerable to observational bias as concerns the ascertainment of drug use. Thus, reliable sources on medication are needed. We will describe how phamacy databases can be useful in this respect. Further, we will use drug databases in order to describe changes in therapy as a 
possible marker of changes in the condition of individual persons. The drug histories will also be used to study cessation of therapy at hospital admission.

These different subjects are studied with the same type of community pharmacybased drug histories. The fact that these data are readily analyzable as they are stored on magnetic medium is relevant in the light of the need for speed which is often felt when a problem with a drug arises. We hope that the availability of these data can help to cope with some of the problems in pharmacoepidemiologic studies described in this chapter.

\section{References}

1. Boston Collaborative Drug Surveillance Program: Regular aspirin intake and acute myocardial infarction. Br Med J 1974; 1:440-443

2. Jick H, Miettinen OS: Regular aspirin use and myocardial infarction. Br Med J 1976; 1: 1057

3. Van Heyningen $\mathbb{R}$, Harding JJ. Do aspirin-like analgesics protect against cataract? A case-control study. Lancet 1986; i: $1111-1113$

4. Edlavitch SA. Postmarketing surveillance methodologies. In: Hartzema AG, Porta MS "Tilson HH ed. Pharmacoepidemiology, an introduction. 2nd ed. Cincinnati: Harvey Whitney Books, 1991

5. Venning GR. Identification of adverse reactions to new drugs. I- What have been the important adverse reactions since thalidonide? $\mathrm{Br}$ Med J 1983; 286: 199-202

6. Venming GR. Identification of adverse reactions to new drugs. II- How were 18 important reactions. discovered and with what delays? Br Med J 1983; 286: 289-292

7. Venming GR. Identification of adverse reactions to new drugs. III- Alerting processes and early warning systems. Br Med J; 286: 458-460

8. Moore N. Adverse drug rection monitoring: doing it the french way. Lancet 1985; ii: 1056-1058

9. Koning GHP, Leufkens HGM et al. A regional pharmacy-based adverse drug reactions surveillance program. Pharm Weekbl [Sci] 1987; 9: 143

10. Wiholm BE, Olsson S. Spontaneous reporting systens outside the United States. In: Strom BL. Pharmacoepidemiology. New York: Churchill Livingstone, 1989

11. Stricker BHC, Meyboon RHB, Lindquist M. Acute hypersensitivity reactions to paracetanol. $\mathrm{Br}$ Med J 1985; 291: 938-939

12. Royal College of General Practitioners. Oral contraceptives and health. London: Pütman Publishing, 1974

13. Inman WHW, Vessey MP. Investigation of deaths from pulmonary, coronary and cerebral thrombosis and embolism in women of childbearing age. Br Med J 1968; 2: 193-199

14. Vessey MP, Doll R. Investigation of relation between use of oral contraceptives and thromboembolic disease. Br Med J 1968; 2: 199-205.

15. Itman WHW. Postmarkeling surveillance of adverse drug reactions in general practice. II. Prescription event monitoring at the university of Southamplon. 13r Med J 1981; 282: 1216 1217

16. Rawson NSB, Inman WHW. Prescription event monitoring. Recent experience with five NSAIDs. Med Toxicol 1986; suppl 1: 79-87

17. Inman WHW. Blood disorders, mianserin and antitryptyline. PEM News 1988:5: 19-20

18. Herbst AL, Uffelder H, Poszkanzer DC. Adenocarcinonna of the vagina: association of maternal stilbestrol therapy with tumor appearance in young women. N Engl J Med 1971; 284: 878-881

19. Carson JL, Strom BL, Maislin G. Screening for unknown effecis of newly marketed drugg. In: Strom BL, ed. Pharmacoepidemiology. New York: Churchill Livingstone, 1989

20. Lock ST. The influence of the media. In: Cavella JF, ed. Risk-benefit analysis in drug research. Lancaster: MTP Press, 1981

21. The International Agranulocytosis and Aplastic Ancmia Study. Risk of agranulocytosis and aplastic anemia: a first report of their relation to drug use with special reference to analgesics. JAMA 1986; 256: 1749-1757

22. (editorial). Analgesics, agranulocylosis and aplastic anaemia: a major case-control study. Lancet 1986; ii: $899-890$

23. Hurwitz ES Barrett MJ, Bergman D, et al. Public health study on Reye syndrome and medication. JAMA 1987; 257: 1905-1911

24. Mortimer EA. Reye syndrome, salicylates, epidemiology and public health policy. JAMA 1987; 257 : 1941. 
25. (editorial). Should we case-control? Lancet 1990; i: 1127-1128

26. Armstrong $\mathbb{B}$, Stevens $\mathbb{N}$, Doll $R$. Retrospective study of the association between use of rauwolfia derivatives and breast cancer in English women. Lancet 1974; wi: $672-675$

27. Bostlon Collaborative Drug Survellance Program. Reserpine and breast cancer. Lancel 1974; ii: 669 671

28. Labarthe DR. Methodologic variation in case-control studies of reserpine and breast cancer. J Chron Dis 1979; 32: 95:104

29. Crane J, Flat $A_{\text {, Jackson }} R$ et al. Prescribed fenoterol and death from asthma in New Zealand, 1981 83: case-control study. Lancet 1989; i: $917-22$

30. Mietinen OS, Caro JJ. Principles of nonexperimental assessment of excess risk, with special reference to adverse drug reactions. J Clin Epidemiol 1989; 42: 325-331

31. O'Donnel] TV, Rthea MH, Holst PE, Sears MR. Fenoterol and fatal asthma. Lancet 1989; i: $1070-1071$

32. Petri $H_{s}$ Stumans $F$. Data linkage and intervention; perspective. In: Muller NF, Hekster YA, eds. Progress in clinical pharmacy: rational use of drugs. Noordwijk: Annsterdam Medical Press, 1989

33. Connell VA, Diehr P, Hart LG. The use of large data bases in health care studies. Ann Rev Public Health $1987 ; 8: 51.74$

34. Stergachis AS. Evaluating the quality of linked automated databases for use in pharmacoepidemiology. In: Hartzema AG, Porta MS, Tilson HH, eds. Pharmacoepideniology, an introduction, 2nd ed. Cincinati: Harvey Whitney Books, 1991.

35. (editorial). Databases for health care outcomes. Lancet 1989; ii: 195-196

36. Shapiro S. The role of automated record linkage for postmarketing survellance of drug safety: a critique. Clin Pharmacol Ther 1989; 46:371-386

37. Strom BL, Carson JL.. Automated data bases used for pharmacoepidemiology research. Clin Pharmacol Ther 1989; 46: 387-388

38. Inman WHW, Rawson NB, Wilton NV, Pearce GL, Speirs Cl. Post marketing surveillance of enalapril. Part Y. Results of prescription-event monitoring. Br Med J 1988; 297: 826-829

39. Speirs CJ. Dollery CT, Inman WHW, Rawson NB, Wilton LH. Post-marketing surveillance of enalapril. Part II. Investigation of the role of enalapril in deaths with renal failure. Br Med J 1988; 297: $830-832$

40. Cooper WD, Sheiden D, Brown D, Kimber GR, Issit VL, Currie WJC. Post-marketing surveillance of enalapril: experience in 1170 hypertensive patients. I Roy Coll Gen Practitioners 1987; 37: 36-39 
In order to estimate consumption of a drug many approaches are avaluble, ranging from the measurement of plasma levels in individual patients to the study of gross national sales data.

Consumption data can be divided in two types:

1) data aggregated on the level of a region or a group of persons

2) information on the level of individual persons

1) encompasses sales data from manufacturers and wholesalers. Further insurers often retrieve gross data on reimbursed drugs.

Gross data on the sale of units of a certain drug can be ransformed in standard units, for interregional or international comparisons. The Defined Daily Dose (DDD) method of the Nordic Council ${ }^{1,2}$ is one approach, in which the daily dose for the main therapeutic indication is chosen as measurement unit. The gross salles and rembursement data give an indication of the degree of exposure of a population to a drug. The DDD method provides an estimate of the number of patient-treatment days. Neither duration of therapy nor the actual number of treated patients is known. These drug utilization studies have been a kind of forerunner of pharmacoepidemiological studies that aim to be more explanatory. Inevitably, data on the level of the individual person are needed for such explanatory studies. For a more extensive discussion of the DDD approach, see Lee ${ }^{2}$ and Leufkens. ${ }^{3}$

2) Consumption of drugs on the level of the individual patient can be assessed by several methods. Four approaches are to be compared with the pharmacy data:
A) medical records
B) patient questionnaires
C) external monitoring of drug use
D) biological monitoring of drug use

A) Medical records exist in a variety of forms: they can cover patient contacts in the general practice setting, hospitalized patients, or outpatient clinic care.

While medical records often are indispensable for finding rellewant diagnostic information, they seem less suitable for getting reliable drug histories. Patients often receive medication prescribed by more than one physician. In the situation of a hospital admission, generally a drug history is taken, but the quality and format of this history is variable ${ }^{4,5}$ and the written files are hardly usable for larger-scale surveys.

B) Patient questionnaires on past use of specific drugs have showed a varying sensitivity, depending on the type and duration of use of the medication involved. ${ }^{6,7}$ The recall of current medication in the outpatient setting has been shown also to be a problem. 8,9 The value of patient questionnaires in relation to other sources of information on drug use is discussed further in chapter 10 of this thesis, in the context of a study that compared drug histories from a questionnaire with information from a pharmacy data base.

C) Extenal monitoring of drug use. Prescription or dispensing of a drug is not synonymous with use of the drug. Noncompliance is a substantial problem in 
therapewtios and in clinical trials. ${ }^{10-12}$ As a consequence of this, in clinical trials generally some form of monitoring of the patient's adherence to therapy is included. Most often this is done in the form of counts of the patient's residual number of tablets at clinic visiss. The approach is valid as concerns the aspect that tablets brought back point to noncompliance. However, from pill counts the time patten of non-use cannot be inferred. Even more important is that patients share their drugs with other persons or throw away unused dosage forms before the clinic visit. 13,14

Infomation on the time-dimension of non-compliance is provided by electronic monitoring. ${ }^{15}$ An electronic device in the cap of the drug vial registers the time of opening and closing of the vial. Direct consumption is not measured with this method, but regular opening and closing of the vial without actual use of the drug seems unlikely.

External monitoring is done in clinical trials or with selected persons in patient care. The results add to the insight gained from more extensive type of data on prescribing or dispensing.

D) Biological monitoring of the levels of a drug is done in samples of a body fluid as blood, urine or saliva. Sometimes instead of the drug a marker substance is used. ${ }^{16-19}$ These measurements often are used as a way to monitor compliance in clinical trials. Depending on the plasma half-life of the drug, a plasma level will give an indication of compliance in the hours or clays before the climic visit. This assessment at clinic visits has been shown to introduce a transient compliant behavior just before the visit. ${ }^{13}$ Urine and saliva measurements are more convenient for the patient, but here too measurements cannot give insight in the long-term use of the drug. Changes in this field may come from the wider use of easy-to-perform urine or saliva "dipstick" tests.

For studies on large populations the described approach of external monitoring is practical only for pre-defined groups of patients with a selected drug. To do this however, pharmacy databases can be a useful source to find a group of documented recipients of the subject drug.

Biological monitoring, the other way to monitor use of a drug, is not practical to use on a large scale; apart from this, as we stated earlier, its outcomes are dubious as concerns long- term compliance.

For the studies presented in this work, drug histories of up to 1200 users of a specific drug in a specific formulation were collected (chapter $4 b$ ). In order to get this number, a source population of 120,000 people was needed, as the subject drug was used by about one percent of the general population in a time span of a few years. Thus even when one percent implies a relatively much-used drug, a large reference population is still required. The listed methods of reviewing medical records, interviewing patients, or offering them a questionnaire are impractical for this purpose.

For information on outpatient drug use, pharmacies seen to be a natural source as all prescription drugs are dispensed via the pharmacy. However, to be practical, the data have to be stored in a readily accessible way. Further, in order to get a reliable history of drug dispensing on the level of individual persons, patients have to patronize one phamacy. The use of computers in pharmacies recently has increased in many countries. In spite of this surge of the use of computers in the U.S., drug records there have been described as ".. rarely in a format that is of any help to epidemiologists". 20 Indeed, in the U.S, insurers do not require patients to utilize one pharmacy. "The relatively high density of pharmacies in the U.S. and the mobility of the population is likely to impair the completeness of the data on the patient level. There are 
exceptions, however, notably in health maintenance organizations, which have prowen their value for research. ${ }^{21-23}$ In the U.S. the common phatmacies however have proven their value for prospective drug monitoring as a locition were product users can be recruited when prescriptions are presented for filling. ${ }^{24,25}$

In the Netherlands, the public insurers (ziekenfonds) require patients to patronize one pharmacy for their reimbursable drugs. About $65 \%$ of the population is publicly insured. ${ }^{26}$ For the remaining patients, privately insured, this obligation does not exist. The ziekenfonds pays the pharmacist for drugs dispensed and are entitled to audit the claims; for this complete records for reimbursable drugs are required in the phamacy. For the publicly insured patients the pharmacy databases can be said to be virtually complete for outpatient drugs. Exceptions are drug dispensed at other pharmacies during weekends or when the patient is on holiday. Dutch pharmacies tend to serve a larger population than American pharmacies; the fewer number of pharmacies can be expected to lead to higher likelihood for individual patients to patronize one pharmacy.

The use of computers in Dutch pharmacies increased greatly in the last years: in 1991 computers were operative in $85 \%$ of the pharmacies. ${ }^{2}$ Computers were first introduced for the purpose of billing; later the use was broadened to the control for dosing, double medication, and interaction of drugs prescribed to individual patients.

Besides the community phamacy, there exists in the Netherlands one other channel for prescription drugs for non-hospitalized patients: the dispensing general practitioners. This channel exists in rural areas. About $15 \%$ of patients receive their drugs from the dispensing physicians. ${ }^{26}$ For our analyses we have not used data from this group in patients; it should be kept in mind that this subgroup of people has a somewhat different, notably lower, drug consumption than the rest of the Dutch population. ${ }^{28}$

For non-prescription drugs there exists in the Netherlands the channel of the "drogist" (druggist), where over the counter (OTC) drugs are sold. OTC drugs are also sold in pharmacies; when these non-reimbursed drugs dispensed, in general no personalized data are stored in the computer database.

Summarizing, the features of Dutch community pharmacies are:

- virtually complete prescription drug histories of publicly insured patients.

- for the minority of privately insured patients the information is less complete, especially in towns.

- about $70 \%$ of pharmacies have a computer that stores individual drug histories.

At the same time it should be kept in mind that, while data on large numbers of patients can be collected via the phamacies, the data have their limitations. First, there is the lack on information about the dispensing of OTC drugs. Secondly, there is the aspect that pharmacy data inherently cover dispensing, not use, of drugs.

Undoubtedly, some portion of the drugs dispensed are not consumed, or at a lower rate than prescribed.

With respect to the drug histories from pharmacies, the question remains on the relation of dispense with use. The term "drug use" in context of our studies should be interpreted as use inferred from dispensing data. Certainty about compliance cannot be deduced from individual drug histories. Compliance is doubtful for the case of an isolated dispensing of a drug which is prescribed normally for chronic use. Compliance 
to the prescribed therapy is more likely when the patient returns in time for refills of chronic medication. In chapter $4 b$ this issue is discussed in relation to a possible adverse reaction to a drug meant for prophylactic chronic therapy; a separate analysis is done for incidental and chronic users of the drug. While the compliance problem is clearly present in the interpretation of pharmacy data, it can be expected to be smaller when the histories show regular refills of a drug.

The actual database used was somewhat different among the studies presented in chapters 4-10. In the method sections of these chapters a description is given of the source of the data, the size of the source population and the time period covered.

\section{References}

1. Nordic Conncil on Medicines. Nordic statistics on medicines 1981-1983. Parts I, II, III. Uppsala: Nordic Council of Medicines, 1986

2. Lee D, Bergman U. Studies of drug utilization. In: Strom BL, ed. Pharmacoepidemiology. New York: Churchill Livingstone, 1989

3. Leufkens HGM. Pharmacy records in pharmacoepidemiology: studies on antiinflammatory and antirheumatic drugs. Thesis. Utrecht, 1990

4. Baxer MT, Tourville JF, Fogelsonger LJ. Computer-generated patient medication profiles increase accuracy of medication histories. Am J Hosp Pharm 1986; 43: 11701171

5. Leister $K A$, Edwards WA, Christertsen $D B$, Clark $H$. A comparison of patient drug reginens as viewed by the physician, pharmacist and patient. Med Care 1981; 19: 658-664

6. Harlow SD, Linet MS. Agreenent between questionnaire data and medical records. The evidence of accuracy of recall. Am J Epidemiol 1989; 129:223-248

7. Paganimi fill A, Ross RK. Reliability of recall of drug usage and other bealth-related information An J Epidemiol 1982; 116: 114-122

8. Schwarz A, Faber U, Boner K et al. Reliability of drug history in analgesis users. Lancet 1984; ii:
1163-1164

9. Price D, Cooke J, Singleton S, Feely M. Dowtors' unawareness of the drugs their patients are taking: a major cause of overprescribing? Br Med J 1986; : 99.100 10. Cramer $\mathbb{J}$ A, Spilker D eds. Patient compliance in medical practice and elinical trials. New York:
Raven Press, 1991

11. Levy M, Mermelstein L. Hemo D. Medical admissions due to non-compliance with drug therapy.

12. Vander Stichele R Mer Toxicol 1982;12:600-604

cfincical trialls. Fur J Clin Pharmacol 1991; 41:27-35 Urquart J. Non-compliance: the ultimate absorption barrier. In: Prescont LF, Nimmo WS, eds.

14. Rudd P. Byyny RI. Zachary V, Leve applications. New York: John Wiley \& Sons, 1989 history of nedication compliance in a 1989: 46: $169-176$.

15. Cramer JA, Mattson RH, Prevey ML, Scheyer RD, Quelene VI. How often is medication taken as prescribed? A novel assessment technique. JAMA 1989; 261: 3273-3277

16. Thompson Wl. Clinical pharnacoloy of a narker of patient compulsiveness, Contr Clin Trials
$1984: 5$ (suppl 4): $522-525$

17. Dunlbar J. Adherence measures and their utility. Controlled Clin Trials 1984; 5 (suppl 4):515-521

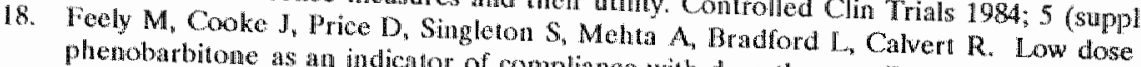
77.83

19. Pullar

investigate compliance in paticnts with a peely MP. The use of a pharmacological indicator to $1988 ; 27: 381-384$ in paticnts with a poor response to antirheumatic therapy. Br $\mathbb{N}$ Rheumatol

20. Rothman KJ. Modern epidenniology. (p. 106). Boston: Little, Brown and Company, 1986 associated with recently stopping the use of The relative risk of incident coronary heart disease 
22. Friedman $\mathrm{GD}$, Collen MF, Harris LE, et al. Experience in monitoring drug resactions in outpatients: the Kaiser-Permanente Drug Mointoring System. JAMA 1971:567

23. Jick H, Madsen S, Nudelman PM, Perera DR, Stergachis A. Postmarkeling follow-up at Group Health Cooperative of Puget Sound. Pharmacotherapy 1984:4:99-100

24. Borden EK, Lee JG. A methodologic study of post-marketing drug evaluation using a pharnacybased approach. J Chron Dis 1982; 35: 803-816

25. Borden EK, Gardner JS, Westland MG, Gardner SD. Postmatketing drug surweillance. JAMA 1984; 251: $729-730$

26. Vademecum of health statistics of the Netherlands. The Hague: SDU Publishers, 1991

27. Bakker A. Drug use in the Netherlands, an introduction. In: Bakker A, Mekster YA, Leufkens HO. Drug use in the Netherlands. Vol 1. Noordwijk: Ansterdan Medical Press, 1991

28. Post D, Been P. Kostenontwikkeling van prescriptie. Apotheekhoudende en niet-apotheckhoudende huisartsen met elkaar vergeleken [Cost development of prescribing. Dispensing and non-dispernsing general practitioners compared] Med Contact 1988; 43: 1485-1487 

The two articles in this chapter are both analyses of drug histories of recipients of the anti-vertigo/anti-migraine drug flunarizine. Material in section 4 a was also used for the later work presented in section $4 \mathrm{~b}$. The work presented in this last section covers a larger set of data. In both articles, and also in chapter 5 , the technique of prescription sequence analysis is used. The three articles reflect that our approach to analyze the data evolved in time. The technique presented in chapter 5 , developed the last, should in general be the most versatile and best applicable for prescription sequence analysis (see also chapter 5 , appendix). 



\title{
PRESCRIPTION SEQUENCE ANALYSIS: A NEW AND FAST METHOD FOR ASSESSING CERTAIN ADVERSE REACTIONS OF PRESCRIPTION DRUGS IN LARGE POPULATIONS
}

\author{
H. PETRI, H. C. W. DE VET, J. NAUS AND J. URQUHART

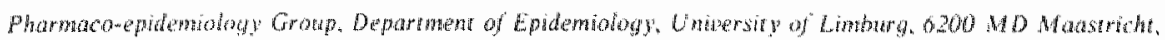 \\ The Netheriands
}

\section{SUMMARY}

Prescription sequence analysis (PSA) uses phamacy-bused prescription ang histories to detech subset of drag effects: those that are themselves indications for changes in the prescribing of another drug. Dutch phamacy practice ensures vitually complete drug histories. With a databuse of 25,000 patients we USed PSA to lest an alleged link between the use of the anti-vertigo drug funarizine and mentat depression. The temporal sequence of anti-depressant use among flunarize users shows no chustering that would suggest a causal link. PSA can be run within a few days, which may make in helphul in resolwhe certain of the periodic controversies aboul adverse arug reactions.

Key wons Prescription sequence analysis Flumarizine Anti-depressants Adverse drug reactions Prescription drugs Pharmacy records

\section{INTRODUCTION}

New drugs are registered on the basis of data from clinical trials usually involving less than 3000 patients. Economic and practical reasons set this limit. A consequence is that newly introduced drugs have a defined safety of less than 3.0 safety-degree units, ${ }^{1}$ that is a per-treatment risk of serious adverse drug reaction of more than 1 in $10^{3}$ patients.

The only way to acheve a higher degree of safety for its complement, a lower level of risk) is to monitor the use of the new drug in a larger number of treated patients than is possible in premarket trials. Yet the history of fonced withdrawals of prescription drugs for serious adverse reactions suggests that drugs not offering unique life-saving advantages need to have a defined safety greater than 4.7 safety-degree units, that is a per-treatment risk of serious adverse reaction of 1 in more than 50000 patients. To attain this level of safety from spontaneous case-reporting requires that at least 1.5 million patients receive the drug, and perhaps many more. The number must be large because the denominator for risk definition is effectively divided by at least 10 , as fewer than 10 per cent of adrerse reactions are reported, ${ }^{2.3}$ and aven the most simple statistic for interpreting non-occurrence divides the denominator again by at least $3^{4}$

Spontaneous case reporting is sometimes complicated by sensational news media coverage, provoking clustered case reporting that tends to create overestimates of the actual risk. This leads to even more sensational reporting, and a vicious circle that creates a perceived crisis in risk management. When such an unstable situation develops, none of the conventional methods for 
gathering relevant new information about prescription drugs can be initiated and completed fast enough to provide reassurance within the limited time period of a few weeks that society appears to demand for resolution of a perceived crisis in pharmaceutical risk management.

During the past two decades, one new pharmaceutical product in about 40 has become embroled in such a crisis: with about 20 new drugs entering the market annually, crises in pharmaceutical risk management oceur biennially.

The vulnerability of at new prescription drug to a crisis in risk management depends upon its rate of adoption in the marketplace. When adoption is rapid in the U.S. or U.K., vilnerability appears to peak at about 9 months after introduction, because by then drug usage will have passed through an important risk zone of one serious adverse reaction in 5000-10000 treatment cycles. This has been the range of risk exhibited by tienilic acid and most of the withdrawn antidepressant and nonsteroidal anti-inflammatory drugs. "If this risk zone is passed through without event, wulnerability then gradually declines as the drug gains a wider range of use, prowided no substantially untoward events occur. However, vulnerability never ends, as illustrated by the antidiarrheal drug, clioguinol, which was used widely for about 40 years without serious problems until the sudden occurrence of the SMON (sub-acute myelo-optic neuropathy) catastrophe in the $1970^{\circ} \mathrm{s}$.

There are two remedies when a crisis in risk management is perceived:

(a) analyse ongoing postmarket studies

(b) initiate and complete new studies.

However, to be effective, one or the other must be concluded within a fortnight. Both are important challenges to clinical research methodology and statistics. This paper describes Prescription Sequence Analysis as one approach to the second remedy.

\section{RATIONALE AND MECHANICS OF PRESCRIPTION SEQUENCE ANALYSIS (PSA)}

Prescription Sequence Analysis is based on the observation that some adverse drug reactions are conditions that themselves are indications for the use of prescription drugs. In such situations patients' drug histories should reveal an unusual frequency of some particular drug sequence:

$$
\operatorname{drug} A \rightarrow \operatorname{arug} B \text {, }
$$

where $A$ is the drug presicribed originally whose side-effect is the indication for the prescription of drug $B$, or more aptly one of the class of drugs represented by $B$. Obviously, PSA cannot detect adverse reactions that do not constitute or create specific indications for a change in the prescription of a particular drug or class of drugs. Also, PSA requires reliable and complete
prescription drug histories. A variant of PSA that should be mentioned, although we did not study it, is to look for post-
treatment cessation or other changes in the pattern of drug use.

\section{Uniqueness of Dutch pharmacy practice for PSA}

About 70 per cent of the Dutch population is errolled in the Sickfunds insurance system, which requires each patient to designate a single pharmacy from which they receive all reimbursed
prescription drugs. This administrative about each patient's prescription drug history is ensures that virually complete information Without some such mechanism to ensure the pha is contained within one pharmacy's records. records cannot be relied on to show the sequence of mecy"s exclusive use by the patient, pharmacy location may in some instances be another basis of medicines taken by the patient. Geographical 
have used this as a qualifier of privately insured Dutch patients who, though they do not have an administrative requirement for single-pharmacy dispensing, live in a village with a single pharmacy, lar enough from competing pharmacies to ensure exclusive use.

'Repeat' prescriptions give evidence of continuing use of both the drug and the pharmacy: Compliance may be gauged from the directions recorded on the prescription and the interval between visits.

A further essential feature of Dutch pharmacy practice is that about 75 per cent of all 1300 pharmacies operate with fully computerized dispensing records. Most Dutch pharmacies serve between 8000 and 14000 patients, which implies 4108 general practitioners per pharmacy. In urban areas, the patients of any one doctor are served by many phamacies, whereas in rural areas one doctor's patients are usually served by a single pharmacy.

\section{What does a prescription drug history reveal?}

A prescription is a functional surnmary of the physician"s decision about the patient"s medical needs at the time of writing. There are inevitable differences between acadenic and prevailing standards of diagnosis and between labelled and prevailing indications for drug use. Understanding those differences is obviously important to the interpretation of PSA. The problem of idiosyncratic prescribing is best dealt with by studying large numbers of pharmacies, physicians and patients.

When a doctor prescribes a drug indicated for the prevention and management of depression, it signifies the doctor's conclusion that the patient is depressed. When a large, geographically dispersed sample of Dutch physicians are seen writing prescriptions for anti-depressant drugs in a certain temporal sequence related to the patient's use of another drug, it is an early, and possibly first, warning of an epidemic of a drug-induced abnormal mental state. It may or may not be depression, but it is in any event a serious condition because non-trivial drugs have been prescribed for it.

A prescription that has been dispersed by a pharmacy shows that the patient has accepted the principle of treatment with the drug, for there is a minimum fee that the patient must pay to collect the prescribed drug. A prescription that has been repeated within a time period consistent with drug use according to the instructions on the earlier prescription is prima facie evidence of drug use by the patient. A drug used in the treatment of chronic disease that has been dispensed once and never repeated is an ambiguous indicator of use.

\section{Operation of PSA}

We applied PSA to test the validity of case reports that the anti-vertigo/anti-migraine drug, flunarizine, causes mental depression. ${ }^{5-9}$. From computerized pharmacy records, we selected all patients with a drug history recording use of funarizine. For each patient, a plot was made of the periods of prescription of flunarizine and anti-depressant drugs. Under the null hypothesis, assuming no association between the use of these $d$ rugs the chance of starting anti-depressant drug treatment during or just after use of funarizine is directly proportional to the duration of use of flunarizine relative to the total period of observation. The statistical analysis is based on a Monte Carlo simulation model which predicts the number of times that an anifidepressant drug is started within a defined period of use of flunarizine. Specifically we assumed that flunarizine-induced events would have occurred within the interval from the first dispensing of flunarizine to 30 days after the last prescribed dose of funarizine should have been consumed. In the simulation the 'starts' of anti-depressant drug treatment are allocated randomly over the total period of observation assuming a uniform distribution; the number of starts allocated to each individual 
history is equal to the observed number of 'starts" in the original patient medication history. The allocation process is repeated 1000 or more wmes for each history to generate a distribution of the number of expected starts of anti-depressant frug treatment within periods of flunarizine use.

Medication histones that contain a record of anti-depressant use in the first 90 days of the observation period are exchded, as previous funarizine prescriptions cannot be ruled aut. Imipramine, an antidepressant which is used in low dosage to treat enuresis, was included only if prescribed at doses normal for anti-depressant use.

\section{Pilot study}

Two pharmacies participated in the pilot study; they served a total of 25000 patients, among whom 274 received flunarizine during the $2 \frac{1}{2}$ to $3 \frac{1}{2}$ year period covered by computerized pharmacy records. Of these 274 patients, 16 per cent (44) were also prescribed an anti-depressant drug within the same interval. By contrast, only 5 per cent of age- and sex-matched patients who were not prescribed flunarizine received prescriptions for anti-depressant drugs in the same interval.

We need to know when in relation to the start of flunarizine use was an anti-depressand drug first prescribed.

\section{Temporal sequence of flunarizine and anti-depressant drug dispensing}

The number of 'sharts' of anti-depressant drug use observed during or within 30 days after flunarizine use was 5 out of a total of 34 histories. Ten of the original 44 histories were excluded because of anti-depressant use in the first 90 days of the observation period.

With only 5 patients for whom an anti-depressant drug was prescribed within the interval for flunarizine-induced events, we can estimate that the maximum per-treatment risk of serious depression appears to be less than 1 in $274 / 5$ or 1 in 55 flunarizine-treated patients.

But how much less? We can hazard a rough estimate, based on the results of the Monte Carlo simulation analysis, which show that the generated number of "starts" of anti-depressant drugs in the periods during and 30 days after flunarizine use was about 20 per cent more than the number observed in the medication histories. Thus, whatever risk there may be of flunarizine-induced depression, it would appear at least an order of magnitude lower than the background risk. To give better precision to such risk estimates, we are presently endeavouring to expand the coverage of the PSA method to one million pharmacy patients.

The relatively high rate of anti-depressant prescribing in patients dispensed funarizine suggests that this group of patients, if not having mental depression in a narrow sense, are at least prone to receive anti-depressant drugs for mood disturbances. That association deserves further study. Perbaps it accounts in some way for the spate of case reports suggesting an association of funarizine with depression.

\section{Time required to complete a PSA study}

The first phase of this study was performed by hand and was completed within 3 working days. It included data from a single pharmacy with 100 recipients of funarizine during a 3 year period. However additional time was required to write the general program that assembles complete drag histories of users of a specified drug or group of drugs from the pharmacy computer system. With such a general program, one can search a large database of dispensing records from multiple pharmacies, and within a few hours compile drug histories of hundreds or thousands of recipients of any specified combination of drugs. The Monte Carlo simulation analysis to search for unusual temporal clustering of prescriptions takes less than I hour of machine time on a desk top computer for several dozen patients if about one thousand runs of the simulation are made per patient history. 
It is therefore evident that, with access established to a large archive of pharmacy dispensing records, a PSA study could be defined and executed within a fortnight. Thus, PSA can be a practical tool with which to develop information during a period of perceived crisis in risk management of a pharmaceutical product.

\section{Confidentiality}

Anonymity of patient records is ensured by the algorithm that transfers dispensing data from the pharmacy records to the database. Individual sets of data are identifed only but adequately by birthdate, sex and pharmacy.

\section{CONCLUSION}

PSA is an inexpensive, fast method for assessing certain kinds of drug reactions, specifically those that are indications for change in the use of other prescrption drugs. The simplest change is the commencement of another drug, but in principle, one could look for changes in prescribed dose or cessation of use of a drug prescribed already. Dutch pharmacy practice virtually ensures that prescription drug histories are complete. However, PSA should be validated; one way would be to detect a recognized prescribing pattern linking drug reaction and subsequent prescription, for example potassium supplementation after use of a diuretic drug.

PSA can serve by providing both a qualitative alert and a measure of the evident risk of drug use. It seems possible to obtain a risk measurement within a two-week period, once a database of pharmacy dispensing records is available. A risk measurement may have great vallue at a time of crisis in the perception of the risk of using a widely prescribed pharmaceutical product.

\section{ACKNOWLEDGEMENT}

The authors acknowledge grant support from Pfizer International and the Janssen Foundation for this work. The authors are indebted to Professor Bradley Efron for discussion of the statistical issues in analysing PSA data.

\section{REFERENCES}

1. Urquhart. I. Risk Perception and Measurement in Therapewtic Risk: Perception, Measurement, Managem ment. Inman, W. H. W. and Burley, D. M. (eds.), Wiley, Chichester 1988 (in press).

2. Urquharh, J. "Two cheers for NSAIDs", Gut, 27, 1287-1291 (1986).

3. Speirs, C. J. Prescripnon-related Adverse Reacion Profiles and their Use in Risk-benefit Analysis, in D'Arcy, P.J. and Griffn, J. P. (eds.) latrogenic Disease, 3rd ed. Oxford Uniwersity Press, Oxford 1986.

4. Hanley, J. A and Lippman-Hand, A. "If wothing goes wrong, is everything all right?" Journal of the American Medical Association, 249, 1743-1745 (1983).

5. Chouza, C., Caamano, J. L., Alijanti, R, Scaramelli, A., De Medina, O and Romero, S. Purkinsonism, tardive dyskinesia., akathisia, and depression induced by flunarizine", Lancet, $\mathrm{i}, 1303-1304$ (1986).

6. Laporte, J.R. and Capella, D. "Useless drugs are noi placebos: lessong from thuarizine and cinuarizine", Lencet, ii 853-854 (1986).

7. D'Allesandro, R. Benassi, $G$ and Morganat, $G$."Side-eflects of flunarizine' Lancet, it, 463 (1986).

8. Amery, W. 'Side-effects of flumarizine', Lancer, i, 1497 (1986).

9. Meyboom, R. H. B., Ferrari, M. D. and Dieleman, B. P. Parkinsonism, tardive dyskinesia, akathisia, and depression induced by flunarizine, Lancet, ii, 292 (1986). 



\title{
RAPID METHOD FOR ESTIMATING THE RISK OF ACUTELY CONTROVERSIAL SIDE EFFECTS OF PRESCRIPTION DRUGS*
}

\author{
Hans Petri, 'Hubert Leufkens, ${ }^{3}$ Jack Naus, ${ }^{3}$ Reinhilloe Silkens, ${ }^{3}$ \\ PAULIEN VAM HESSEN' and JOHN UROUHART T'
}

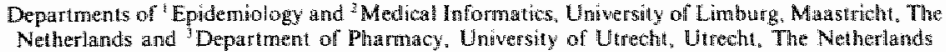

(Recoived in rewsed fow 28 sementer 1989 )

\begin{abstract}
When controversy suddenly erupts about the risk of using a prescription drug, there is an urgent need for fast methods of risk estimation. Some unexpected side-effects of preseription drugs are indications for the prescribing of another kind of drug. If the risk of such a side-effect is high, if should be neflected in clustered prescribing of the side-effect-alleviating drug in sequence with the side-effect-causing drug. The risk of thug-attributable side-effects can be estimated by comparing average incidences of imitial prescriptions for the side-eflect-alleviating drug before, during, and llong after the dispensing of the presumed side-effect-causing druge We monitored computerized, complete drug dispensing necords of anonymous outpatients for use of Aunarizine, an antj-vertigo/anti-migraine drug that case reports had suggesied causes mental depression and/or Parkinsonism. Among 1284 patients tho eventually got flunarizine during a 31 month period, 1 in 7 was started on am andindeprossant before or long after funarizine; only 1 in 82 might be said to have been started on an anti-depressant because of flunarizine. There was no evidence that anti-Parkinson drugs were started because of flunarizine, though the numbers are small. The analysis takes only a few days, and can help set bounds on risks of the subset of adverse drag reactions that are themselwes indications for use of other drugs.
\end{abstract}

Adverse drug reactions Prescription sequence analysis Phamacy records
Flunarizine Arti-depressant drugs Anti-Parkinson drugs Mental depres
sion Parkinsonism Wertigo Migrane Pharmaco-epidemiology

\section{ANTRODUCTION}

Premarket trials of new drugs have well-recognized limitations on size and patient selection criteria. Consequently, certain adverse drug reactions only become apparent after market introduction, as general use expands both

A preliminary report on a portion of this work has been published [T]

\#All corresondence should be adesed to: Dr I. Unquart, Deparmient of Epidemiology. Universily of Limburg. PO $10 x \quad 616,6200$ MD Magericht. The Netherlands. [Tel (31) $43 \mathrm{~m} 887379$ ) numbers and diversity of patients receiving the drug. When first case reports of possible adverse reactions appear, there is strong desire but usually no capability for urgently gathering more information to estimate risk by defining incidence and probable causality. Confusion and usually exaggerated fears tend to prevail at such times, precipitating regulatory action on incomplete data. These actions taken in the name of risk reduction, are not wilhout the potential to create risk to patients. who are subjected to hasty and sometimes unwarranted changes in therapy $[1,2]$ 
Thus, werc is a need for methods of analyzing matket-experience data within a few days to assist in risk estimation. The objective of this sudy was to identify and apply ane such method, based on drug dispensing data from retail pharmacies.

The study analyzed aln episode of reported wdverse reactions involving flunarizine, an antimigraine and ant-kertigo drug. This fuorinated derivatiwe of cinmarizime entered European markets in 1983 with known side-effects of sedation and epigastric discomfort [3]. In 1986, several reports linked mental depression to finnarizine use. Table I summarizes these reports. showing major gaps in information that, though unique to this episodg, are representative of the quality of information that usually prevails in the immediate aftermath of first reports on a previously unsuspected adverse reaction.

Adverse arug reactions can be divided into two classes: those that do and do not have a specific pharmacotherapy. Both depression and Parkinsonism belong to former class, because they are indications for the prescribing, respeclively, of ant-depressants and anti-Parkinson angents. If flunarizime indeed has a high risk of causing either or both depression or Parkinsonism, one would expect to see a clustering of initial prescriptions for anti-depressant or antiParkinson drugs during the period of funarizine use and for a certain time afterwards. Consequently, we anallyzed the sequences in which amti-depressants and anti-Parkinson drugs were first prescribed and dispensed to a sizeable population of funarizine recipients. We compared incidences of first prescriptions of antidepressands or anti-Parkinson drugs before, during, and it relatively long lime after the initial prescruptions for flunarizine.

\section{METHODS}

Collaborating conmunty phamacists iden. tified ever-recipients of funarizine in their computer files and supplied us with anonymous drug dispensing histories, in which patients were ideruifiable only by sex and birthdate. Each phamacist used one of three differen computer systems, two of which were flexible enough to provide complete drug dispensing histories on all ever-recipients of flunarizine. One system posed difficulties that made it economically feasible only lo gather a count of ever-recipients of funarizine and the dispenising details of finnarizine only, and any anti-depressant drugs they received. For several reasons, computerized dispensing records are held to a high standard of accuracy, not least because they are the audited basis on which pharmacies are paid by the State insurance system.

The drug duspensing histories spanned a mean period of 31 months (range $10-40$ months). The database we created from these histories began at the start of the complete computerized data file of drug dispensing in each pharmacy. Our database ran through 30 August 1987 . In five urban pharmacies only data from patients insured by the Sickfund (Ziekenfonds) were studied. Sickfund-insured patients, who comprise about $70 \%$ of the population, are required to designate a single pharmacy for all reim. bursed prescription drugs, which include all drugs involved in this situdy. Privately insured patients might have used a second pharmacy for some prescription drugs, thus permitting some prescriptions to escape our amalysis. In wo rural towns, each served by a single pluarrwacy, and in one town where all four pharmaces stare a common patient data bank, both Sickfund

Table 1. Number of funarizine treated* patients woth and withowi adverse reactions

\begin{tabular}{|c|c|c|c|c|c|}
\hline \multicolumn{4}{|c|}{ Wint } & \multirow[t]{2}{*}{ Widhout } & \multirow[t]{2}{*}{ Ret } \\
\hline $\begin{array}{c}\text { Depression } \\
\text { bully }\end{array}$ & $\begin{array}{c}\text { Parkinsonismy } \\
\text { ondy }\end{array}$ & Both & $\begin{array}{l}\text { Either } \\
\text { or bouhn }\end{array}$ & & \\
\hline$\theta$ & 1 & 11 & - & $?$ & {$[4]$} \\
\hline 21 & 0 & 1 & - & $?$ & {$[5]$} \\
\hline 2 & 0 & 7 & - & $2 !$ & {$[6]$} \\
\hline- & 6 & $\ldots$ & - & $?$ & 17 \\
\hline$-x_{-1}$ & $\ldots$ & - & 17 & 3250 & [8] \\
\hline
\end{tabular}

Dosade varied, with some pationts receiving a higher dosage and the recommanded 10 mgdey.

tThe termindogy of the case meports differs: "Parkinsonism" refers to a hetero geneous group of reported motor problems.

t Not thlofited separtely ing the report.

"-." "The eategory was now considered in the report.

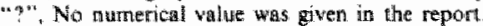




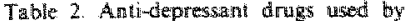
patients who also reckinge the

\begin{tabular}{|c|c|}
\hline Anhi-deprissant & Number of users \\
\hline Amintropline & 60 \\
\hline Maprothine & 45 \\
\hline Miganserine & 40 \\
\hline Clomipramine & $\| 3$ \\
\hline Mmis ramine & 13 \\
\hline Opipramol & 8 \\
\hline Flupoxamine & 5 \\
\hline Doxepine & 5 \\
\hline Dosnlepine & 4 \\
\hline Mloneiflentune: & 4 \\
\hline Tranodone & 1 \\
\hline Miortriptystine & 1 \\
\hline Trimipramine & 1 \\
\hline
\end{tabular}

and privately insured patients were studied; there the likelihood of missing some prescriptions seemed small.

The anti-depressant drugs listed in Table 2 were prescribed to ever-recipients of funarizine. As imipramine is used in low dosage to treat enuresis, it was included only if prescribed at a dosage of $50 \mathrm{mg}$ a day or higher. The anti. Parkinson drugs listed in Table 3 were found to be used in ever-recipients of funarizine. For convenience, we refer hereafter to anti-depressant and anti-Parkinson drugs as "marker drugs".

The period of flunarizine or marker drug use was considered to begin with its first dispensing, and to continue as long as refil. occurred within 30 days after the legend duration of the previous prescription. The legend duration is the number of dosage forms dispensed divided by the prescribed number to be taken per day. The duration of drug effect, after the last prescription, was taken as the legend duration plus 30 days. Some patients had more than one period of use of a drug. The vast majority of flunarizine refills had legend durations of 60 days.

From the case reports, no clear picture emerges of the time relation of funarizine use and subsequent development of problems: reactions within days and after several months of use were reported. We considered a reaction to

\begin{tabular}{|c|c|}
\hline Drutig & Number of users \\
\hline Levodopa berserazide & 4 \\
\hline Espendione & 3 \\
\hline Arou artedine & 3 \\
\hline Henzatropiarse & 2 \\
\hline Lewodopa & 男 \\
\hline Levodopa carbidopa & 目 \\
\hline Dexethind & 1 \\
\hline
\end{tabular}

be possible during the wholle time of exposure of funarizine and andlyzed the data accondingly.

When a marker drug was already in use at the beginning of the observation period, there wh no way of knowing whether it had been preceded by flunarizine use. To avoid this ambiguity. the firs 90 days were excluded from the beginning of each analysis period. For the patients who had a marker drug prescribed in this 90-day interval, the period of analysis was taken to begin the 31 st day after the end of the legend duration of the last narker arug prescriplion

The incidence of first prescriptions of matker drugs during funarizine use ( $I$ u) was compared to the incidence in the period before and after flunarizine use (fnu), ice the period of fun arizine non-use. The incidence is defined as the number of first prescriptions ("starts") per 1000 observation days in the corresponding period of flunarizine use or non-use, aggtegated across patients. An incidence ratho (R) was determined as I $\mathrm{w} / \mathrm{hu}$. The null hypothesis is $I u=I \mathrm{nu}$, or, $I \mathbb{R}=1$.

A.t least 2 weeks are required for most antidepressant drugs to show therapeutic effect, and full therapeutic benefit is not usually evident before 48 weeks of treatment [9]. Shorter use of anti-depressant drugs is a somewhat ambiguous indicator of the existence of depression. Therefore, the analysis was also done separately for the histories in which the anti-depressant, use exceeded 60 days.

To gauge the extent of co-medicktion besicles. flunarizine and the marker drugs, we determined the number of other drugs prescribed during 60 days prior to each dispensing of flumarizine in all 777 flumarizine recipients in the "flexble" database. We first made a per-patient average, and then averaged across patients.

Patients. ages were determined as of the end of the observation period.

\section{RESULTS}

Among 11 collaborating phamacies serving approximately 105,000 people, 1284 patients were prescribed and dispensed flunarime at some time in the 31 -month observation period. Among the recipients of flumarizine, $180(14 \%)$ also recenved prescriptions for one of the antidepressant drugs listed in Table 2 sometime during the period of observation. In contrast. only $4 \%$ of the ever-recipients of any prescrip. tion drug from the collaborating pharmacies 


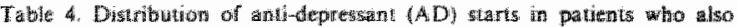
received fifumatizine

\begin{tabular}{|c|c|c|c|c|}
\hline & & $D_{2}=$ & $A D$ stadistes & Incidericet \\
\hline \multicolumn{5}{|c|}{ (a) Tolal grow $(\mathrm{N}=155)$} \\
\hline 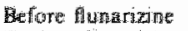 & 1 & 55038 & 87 & 1.58 \\
\hline 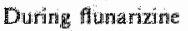 & If & 29746 & BI & 2.05 \\
\hline After funnaringe & III & $\$ 3613$ & 79 & 1.47 \\
\hline \multicolumn{5}{|c|}{ 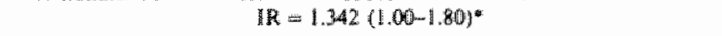 } \\
\hline \multicolumn{5}{|c|}{ 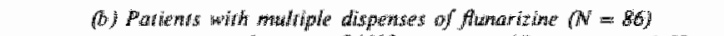 } \\
\hline & 1 & 24624 & 37 & 1.50 \\
\hline & II & 25963 & 49 & 1.88 \\
\hline & mI & 2809 & 43 & 1.53 \\
\hline \multicolumn{5}{|c|}{$T R=1.242(0.97-1.27)^{*}$} \\
\hline \multicolumn{5}{|c|}{ 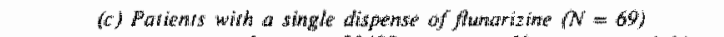 } \\
\hline & 1 & 30467 & 50 & 11.64 \\
\hline & II & 3783 & 12 & 3.17 \\
\hline & III & 25975 & 36 & 1.41 \\
\hline \multicolumn{5}{|c|}{ IR $=2.065(1.13-3.78)^{4}$} \\
\hline
\end{tabular}

* $95 \%$ conflidence interval.

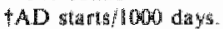

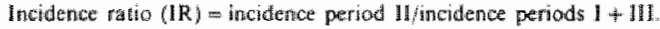

were prescribed an anti-depressant during the same time period. For andindepressant use to be considered atributabla to funarizine, however, it must occur in atemporall sequence consistent with watuality.

Among the 180 ever-recipients of both fin arizine and an anti-depressami, 25 were excluded because their only prescriptions for an antidepressant drug occurred during the first 90 days of pharmacy records. Among the 1.55 remaning patients, 227 anti-depressant "starts" were recorded; thus, some patients had more than one "start" during the observation period. The ever-recipients of both flunarizine and an anti-depressant had a mean age of 56 years; $77 \%$ were fernalle.

The incidence of antl-ediepressant "starts" in the periods before vs after we of flunarizine, shown in Table 4, did not differ signifcanty, so these periods were merged into one period of "flunarizine mon-use". The incidence of antidepressant "starts" during periods of flumarizine use is somewhat higher than in periods of flunarizine norn-use, as shown in Table 4 . In all 155 patients (Table 4 (a), the computed incidence ratio for the start of anti-depressant prescribing during fhunarizine used was 1.34 , and is marginally statistically significantly elevated; assuming a normal distribution for the logarithm of the incidence rate the 2-tailed $p$ value was precisely 0.05 .

In 86 of the 155 rechpients of both flumarizine and an antimdepressant, funarizine prescriptions were refilled al least once, suggesting that the patients took their flunarizine at least approximately as prescribed, and did so for am extended period of time. In this group of patients (Table $4(\mathrm{~b})$ ), the incidence ratio of anti-depressant "starts" was not statistically significandy elevated. In the remaining 69 patients, who

Table 5, Distribution of starts of anti-depressants (AD) used longer that 60 days in patients who also received flusarizine

\begin{tabular}{|c|c|c|c|c|}
\hline & & Days & AD starts & Interidence \\
\hline \multicolumn{5}{|c|}{ 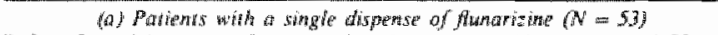 } \\
\hline Defore flunarizine & 1 & 945 & 36 & 185 \\
\hline Dongring numatizina & 11 & 2502 & 10 & 3.90 \\
\hline Alter flumarizine & III & 1669 & 28 & 1.68 \\
\hline \multicolumn{5}{|c|}{$I R=2.204(1.13-4.29)^{*}$} \\
\hline
\end{tabular}

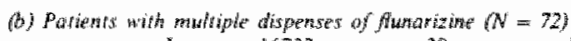

\begin{tabular}{cccc}
1 & 16732 & 30 & 1.79 \\
11 & 20954 & 42 & 200 \\
111 & 19764 & 34 & 1.72 \\
11 & $1.14310 .77-1.69 y^{\circ}$ & & \\
\hline
\end{tabular}

-9. $5 \%$ confuderee interval

† D starts 1000 days.

Ineidence ratio (IR) incidenoe period II incidence periods + +II 
Table 6. Distribution of ant-Parkinson (AP) medication starto in patiens who also received fumarizine

\begin{tabular}{|c|c|c|c|c|}
\hline & & Disys & AP starts & Incintenter \\
\hline \multirow{2}{*}{ (A) } & During flunarizing & 2587 & 4 & 1.55 \\
\hline & 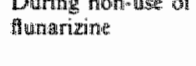 & $\begin{array}{c}4577 \\
I R=1.01\end{array}$ & 7 & 1.53 \\
\hline
\end{tabular}

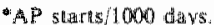

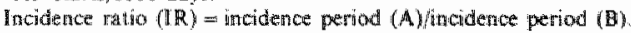

received only one prescription for flunarizine, and whose actual use of the drug is therefore ambiguous (Table 4(c)), the incidence ratio was $2.05(p<0.05)$. As shown by Table 5 , the results are similar if relatively short periods of antidepressant use are excluded.

In the group of 155 recipients of both flunarizine and an anti-depressant. 61 antidepressant "starts" occurred during flunarizine use, while 45.4 is the calculated expected number, based on the incidence of antidepressant "starts" in the periods of funarizine non-use. The difference of 15.6 "starts" can be considered as the number of "starts" of antidepressant drugs attributable to flunarizine. With 1284 patients having ever received flunarizine in the entire observation period, one may estimate that 1 flunarizine recipient in 82 (128.4/15.6) received a drug-attributable cycle of anti-depressant treatment. During the same period of time, but unattributable to flunarizine use, 1 in 7 flunarizine recipients received a cycle of anti-depressant treatment.

Flunarizine recipients also receive a good deal of co-medication, besides just the marker drugs: $43 \%$ of the flunarizine recipients were dispensed 2 or more drugs, $30 \%$ were dispensed $1-2 \mathrm{drugs}$, and $27 \%$ averaged less than 1 .

In the subset of data from the flexible databases, there were 777 flunarizine recipients, among whom 10 also received prescriptions for one or more of the anti-Parkinson drugs listed in Table 3. The mean age of these patients, 6 of whom were female, was 75.1 years. Two patients had to be excluded from further analysis because their only start of anti-Parkinson medication was in the first 90 days of the observation period. The incidence of starts of anti-Parkinson medication during. periods of flunarizine use and non-use was almost equal (incidence ratio 1.01; Table 6). None of the 10 recipients of anti-Parkinson drugs received prescriptions for anti-depressants. This analysis was completed within 10 working days.

\section{DISCUSSION}

Sequence is crucial to the inference of causality. The high rate of anti-depressant prescribing before funarizine was ever prescribed cannot have been caused by flunarizine. This high, pre-flunarizine rate of anti-depressant prescribing underscores the difficulty in selecting controls, thad we chosen 10 assess the risk of funarizine use with conventional case-referent or cohort study designs. A case-referent study would logically start with recipients of antidepressant drugs, but out data indicate that there would be an unusually high representation of flunarizine recipients among patienis prescribed anti-depressants. For a cohort study , the ideal control would be some other group of patients who newer received flunarizine, but were alike in all other respects. Flunarizine is in a pharmacological class by itself, as the only drug with indications for vertigo as well as migraine; thus there is no obvious other drug as a control. Moreover, flunarizine recipients appear to be rather extensively medicalized patients, as shown by the high proportion receiving prescriptions for other drugs. Considering these factors, we chose as controls the fluna rizine recipients themselves, during periods before and long after flunarizine use. The equal rates of initial prescribing of anti-depressants before and long after flunarizine use support this choice.

In the strictest sense, of course, the preflunarizine period is not a wholly satisfactory controll for events occurring during and shortly after the period of flunarizine use. For example, some depressed patients may develop vertigo or migraine, which would lead to the prescribing of funarizine or other anti-vertigo or antimigraine agents. This potential confounding of indication with outcome may have occurred in a few cases, but it involves a process opposite to the one of concern in the present situation. It defies imagination to suppose that this type of confounding so perturbed the prescribing rates to have masked a sigrificant risk of 
funarizine-particularly so in light of the multple agenis used in the treatment of depression and their long time availability without evi. dence that they pose major risks of vertigo or migratine.

While ani-depresant drug use was intiated in $14 \%$ of the ver-rectpients of flunarizine, only $4 \%$ of the recipients of any prescription drug were prescribed an anti-depressant drug during the same time period in the moni lored population. In contrast, Aworn ef al. found that $23 \%$ of ever-rectpients of $\beta$-blockers were prescribed an anci-depressant drug during a time period of approximately similar lemeth [10]. Awom"s work did not show the temporal sequences of prescribing, so whether this high rate of antidepressand drug prescrib. ing was coincidental or perhaps causally linked to $\beta$-blocker use is unclear. Whatever its bass, the high frequency of anti-depressant drug usage in these groups deserves further study because of its medical and economic implications.

In our study, ant-depressant drug prescribing did chuster more conspicuously with single than with multiple prescriptions for flumarizine. The study design did not allow us to distinguish among several possible explanations. One is that patients with nonspecific camplaints were initially prescribed flunarizine, but, when the complaints persisted, tended to be switched to an anti-depressint. Another explanation is that patients most sensitive to flunarizine rapidy developed signs and symptoms of depression, leading their physicians to discontinue the funarizine and institute treatment with an anto depressant. Whicthever the case, we found overull only 15.6 starts of anti-depressant drugs, in excess of the background rate, during the periods of flunarizine use. These is.6 attributable starts of an anti-depressan drug occurred in 1284 recipients of flumarizine. Thus one fumarizine recipient in $1284 / 15.6=82$ might have obtaned a prescription for an antidepressan drug due to an unwanted reaction 10 funarizine.

This attributable risk is to be contrasted with a background rate of anti-depressant drug prescribing that is 12 times higher: I flunarizine recipient in 7 contemporaneously began a course of anti-depressant drug treatment, but in a time sequence incompatible with a causal role of funarizine. Perhaps this high background rate is atributabla to some confounder, e.g. migrane, which is both an indication for flun- arizine use and has a recognized association with depression $[11-13]$.

Our estimate of the attributable risk of depression due to flumarizine is subject to several sources of error. We would have missed any cases where the physician responded 10 signs and symptoms of depression by simply discontinuing flunarizine, but not prescribing any antidepressant drug. This conservative practice may have occurred in a minority of cases, but it is mot consistent with the relatively liberal prescribing we found in the group as a whole. Another source of error is that anti-depressant drug prescribing is not a reliable indicator of true depression because anti-depressani drugs are used in a variety of mond disturbances [9] of lesser severity than depression, that meet an accepted diagnostic standard [14]. For this reason, the figures on incidence and attributable risk relate to initiation of anti-depressunt drug use, not of true depressian.

These uncertainties necessarily limit the conclusions one can draw from prescription sequence dath, but they would appear to be small in relation to the uncertainties inherent in other post-market survelliance methods. For example, Table I illustrates what case reports do and do not lell, and the spontaneous reporting systems, such as the British Yellow Cards, are complicated by gross under-reporting [15]. Dutch pharmacy data have a high degree of accuracy as to drug identity, quantity, and date dispensed, and the reimbursement arrangements insure virtual completeness of outpatients records. This historical record constrains the interpretations that can justifiably be considered in any adverse reaction situation. In some medical circumstances, the sequence of prescrip thions effectively outines the nature and sequance of medical ewents, whereas in others it cannot. In the present situation, the residual uncertainties are ones of inerpretation. why the drugs were prescribed, the occurrence of adverse events that are not signalled by outpatient prescriptions, and how often an adverse etiot was masked because the first drug was discontinued instead of a second drug being added. Notwithstanding these limitations, the data allow us to say with confidence that many hundreds of patients received flunarizine over a period of many months with only a minor atributable risk of mental depression severe enough to warrant treatment with anti-clepressant drugs. Had there been an epidemic of depression created by use of this drug, it surely 
would have been clearly reflected in these drug hisionies.

Ten of the 777 users of flunarizine in the flexible database had an anti-Parkinson drug in their medication history. There was no indication for clustering of the starts of antiParkinson drug preseribing during funarizine use. A much larger population of patients would have to be monitored in order to put this conclusion on a firm ground. The significance of this part of the study lies not so much in the relatively sparse amount of data, but more in the rapidity with which the database, once built, was analyzed for prescription sequences. The actual analysis time of 10 working days was dependent only in a minor way on the volume of prescribing. Thus, one can expect to be able to use dispensing data from communicy (and, where possible, hospital) pharmacies to provide prescription sequence data on an urgent basis when questions about the risk of adverse reactions suddenly arise. The method depends on the completeness of the records and the specificity of available pharmacotherapy for the adverse reaction in question. Obviously, many types of adverse reactions are not reflected by physicians choices of prescriptions for outpatients, in which cases the method cannot be used.

Outside The Netherlands, complete dispensing records are likelly to be present in certain health maintenance organizations and other insurance schemes. Perhaps the forthcoming Medicare system of prescription drug reimbursement in the U.S. will allow prescription sequence analysis on a broader base than could be possible in a small country like The Netherlands. Probably the main value of the method is 10 give rapid estimates of risk when case reports describe side effects but leave the risk of their occurrence to the imagination. While the randomized controlled trial remains the paradigm for definitive answers to such questions, the time and costs involved often preclude its use in situations where regulatory decisions have to be taken on incomplete and imperfect data. In that situation, prescription sequence analysis can rapidly provide an estimate of likely risk.

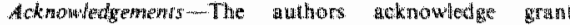

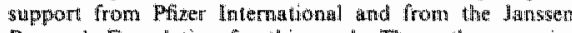
Research Foundatian for this work. The withars are indebted to Professor Bralty Fron and to Dr Fors Kessers for stmistical consultation, and to Riekit de Var for assistance in the early ptrases of the work.

\section{REFERENCES}

1. Petri $\mathrm{H}_{\text {c }}$ de Ver HCW" Naus J. Utquhart J. Prescrip tion sequetree analysis. Sta Med 1988:7: 11711175

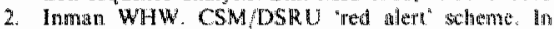
Prescriptom Eveat Nets. No, 5. Southamplon; U. K. Hamble Valley Press: 1988

3. Holmes B. Bropden RN, Hol RC, Spenth TM, Avery

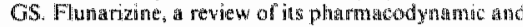
pharmacotinetic propertics and therapentic use. Drugh 1984: $2 \%, 6,44$.

4. Chotza C Cammano JL. Alijanti Th, Scaramelli A, Do

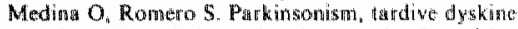
sia, ahathisis and depression induced by founariatuc Lancel $1986,0.1303-1304$.

5. Meyboom RHB, Ferrati MD, Dictedeata BP Parkinsonism, hadive dysthessa, akathisis and thpression induced by fundrizine. Lamet 1986 ; 1292

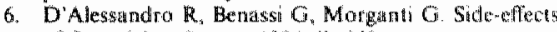
of funarizne. Luncet 19186; î: 463

7. Laporte JR, Capella D. Uselers drugs an re rico phtactotos lessons from fumarizishe and cinnanizine. Lancel 1986 ij: $85 \%$

8. Agnoli A Nappi G. Useless drugs? Lanket 1966 ; 1217.

9. Badessarini RJ. In: Goodman Gilman A, Goodman L. Eds. The Pharmacological Basis of Ther apewatics, 7th edn. New York: Macnillan; 1985: 413-431

10. Avorm J, Eiverill $D$ Weiss $\$$. Increased antideprossant wse in patienns prescribed beta-blockers. AMA 1986 255: $357-360$.

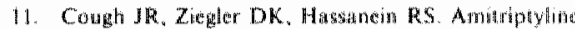
in the prophylan of migraine. Heuralongy 1976,26 $121 \cdots 127$

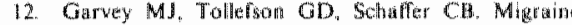

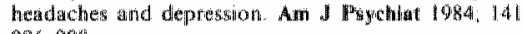
986 m.98\%

13. Hudrow L. Current aspects of migrame bendache Psychasom 1978; 1: 495,57 .

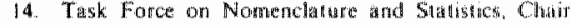

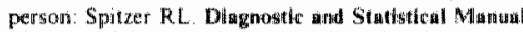
of Mental Disorderi (DSM-III), 3nd edn. Chrmbribe: 1987.

15. Urquhart 1. Two cheers for NSAIDs Guh 1986, 27 $1287-1291$ 



\title{
Markers of adverse drug reactions in medication histories
}

\author{
An analysis of inhaled steroid utilization
}

\section{H. Petri Fesels and T. Kamakuta}

\section{Introduction}

A. therapentic effect of a new drug is generally assessed by means of randomized clinical trials Unwanted effects of drugs, however, are usually much more difficult to detect. Only a limited number of patients taking a drug experience an adwerse reaction, and serions on fatal reactions are generally rare, though they may cluster in patients with special attributes. Until such attri. butes are understood, however, the incichence of the adwerse reaction is expressed for the general population of patients. For the detection of rare adwerse drug reactions, physician's repurts on reactions in individual patients have been in dispensable. Causality in individual cases, hovgever, is difficult to assess, and adverse reactions that are conditions with a sizeable background incidence in non-users of drugs are, in general, overlooked. The publication of case reports presses for further investigation on a population levell, and if a perceived problem gets general publicity, society seems to demand information about risk at short notice.

We have deviced a method to study a subset of possible adverse drug reactions on a screening basis, within a few weeks. The approach is based on the observation that some unwanted drug ef fects lead to a condition that is treated with another drug. This conceph of prescription sequence analysis can be depicted as:

$$
\mathrm{d} n \mathrm{ag} \mathrm{A} \rightarrow \operatorname{adwerse} \text { reaction } \longrightarrow \text { drug } \mathrm{B}
$$

$A$ is the drug that causes an adverse drug reac tion and $B$ is the drug, or group of drugs, given to treat the condition that followed the use of $A$. Patient drug histories should reveal in this situation a relatively high frequency of delivery of drug $B$ anter use of drug $A$ [1 2 2].

Application of prescription sequence analysis is limited to the group of adverse drug reations where a spocifio drug therapy is arailable to treat whe adverse reaction. Therapy should not bo given to prevent an adverse reaction. Insight into the general use of the drugs should detw mine whether it is suited for prescription sequence anatysis: a temporal relation of the wee of two drugs unay be determined by a third variable, ise when tho digg are given fon difrerent stages of the same disease. Sometimes additional information, such as the indication for the use of $\operatorname{drugs} A$ and $B$, will be needed. The analysis should take into account a certain lag time for the adverso reaction to ocent. Primarily, complete and reliable drug histories are needed as a basis for the amalyses; to study rare reactions large numbers of drug histories are needed.

In the Nethertands, $70 \%$ of the population are insured in the health insurance funds, which te quire their members to designate ono pharmacy to obtain all preseribed drugs. The nagorily of pharmacies have a computerized data base.

\section{Application of prescription sequence analysis}

As an application of prescription sequence analysis, we studied one class of drugs with a known side-effect, the inhalational steroids for asthma treatment are seported to cause oral candidiasis in $1.5 \%$ of the patients $[3-61$. There is a specific therapy available for oral candidiasis: topical oral forms of drugs that counter the eandida infection. Schemantically presented:

$$
\text { inhaled steroid } \longrightarrow \text { oral candidiasis } \longrightarrow
$$

antilunest drats

Oral candidiasis is not necessarily followed by antifungal therapy, but the more overt intoctions

\author{
Keywords \\ Artifungan agents \\ Data collection \\ Pharmanciess \\ Rewression analysis \\ Side-effects \\ Sheroids
}

$H$
$F$
Epi
Lin
Mas
7.
Ind
Eng
1.13
Tok

$H$
Epi
Lim
Mas
7.
Ind
Eny
1.1
Tobs
Sorels: Deparanene of ology. Uninersity of P.O. Box 616, $6200 \mathrm{MD}$ tricht, the Nethertiands. arta: Departiment of ngineerjng, Cha Uniwersity, 1.27 Kasuga, Pungoku,

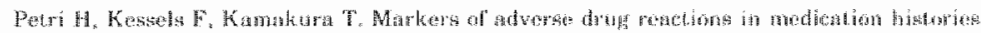

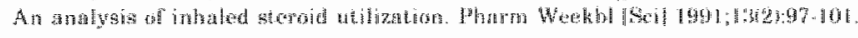

\begin{abstract}

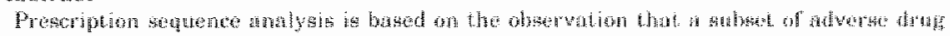

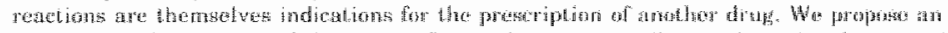

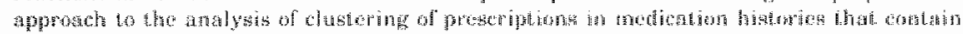

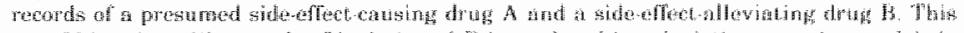

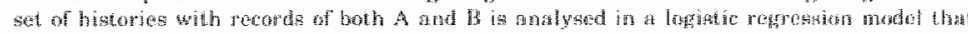

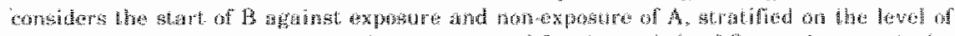

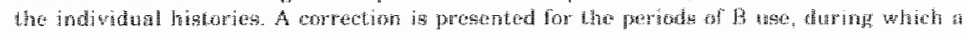

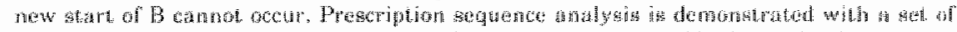

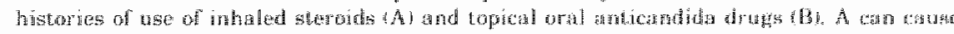

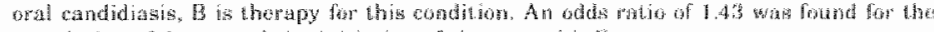

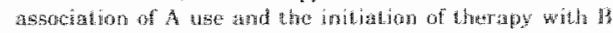

Accepted 15 Fobruary 1990 . 


\section{Table 1}

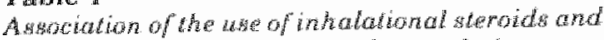
anticandido drutgs in the suludy population

\section{1 peference population}

II users of inhalational steroids (A)

III users of gelected anthingal drugs (B)

Wis users of both and $B$

$$
\text { Crude odds ratio: } \frac{(I+I V-I I-I I) \cdot I V}{(I-I V)-(I I-I V)}=2.58
$$

are likely to be. Nystatin and miconazole, the two antifungal drugs awallable in the Nether lands for topical on al ase, are specifieally labelled for the treatment of candidiasis [7].

A data base of all patient drug histories from 5 Dutch community phamacies was set up. 64,712 histories spanning a mean perbod of 31 months (range $21-40$ monthis) were ayailable. The data were anonymized before lleaving the pharmacies, but could be recognized to belong to one pationt. Due to Dutch administrative requirenents the data base can be comsidered to contain vitually complete information on the non-hospital medjeation.

A talection was made of all medication his tories that contained tecords of the dispensing of" irhalational steroids as well as antrungal drugs (Table 1 ).

Out of 700 users of steroids $22(3.1$ of had a topical antifungal drug at one time. This is in contrat, with the $1.3 \%(815$ out of 64,712$)$ users of antifungal drugs in the reference population. However, as stated earlier, to assess causality we will have to consider the temporall association of use of $\mathrm{A}$ and $\mathrm{B}$. The $3.1 \%$ can be seen as a max. mum of drugtreated adverse reaction, since $B$ that precedes A carnot be cansed by drug A.

\section{Data analysig}

"The usual cohort-type approach, where a drugs which may eatas a side effect is compared with a control dug is questionable here, because of the difficulty of the choice of an appropriate control drut ard becanse of the absence of data on morbidity and behavioural co-variates of the use of the different drugs. Therefore, wo chase another comparigon, whith the patient nuedoation history tewl using the fact that most patients who are prescribed a drug have records covering potiodu of time both prior to and alter thatr tase of tho subject drugs.

Patient mediction hibtories were selected from the described data base. The selection critorion was; records of the use ever of A (inha lational steroids) and $B$ (antifungal medication) should be in the history, In these histories the in. itiation of $\mathrm{B}$ medication is to be compared for the periods before, during and after wse of $A$. 'In. itiation" is the frest day of an inferted period of the use of $B$, i.e. the first of a series of dispensing of the drug. The periods of use of inhalational steroids were astinated from the mount of drug dispensed and the prescribed daily dose (PDD). A period of 30 days was added the end of the cal. culated period to adjust for irregular use and phamacologica hallife. For the antifutegal drugs, wich are typically used for short periods of 1.3 week and have a mell-documented brief duration of action, no period at the end was added however, a repeat prescription was considured to be continuous with the prevous one if it was filled within 30 days after the calculated end of use.

Because drugs used in the first part of the observation period but prescribed before the start of the rocords, will not show up in the patient drug history, andow or 90 days was set at the beginning of the obseryation period. As the typicall duration of the use of one steroid dispense is go days, dugs delivered in this period will appeas at the redefined stant of the medication histories (day 91), whereas before this point no certanty exists if a drug was used. Histonies where the single dispense of $B$ was usta in the first three months of the observation penod are excluded: in the redefined obervation period after day 90 the condition of use of both drugs $\mathbb{A}$ and $B$ is not met

We wart to apply a measure of temporal assoct. ation of $A$ and $B$, stuatificd on the level of the individual histories. The reason is that it seens not sulable to aggregate the data to obtain a one. level overall measure; the length of use of A and the number of $B$ starts may vary considerably betwen histories of different patientis. Con. founding of the results to a positive association would occur if the number of $B$ starts in the history is correlated to the fraction of thme of $A$ use. even if the B starts are distributed uniformly over the whole history. A measure of association of $A$ use and the initiation of $B$ should adjust fon these differences in density of use of drugs between the individual histories.

A new period of dispensing of a drag can obviously only start after cessation of the previous period of we of the drug. This aspect is relevant Con the periods of the use of $B$, the marker drug for a possible adverse reaction, for which the initiation of therapy is considered, i.e. the start of a period of treament. In the analysis the period of use of $B$ aftor its day of start will not be considered. The number of days with no start of $\mathrm{B}$ are composed from the periods before the start. and after the end of the use of $B$ (Tick $I)$. The intervals of the wse of $B$ are deleted from the his. tories.

\section{Patient-stratified analysis}

Two varidubs, both of a binary nature, are to be considered: on aray day medication $B$ may be initiated on not; this initation occurs during wse or mon-use of $\mathrm{A}$. Each medication history can be considered to have a number of $\mathrm{r}_{\text {f }}$ observation days, whith an outcome of two binary variables $x_{i}(t)$ and $y(t)$ on each day

(i) (1) use of A, O non-use of $A$ )

$y(t)$. C intiation of $\mathrm{B}$ therapy.

Q no initiation of $B$ ) 
betgin of

observation

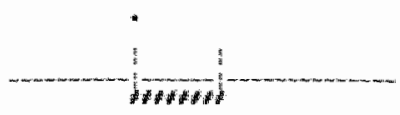

_... - : period of use of medication $A$

- initianion of medication $\mathrm{B}$

and period of use of medication $B$

Figure 1

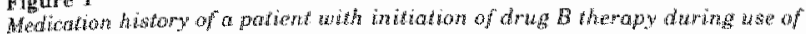
drug A

\section{Figure 2}

Pirthods of use of

steroid drugs

(drug A) and

antifungot dirugs

(atring B) of

seilected porinime

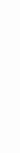
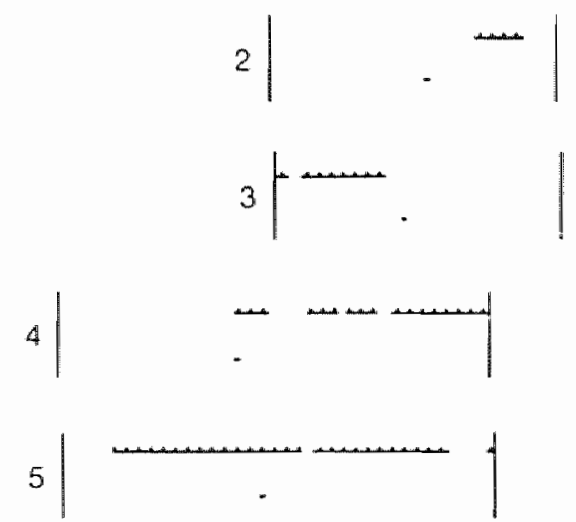

find of

obserwation

over the set of obserwation days for pathent

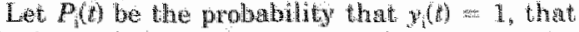
is, the probability that pejeon istarts to lake drug $B$ at day the logrt model in ou" data set is expressed is:

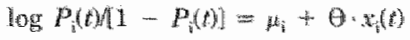

Our main conern is wo assess the association of the rse of drug $A$ and the initiation of $d r u b$; the mull hypothesis can be defrned as $\mathrm{H}_{0}$ : $\mathrm{O}=0$.

The analysis is performed stracifued to the level of the indiwidual medication history, $i e$ over lhe sets of $T$ days of the $i$ porsons The madal is
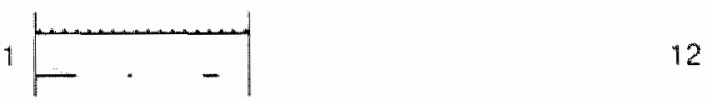

13

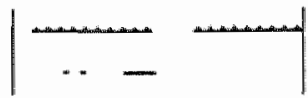

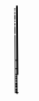

15

16

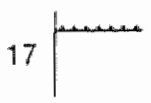

18

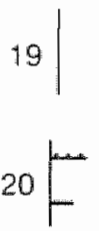

21
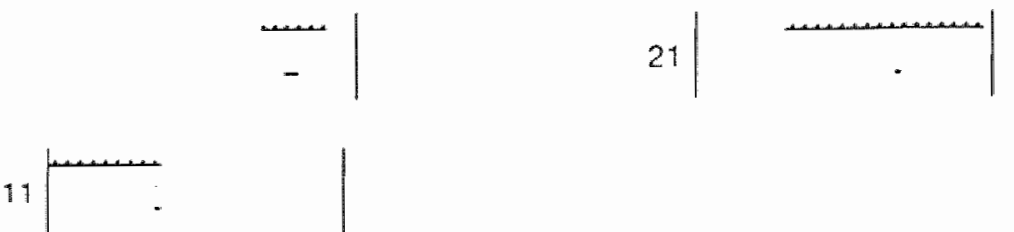
ritued by the use of a logistic regrossion pro grame [8], which makes cotimates of te walueg of the individual histories and of the common value of 0 . The approach dimbram frome com. mon applicution of a logistic regrestion analyois in the stratideation, here each stratum is one of Whe individual patent data sets. "The $\theta$ prr. arneter denoteg the assocation of $\mathrm{B}$ gtarts to nse

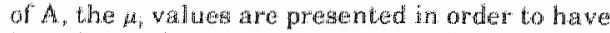
knowledge about the interindividual wariation of starts of $\mathrm{B}$

$A$ biromial distribution is implicit for the use of a logistic regreston model, but as in this case $P_{i}(t)$ is small, also the approximation of a Poison distribution could be used. The design presented here could create the imprestion of a matched case-control study, which typically has 2.6 obsowations per stratum. By analysing a person"s history in its component days a large number of observations is obtaned, suffecient to apply the maximum-likelihood approach.

Susceplibilaty for an adverse reaction may in. crease with age, ine ower the $T_{\mathrm{i}}$ observation days, as the time frame of the data base is small compared to a life span no adjustment will be presemted heles. Chronie therapy, is use of $\mathrm{A}$ over most 7 , abservation days reduces the infor. mation content of the histories, as the logrit model considers bo each history days of $A$ use againgt days of non-use of the drug.

\section{Results}

The crude adds ratio of the use ever of $B$ of patients who had $\mathrm{A}$ is 2.58 (data from Table 1).

In the group of 22 users of $A$ and $B$ one history was excluded because the only dispense of $\mathrm{B} O C$. curred in the first 90 days of the recorded hisitory. A graphical presentation of the remaining 21 histonies given in Figure 2. The crude odds ratio of the one-shatum aggregated 21 histories is 1.66 (Thble 2). For these histories the association of $A$ use and the intiation of therapy with 19 wa analysed stratifiod in a logit modol, as described. Wheth deletion of the periods of $B$. nes the odds ratio is 1.48 iP 0.22 , one sidted. The odde ratio has a whuo of 1 .40 when the periods of B wse are not deloted.

\section{Discussion}

In this papere we considered the measure of as-

\section{Table 2}

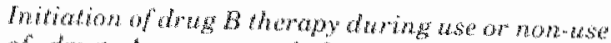
of drug A, stamated for the 21 medication historien

$\begin{aligned} 2 a_{i} & =16 \quad \Sigma b_{i}=15 \\ 2 b_{i} & =8.011 \quad \Sigma d_{i}=12,451\end{aligned}$

Crude odds smatio $=\frac{16}{15} \cdot \frac{12,451}{8,011}=1.66$

*h: starts of $B$ during $A$ ase: $b_{1}$ : starts of $B$ during $A$ non-use; $c_{2}$ : days of $A$ use; $d_{i}$ : days
without A use.
Sociation of the use of inhaled steroids and in utation of topical oral andeandra therapy in a bogitic regression model. The logistic approach makes sense in that multiple maxima of the like lihood function are unlikely unless data are sparse of if gross discepuncie from the whold exist 19 101. The Mantel Hacnazel estmate is less appropriate for the data presented because of the occurrence of a 2 aro walue in ane cell of each of the 212 - 2 tables 111 .

In our set of data, which has a relatively mod. egt size, combining all histories into one stratum (Table 2 ) results in a higher odds ratio that stratified analysis. This higher odds ratio, how ever, grves a distorted vien due to the con founding resulting from a comelation between che number of $B$ starts in a history and the fraction of time of A use, regardless of the distri. bution of the B statts.

Also, the crude odds ratio of the use ewer of both types of druge (Table 1) is higher than the one callulated in the logistic regression. Here, the temporal relationships of drug use were not taken into account; further, the crude odds ratio may be confounded by a medicalization of patients wh a chronically treated condition. Wke asthma, i. these patents tend to be treatied also for other conditions

Stratification to the level of the individual medication histories yields a moderately positive association here. The correction for periods of $\mathrm{B}$ use has no strong impact, as the anticandida drugs tended to be dispensed ron a short period (Fig. 2). For more chronic types of therapy the situation may be wery different, with a clear of. feact of the correction.

As was stated before, a larger fraction of users of inbalational steroids had at some time one of the selected antifungal drugs, compared to the reference population (3.1\% versus $1.3 \%$ (Table 1) the logistic regression still yields a pasitive association, but snallen than would be subgasted by the raw comparison of the use over of the druge in table 1. Thus, while the figure of 3. 1 se sets an upper limit foy druglreated risk. the inclusion of time relationships in the araly. sis lowers the degree of association.

This result suggestis that a substantial patt of oral candidasis was not caused by inhaled ster. oids. Unrecognized background incidence of this condition is perhaps one explanation for the con flicting reports (3-6) on the frequency of oral can. didiags as ande-effoct. These reponts were based on patiend series or cohort studies without a con. trol group and were thus missing imformation on background incidence.

As only some of the people are treated medicalty for an adverse reaction, causality can be studied by looking at the time relationships of drug dispense, but not the actual absolute risk. Thus, the logit analysig performed here has solely the aim to be used in the assessment of causality, not in estimating the incidence of a reportad problem.

\section{Acknowledgement}

Part of the work of this paper was done at the Department of Statistics of Stanford University 
where two of the authors (H. P and T.K. ) noyd hospitality in 1989. We we indebted to Prof. Dr. B. Erron and Prof. Dr. J. Urquhart ror helphil discussions.

\section{Reterences.}

1 Potri I. De Wet R, Nans d, Utouhart of Preseription

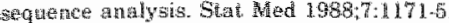

2 Petri H, Letukens Ho Nas d, Silkens R, Van Hespen P. Urouhart of. Rapid method for estimating the risk of

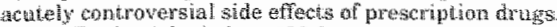
3 Clin Epidemiol 1990-43:433-9.

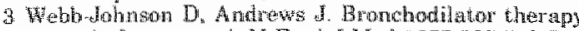
\{acond of wo partet. N Eingl J Med $1977 ; 297,758.64$

4 Reed CE. Acrosols in chronic aigway obetruction. $\mathbb{N}$ Enggl d Med 1986; 158889

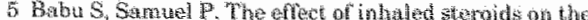

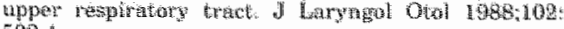
5024

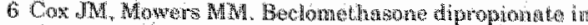

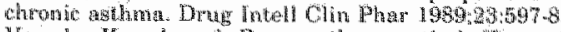

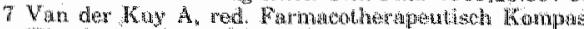
Tharmacotherapertic Compasel. Amotolyeen

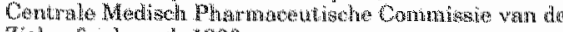
Ziekenfondsatat 1590 .

8 Anorymous. BMDP Gtatibutal Soluwa Mratual. Berkeley: University of Callomin Pres, 198:

9 Cox DR. "The analysis of bimary data. Landon: Nethuen, 1970

10 Everit BS. Thtoduction ho optimingation mathoths and their application in statisties. London: Chamanan and Ha11. 1987

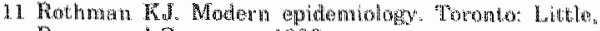
Brown and Company, 1980 
APPENDYX TO CUAMTER 5.

(included for this thesis)

The study described in this chapter and the wo articles reproduced in chapter 4 show applications of prescription sequence analysis. The three articles reflect the different ways by which we analyzed the data. In all three articles analyses were made to ascertain the temporal clustering of prescriptions in medication histories that contain records of a presumed side-effect causing drug $A$ and a side-effect alleviating drug $B$. The initiation (or "start") of therapy with drug B is considered against the periods of inferred exposure and non-exposure to drug $A$ in the drug histories.

The two articles in chapter 4 are both analyses of drug histories of recipients of the anti-vertigo/anti-migraine drug flunarizine. In the analysis of chapter $4 a$ the observed number of starts of drug $B$ over the periods of inferred use and non-use of drug. $A$ is tested with help of a distribution generated by a Monte-Carlo simulation. In this simulation, for each person's drug history, starts of drug B are generated at random over the periods of inferred use and non-use of drug $A$. In chapter $4 b$ the incidence density of starts of drug $B$ is determined for periods of inferred use of drug $A$ and periods of non-use of drug A. An incidence density ratio is determined from the results of the rwo periods.

A need for another way to analyze the data was felt for three reasons:

A) After start of drug B, B is used for a certain period, that varies within the drug histories and between the histories. The analysis should correct for these periods of use of $B$, during which no new start of $B$ can occur.

B) Aggregating the data to obtain a one-level overall measure as was done in chapter $4 b$ may confound the results and can yield a spurious association. In chapter $4 b$ the incidence densities of starts of drug $B$ were established for the periods of inferred use and non-use of $A$. For these both types of use the number of starts of $B$ were aggregated across persons. The durations of use of $A$ and the number of starts of B vary considerably between dnug histories of different persons.

C) For fulture studies, analyses should be possible with more than one drug variable and with other exposure variables.

A) In chapter 5 a correction was introduced for the inferred periods of $B$ use, during which a new start of $B$ cannot occur. The approach was to delete the periods of inferred $\mathbf{B}$ use from the drug histories before performing the logistic regression analysis. Thus, the problem reduces to describing the probability in a person of the occurrence of a condition (inducing the prescription of B) that lasts only one day, after which the person is again at risk to develop this condition. In the analysis presented in this chapter the periods of $B$ use were rather short (figure 2), and the correction had no strong impact. For other studies, with longer periods of treatment with a drug $\mathbf{B}$, this correction will have a more important effect.

B) Prescription sequence analysis tests whether the initiation of therapy with drug $B$ is dependent on exposure to drug $A$. In the selected patient drug histories initiation (or "start") of therapy with drug B occurs at least one time. 
The problem is to estimate the risk of occurrence of the use of drug B dependent on the use of drug $A$ and adjusted for individual determinants that could influence the relationship between the use of drug $A$ and of drug $B$.

After deleting the periods of inferred $B$ use, each day of the remaining drug history is an observation that is assumed to be independent of the use of B on other days. After one day of use of drug $B$ the person is again at risk.

A logistic regression model is used to estimate the probability of the use of drug $B$ dependent on the use of $\operatorname{drug} \mathrm{A}$ and on the individual determinants.

The common application of logistic regression analysis considers for each person in a study group the value for the outcome variable and the values of each of the independent variables, that can be categorical or continuous.

In our data set for each person an outcome parameter (start or non-start of B) has to be considered for each day of the medication history. We used a model that considers each person's history as one stratum of observations, where the observations on each day are mutally independent outcomes. Thus, this outcome is only dependent on the use of drug $A$ and on the individual who is observed.

If the variable $Y$ has the value 1 at an initiation of $d r u g B$ and a value 0 when drug $B$ is not started then the probability that $\mathrm{Y}=1, \mathrm{P}(\mathrm{Y})$, is given by the logistic function:

$$
P(Y)=\frac{1}{1+e^{-z}}
$$

with $\mathbf{z}$ a linear function of the independent variables, i.e. the use of $\operatorname{drug} A$ and the individual determinants of the 21 persons whose drug history was observed. For this problem this function $x$ is defined as

$$
z=\alpha+\beta_{A} \cdot X_{A}+\sum_{i=1}^{21} Y_{i} \cdot C_{i}
$$

For every day of a drug history, the variable $X_{A}$ has the value 1 if the $\operatorname{drug} A$ is used and 0 if $\mathrm{A}$ is not used.

The variable $C_{i}$ with $i=1,2, \ldots, 21$ has the value 1 if the data of person $i$ are considered and the value 0 otherwise.

$\alpha, B_{A}$ and the $\gamma_{i}$ 's are the parameters of the model that are estimated by maximizing the likelihood function that is based on the observed data.

For the person $j$ all $C_{i}$ 's are zero when the i's do not equals $j$. Thus, for a day with no use of drug $A$ the value of $z$ equals $\alpha+\gamma_{j}$ and if drug $A$ is used, $z$ equals $\alpha+B_{A}+\gamma_{j}$.

The probability of the use of drug $B$ dependent on the use of drug $A$ and the individual whose drug history is observed, is estimated by

\footnotetext{
- In lact, this model is redundant and one of the terms $Y_{i}, C_{1}$ is superfuous. In the model used in the article of chapter $5, \gamma_{1}$ is set to zero. This means that the tirst person is the reference and the wallues of of all other persons are compared with that of the first person.
} 


$$
P(Y)=\frac{1}{1+e^{-\left(\alpha+\beta_{A} \cdot X_{A}+\sum_{i=1}^{21} \gamma_{i} C_{i}\right)}}
$$

The odds of event $Y$, Odds(Y), is defined as $P(Y) /(1-P(Y))$ and the equation can be rewritten as

$$
\operatorname{Odds}(Y)=\frac{P(Y)}{1-P(Y)}=e^{\alpha+\beta_{A} x_{A}+\sum_{i=1}^{21} \gamma_{i} C_{i}}
$$

For a person $j$ and a day that drug $A$ is not used, the estimated Odds(Y) equals $\exp \left(\alpha+\gamma_{j}\right)$ and on a day that $\operatorname{drug} A$ is used, $O d d s(Y)$ equals $\exp \left(\alpha+B_{A}+\gamma_{j}\right)$. The estimated ratio of $\operatorname{Odds}(Y)$ of days of use and non-use of $\operatorname{drug} A$ equals $\exp \left(B_{A}\right)$, a common parameter for all persons.

Thus, this Odds Ratio $\exp \left(B_{A}\right)$ can be seen as a measure of the association between the use of drug $B$ and $\operatorname{drug} A$, adjusted for the characteristics of the individual whose drug history is observed.

C) For the assessment of the impact of more than one drug variables or other exposure variables and based on the drug histories of $\mathrm{N}$ persons, the model can be adapted to a more general form

$\operatorname{Odds}(Y)=e^{\alpha+\beta_{A} \cdot X_{A}+\sum_{i=1}^{N} \gamma_{i} \cdot C_{i}+\sum_{j=1}^{M} \Phi_{j} \cdot Z_{j}}$

The additional exposure variables are represented by the $M$ variables $Z_{j}$ and $\Phi_{j}$ represents their related coefficients. 


\title{
CHANNELING BIAS IN THE INTERPRETATION OF DRUG EFFECTS
}

\author{
H. PETRI AND J. URQUHART \\ Deparment of Epidemiology. Uniwersiry of Limbtarg. $6200 \mathrm{MD}$ Hastricht. The Netherlowds
}

\begin{abstract}
SUMMARY
Channeling is a form of allocation bias, where drugs with similar therapeutic indications are prescribed to groups of patients. with prognostic differences. Claimed advantages of a new drug may channel it to patients with special pre-existing morbidity, with the consequence that disease states can be incorrectly attributed to use of the drug. For the study of adverse drug reactions, large databases supply information on comedication and morbidity of patients. For diseases with a stepped-care approach, the drug history of patients, as available from some databases, can show channeling of drugs to patients with markers of relatively sewere disease.
\end{abstract}

\section{INTRODUCTION}

When a new treatment is introduced it competes with pre-existing methods of treatment for the same conditions. Claimed advantages of the new treatment may be general superiority over preexisting methods, but often narrowly defined advantages are all that can be claimed. Practitioners may adopt the new treatment method by displacing or supplementing pre-existing treatments or by prescribing selectively to new patients. If the promotion of the new product has succeeded in creating in physicians" minds a particular patient profile for the new product, then comparisons between observational data gathered on recipients of the new product versus recipients of the older products will be confounded by different morbidities in the two patient groups "Channeling is the term we have coined for this application of drugs in groups of patients who have a susceptibility to problems or who have special pre-existing morbidity. ${ }^{1,2}$

Channeling can be considered as a special form of allocation bias, where interventions, selfselected or clinically assigned, are given to people with major prognostic differences. ${ }^{3}$ Drugs with similar actions that enter the market at different times, and thus in different competitive situations, may be channeled to different groups of patients. For example, a latementry drug is more likely to be given to patients who have not responded satisfactorily to therapy with an established, early-entry drug. If competitive claims are made for a later-entry drug that differentiate it from earlier-entry products, the associated promotion may influence physicians to select different prognostic types of patients to receive the various products in a pharmacologic class.

Another factor that may be pertinent is patient and physician age. Since patients and physicians tend to grow old together, elderly patients may be more likely to use early-entry medicines, because they tend to be treated by longer-practising physicians, who tend to adopt later-entry medicines more slowly.

These varied reasons for such channeling by medical or prognostic status also tend to confound patient-related factors with drug-related factors. An often-used claim is less severe or fewer side- 


\section{H. PETRI AMD I. URQUHART}

effects for the new drug. This claim can lead to selective prescription of the drug to patients who experienced side-effect problems during treatment with an earlier-entry drug. Also, a claimed higher efficacy for the drug may channel it to patients where a prior treatment had failed. Thus, the laterustry product is also likely to end up in use by patients with different attributes.

An example of channeling appears to have occurred after the introduction of 'Osmosin', a controlled-release form of indomethacin, for which claims of fewer gastro-intestinal side-effects were wigorously promoted. When Inman studied this product using the prescription event monitoring method, he found a much higher prevalence of gastro-intestinal complaints among patients long after the end of use of the drug. This suggests that the product had been channeled to patients most likely to suffer from these disturbances. The product was withdrawn on the basis of reports suggesting an unexpectedly high occurrence of gastro-intestinal ulcerations, bleeding, or perforation. Inman pointed out, however, that because the drug was claimed to have fewer side effects, it likely had been prescribed for patients who were most likely to develop these sideeffects.

\section{POPULATION-BASED STUDIES}

Adverse drug reactions are often recognized only after market introduction of the new substance. The rarer reactions cannot be assessed in premarket clinical trials which include a limited number of patients. Also, more common but less obvious side-effects often are recognized only after a period of use in a larger and medically more diverse general population group than was studied in premarket trials.

Thus, the study of adverse drug reactions necessarily involves larger groups of patients than can be economically or logistically managed in randomized, controlled trials. However, studies are observational, rather than controlled, and thus are subject to various biases, including chan neling bias. The occurrence of side-effects of drugs in one therapeutic class can be compared. A central issue in this situation is whether the groups of users are comparable in relevant characteristics: the treated disease, co-morbidity, age, sex, and other factors.

\section{CHOICE OF CONTROLS}

The effects of drugs - beneficial or unwanted -are often best studied in comparison to other drugs with similat therapeutic indications. For a new drug which is the first treatment for a condition, comparison to a placebo reference group is appropriate. In contrast, when other therapies exist, the comparison of the new drug should be to the existing therapies. A similar statement can be made for side-effects, especially as a new drug's main benefit is often claimed to be fewer sideeffects than old therapies.

In observational studies channeling will often make this type of comparison invalid. Generally, the analysis for such comparisons tries to correct for relevant patient baseline characteristics. Many can be collected in the data, but obviously some cannot, because the factors are not known or because the data cannot be gathered. This problen is ubiquitous in databases collected for one purpose and later used for other purposes.

Studies with existing databases are comparable in this respect to classical case-icontrol or historical cohort studies where inevitably some relevant patient variables from the past will not be known. Even if a database was conceived for research purposes, later studies will be likely to suffer from a lack of relevant data, be it directly on medical aspects such as comorbidity or medication, or more indirectly on behavioural factors like smoking or occupational activities. ${ }^{6}$ These points are independent of whether the database is computerized or not. 


\section{MEDICATION.USE DATABASE}

The situation is quite different for coding medicine use than for coding other types of therapy or diagnoses. Owing to reimbursement requirements, pharmacy dispensing records are unequivocal about names of drugs, drug regimens, and amounts dispensed. Data are less specific for procedures like surgical operations which often thave many variants. Diagnostic data tend to be the most diffeult to classify, for diagnosis is a process with many uncertainties and many, often arbitrary, criteria.

While the nomenclature of medicines has few problems, other aspects of database use should not be ignored. The data on drugs may not be complete, or may not be identifiable on the individual patient level. Data on outpatient drug use can be collected from pharmacies or from health insurers. Pharmacies in most countries have no complete data on drug use at the individual patient level. An exception occurs in The Netherlands, where the national insurance scheme requires participating patients to designate one pharmacy from which they obtain all reimbursed drugs. In the U.S. a comparable situation prevalls in some Medicaid data " and in some managed care situations. Confidentiality regulations sometimes preclude the use of medication data for research purposes, as, for example, in the rather extreme Swedish case where privacy concerns preclude storing medication data in pharmacies ${ }^{8}$ for more than a day or two.

Having complete records on individual patients is essential, and the longer the duration spanned by the records, the better. A peculiarity of many administrative databases is they do not define a distinct start for the patient's record. Thus, even if the data are complete over a certain period it may be that only the first records of delivered care incicate coverage, leaving the preceding time ambiguous about actual coverage.

\section{AN EXAMPLE: CHANNELING OF MEDICATION FOR ASTHMA}

If a disease is treated in a stepped-care approach, the drugs given can be used as markers for disease severity. We studied the use of asthma medication for channeling of aerosol beta agonists, ${ }^{2}$ as recorded in a large pharmacy database. These aerosol beta agonists tend to be used as a first-line therapy for asthma, while inhalational steroids and other drugs are supplemented for the more severe disease. The three aerosol beta agonists available in The Netherlands differed considerably in concomitant use of inhalational steroids: 23.0 per cent of albuterol (salbutamol) recipients, 35.4 per cent of terbutaline recipients and 42.4 per cent of fenoterol recipients used inhalational steroids. These data support the notion that physicians channel fenoterol to patients with more severe asthma. This channeling of fenoterol may lead to a non-causal linkage of the drug to consequences of severe asthma.

\section{NON-ETIOLOGICAL STUDIES}

Databases are useful for other analyses than just drug intervention effects, for, example, drug and facilities utilization studies. A rational use of health care facilities is promoted by knowledge of such aspects as the indication for prescription of drugs, multiple use of drugs, and markers of the health status of patients. Differences of delivered care in separate insurance schemes may reveal types of procedures or therapies that depend heavily on reimbursement. Between-physician and between-hospital differences in delivered care suggest inefficiencies or underuse or overuse of certain types of care. A strong variation in therapy use across physicians or regions can help identify the less useful therapies, though a final appraisal of efficacy can only come from a. properly controlled trial. 
H. PETRI AND 1. URQUHART

\section{CHANNELING IN SURGERY}

Channeling is especially prominent in surgical therapy, not only because of surgeons" reluctance to operate on high-risk patients, but also when different procedures are perceived to entail different risks. An apparent example of this issue is recent controversy ${ }^{9}, 10$ over a study of the effectiveness and long-term mortality of transurethral versus open prostatectomies for prostatic hyperplasia.

\section{AN APPROACH TO AVOID CHANNELING BIAS}

The choice of an appropriate control group is essential for any form of obserwational study. In studies of treatment effects, baseline characteristics pertaining to the outcome should be identified in advance. Stratification of the subjects into subgroups for these characteristics can correct for imbalances, though oftem not all televant factors are known.

For some questions the selection of control patients can be obviated by comparing different periods of a person's medical history. This is analogous to the crossover design in experimental studies. An example is a recent study, in which we considered whether a widely-used antivertigo/anti-migraine drug, flunarizine, was responsible for causing mental depression. We studied drug dispensing records in a group of 155 patients who had, at some time during the period of data collection, received both funarizine and an anti-depressant drug. ${ }^{11}$ We looked for a temporal clustering of prescriptions for anti-depressant drugs following the start of flunarizine.

Control data were taken not from other groups of patients, but from the patients themselves, in the periods before and long after their use of flunarizine. The within-patient comparisons revealed evidence of only a small risk of flunarizine-related depression because we avoided the confounding effect of what was a very sizeable channeling of flunarizine into use by depression-prone patients. The eventual recipients of funarizine had a $3 \cdot 5$-fold higher background rate of antidepressant drug prescribing than a reference group of recipients of any drug.

The actual within-patient comparison was done by comparing the incidence of initiation of anti-depressant therapy during the periods of flunarizine use ( $I$ il) with the incidence during the rest of the time covered by the database, that is, the periods before and after use of flunarizine $(\mathrm{m} w)$. The incidence is defined as the number of first prescriptions per 1000 observation dawe $A_{\mathrm{n}}$

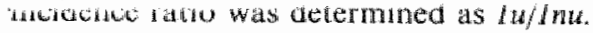

\section{CONCLUSION}

Channeling can be considered as a type of misclassification when not recognized in the analysis of observational studies. A consequence of the misclassification is that disease states can be incorrectly attributed to use of a drug. Alternatively, when there is knowledge about the differential use of a drug in different stages of a disease, or if a disease has a stepped-care treatment with medicines, the information about a patient's medication can be used to stratify for severity of condition. Within-patient control data can also help avoid channeling bias.

\section{REFERENCES}

1. Urquhart, J. 'ADR crisis management - before and after', Scrip, 1388, 19-21 (1989)

2. Petri, H., Naus, J. and Urquhart, J. 'Channeling of aerosol beta agonists and the interpretation of a concomitant adverse event', Joumal of Clinical Research and Drug Development, 3, 224 (1989).

3. Feinstein, A. R. Clinical Epidemiology, Saunders, Philadelphia, 1985.

4. Inman, W. H. W. "Comparative study of tive NSAIDs", PEM News, 3, 3-13 (1985). 


\section{CHANNELING BIAS IN THE INTERPRETATION OF DRUG EFFECTS}

5. Petri, H., De Vet, H. C. W., Naus, J. and Urquhart, J. "Prescription sequence analysis: a new and fast method for assessing certain adverse reactions of prescription drugs in large populations', Statistics in Medicime, 7, $1171-1175(1988)$.

6. Connel, F., Diehr, P. and Hart, L. "The use of large databases in health care studies", Ammal Review of Public Health, 8, 51-74 (1987).

7. Aworn, J., Everitt, D. and Weiss, S. 'Inereased antidepressant use in patients prescribed beta-blockers', Journal of the American Medical Association, 255, 357-360 (1986).

8. Bergman, U. "Pharmaco-epidemiological perspectives", Pharnaceutisch Weekblad Scientific Edition, 11. $151-154(1989)$.

9. Roos, N., Wennberg, I., Malenka, D., Fisher, E., McPherson, K., Andersen, T., Cohen, M. and Ramsey, E. 'Mortality and reoperation after open and transurethral resection of the prostrate for benign prostatic hyperplasia:, New England Journal of Medicine, 320, 1120-1124 (1989),

10. Klotz, L. H. "Mortality and reoperation after prostatectomy for benign prostatic hyperplasia", New England Joumat of Medicine, 321, 1122-1123 (1989).

11. Petri, H., Leufkens, H., Naus, J., Silkens, R., VanHessen, P. and Urquhart, I. "Rapid method for estimating the risk of acutely controversial side effects of prescription drugs", Journat of Clinical Epiderniology, 43, 433-439 (1990). 



\title{
Characteristics of Patients Prescribed Three Different Inhalational Beta-2 Agonists: An Example of the Channeling Phenomenon
}

\author{
Hans Petri John Urquhart

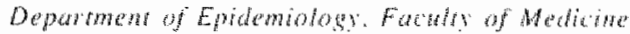

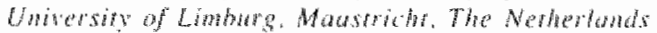 \\ Ron Herings Alber Bakker

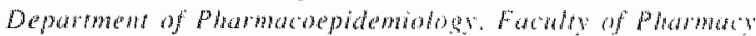 \\ Universiry of Ureche Urech. The Neiheriands

\section{Summary}

In order to detect channeling of medication for asthma to patients diflering in disease severty. prescription drug histories of wsers of three inhalational beta agonists were compared. We looked a markers of asthma severily and of concomitan cardiovascular disease and diabetes.

We found 2-2.5 times more concomitant systemic steroid therapy prescribed to fenoterol recipients than to salbutamol recipients. Terbutaline tecipients were intermediate. We found the highest proportions of other anti-asthma medications among fenoterol recipients, intermediate proportions among terbutaline recipients, lowest proportions among salbutamol recipients. Thus, Dutch physicians seem to channel terbutaline and especially fenoterol to patients with more severe forms of asthma. 
There were no differences with respect to prescriptions for cardiovascular of diabetic drugs.

If not recognized. channeling may result in allocation bias in observational studies on drug eflects.

Key Worls - Pharmacoepidemology: asthma fenoterol: gerbutaline: salbutamot: aerosol therapy: adverse drug reacions

\section{Introduction}

Increase of asthma mortatity has been reported in the last two decades from several countries. " An earlier apparent epidemic occurred in the mid-sixties in Britain. Australia and New Zealand. "-to More recently, increase of asthma mortality is reported in more countries, especially in New Zealand. where a marked increase was observed in the late seventies. Feveral reasons for the observed increased asthma mortalthy have been forwarded: increased prevalence of asthma increased severity, changes in diagnostic classification. better ascertainment, changes in therapy includiag the use of multiple drugs. $6.5 \%$

Since their introduction in the 1960s. inhalational beta agonist drugs have been a comerstone in asthma therapy. However. concern about increased risk of sudden death of asthmatics in relation to use of the drugs has frequently been raised. 10.1? The existence of a causal link between death from asthmand the use of pressurized aerosols has been controversial. A problem is that there are many pitfalls in observational studies on a disease such as asthma which is diticult to stage with respect to severity and tends to be treated with mulliple druggis.

A recent study suggested a dibterence in risk of fenoterol and salbutamol. In this case-control study. mortality was found to be associated to patients who were prescribed tenoterol in metered-dose inhale form.

The study of infequent adverse drug reactions relies on methods that unlike mandomized controlled trials, are inherenty susceptible ro biases. "is In case-control studies on drug effects, the choice of an appropriate control group is a special problem. and the debate on fenoterol-associated mortality "was locussed especially on the selection of the control patients. ${ }^{15}$.17ditional issues are whether the drug was actually used during the atack and whether the drug has a direct adverse eflect or its use leads to delay in seeking help.

Initial experiences with a new drug tend to establish a pattern of subsequent use. leading 10 "channeling", the term we use for selective prescribing of a drug to patients with special prognostic characteristics or degrees of disease severity. 
In obserwational studies. channeling will act as a form of allocation bias if differences of baseline chatacteristics go unrecognized or not adjusted-for. The subject of our study relates to the comparability of patients using the various inthational betam 2 agonist drugs. In The Netherlands, salbutamol was introduced in 1968 . rerbutaline in 1970 and fenoterol in 1971. Later-introduced drugs are more likely to find their principal first uses in patients who have not responded satistactorily to previously available drugs. 2

Asthmatics are often treated with a stepped-care approach, with apectrum of drugs of presumed increasing potency bu decreasing therapeuric benctiv/rist ratio.

Established practice in The Netherlands and other countries is that inhalational beta-2 agonists are used initally, and if this mode of trextment proves insurticient. inhalational steroids are added. and then. if that proves still insurricient. systemic treatment with theophylline is added. followed (or replaced). il necessany, by systemic steroid treament. " European practice ditters from North American in reserving systemic theophylline treatment for patients who have not responded sulistactorily to inhalational drugs.

We used outpatient prescription drug histories as markers of severity of asthma. based on the assumption that prescribing was substantially driven by physcians" adherence to the foregoing stepped-are system of treatment. We also used these histories to identify patients wh concomitant cardiovascula disease or diabetes. both being conditions with characteristic and specitic drug therapy. Cardiovascular disease and diabetes are also two major recognized causes of sudden death.

We used a large database of outpatient drug dispensing histories. In The Netherlands. the majority of the patients are insured in a general heallh insurance system called Ziekenfonds. which requires patients to designate one pharmacy from which they obtain all reimbursed drugs. Also, pharmacies have computerized record-keeping as the basis for reimbursemen. These wo factors insured that almost complete medication histories were available for our study.

\section{Methods}

The five inhaled bella agonists available in The Netherlands are sallatamol. rerbutaline, fenoterol, isoprenaline, and rimiterol.

The data source was a 12-pharnacy database covering all medications prescribed and dispensed in the year 1988 (reterred to hereater ws the "one-year database"). This reterence population encompasses 121,000 patients, two thirds of them insured by the Ziekentonds.

Patients drug histories and data relating to the prescribing physicians were anonymized before leaving the pharmacy. In our database all prescriptions dispensed 
to cach patient had a unque code number to maintain separate but anonymous identily of each patient's prescription drug history.

We studied beta-2 agonists that were dispensed to at least 10 patients in the metered-dose aerosol or inhaled dry powder formulation.

We determined the following:

- recipients of prescriptions for each inhalational beta-2 agonist. their sex distribution and median age, in the one-year database (Table T); the recipients of inhalational beta- 2 agonists who:

- were prescribed and dispensed systemic steroids within a six-month time window (Table II):

- were prescribed $1,2,3$ or more different categories of anti-asthma medications within a six-month time window (Tables III and IV);

- were prescribed cardiovascular or antidiabetic medication, within a six-month time window (Tables $V$ and VI).

The six-month time window for assessing co-medication was set to indicate concomitant use of the various types of drugs, recognizing that most prescriptions are dispensed in quantities sufficient to last for 2-3 months. A 6-month time window is a compromise choice - long enough to see at least one dispense in chronic medication, but not so long as to make it likely that agents were used in different periods, rather than concomitantly, within the time window.

Following the age grouping defined by Crane et al. "we divided patients into those aged $5-45$ years and those aged over 45 years, at December $31,1988$.

To judge co-medication with inhalational beta-agonist drugs, we selected categories of drugs according to the ATC drug classification, 23 as follows:

respiratory drugs (Tables II. III and IV)

- inhaled glucocorticoids (R03BA)

- theophylline and derivates (RO3DA)

- cromoglycate (R03BCOI)

- systemic beta-agonists (R03CC)

- ipratropium (R03BBOH)

systemic glucocorticoids (H02 AB)

antidiabetic drugs (Tables V and VI)

- insulines (A10AA)

- biguanides (A 10BA)

- sulphonamides, urea derivates (A IOBB)

systemic cardiovascular medication (Tables $V$ and VI)

- cardiac glycosides (COLA)

- beta-blockers (C07A)

- calcium re-entry blockers (CO2DE)

- coronary vasodilators (COlDA)

- diuretics (CO3) 
- antithrombotic agents (BOIA)

- anti-arrhythmic drugs (COIB)

- lipid lowering drugs (B04)

- ACE-imhibitors (CO2EA)

\section{Results and Discussion}

The results are shown in Tables 1-VI. Table I shows that sabutamol is the most prescribed inhalational adrenergic drug in The Netherlands. Fenoterol and terbutaline have far less users. Not included are the inhaled powder form of terbutaline and all inhaled forms of rimiterol and isoprenaline: these products did not rench the criterion of 10 users to be included in the analyses. For salbutamol it is also evident that the dry powder form is used much more than the pressurized aerosol t table 1). Because some patiens had received both aerosol and dry powder capsules of a drug. results in the lables cannot be added.

The 5-45 year age group is chosen in order to compare the data with the results of the New Zealand Asthma Mortality study. "In which this same age grouping was used. The data presented here are for patients with all degrees of atsthma severity. with drug dispensing taken as selection criterion. Obviously. the New Zealand study covers a very different patient group: cases and controls were selected, respectively, for death due to asthma or for hospitalization for asthma. The effects of these selection criteria are reflected in the degree of drug use of the parients: $44 \%$ of the control patients in the New Zealand study were using three or more asthma drugs at the time of hospital admission. while in our study the patients tended to receive less drugs (Table III). For example. 49 of 250 salbutamol aerosol users $(19.6 \%)$ were concomitantly treated with two or more other antiasthima drugs.

Our assessment of co-medication, which encompassed a 6-monih period. will lead to a somewhat higher count than an assessment encompassing one reterence day. as was done in the New Zealand study. Exen so, patients in different subgroups of the 5-45 year age group had a lower number of asthma drugs than found in the New Zealand study (Table III). Both differences point to a greater severity of disease in the patiens in the New Zealand study than in ours.

The fraction of younger recipients of three or more other types of asthma drugs was highest in the fenoterol aerosol group and lowest in the salbulamol groups (Table III); recipients of terbutaline aerosol had an intermediate position. We found a simblar pattern of differential use of multiple anti-asthmadrugs in the older group. against a background of more co-medication in all subgroups of older palients. compared to younger patients (Table IV). 


\section{TABLE}

Numbers and median ages of mate (M) and femate (F) users of inhaled beta-? agonist drugs of all ages. dwing a one-year observation period

\begin{tabular}{|l|c|c|c|c|}
\hline & No. of Users & \multicolumn{2}{|c|}{$\begin{array}{c}\text { Median Age } \\
\text { (years }\end{array}$} \\
\cline { 2 - 5 } & $\mathrm{M}$ & $\mathrm{F}$ & $\mathrm{M}$ & $\mathrm{F}$ \\
\hline Fenoterol aerosol $0.2 \mathrm{mg}$ & 43 & 46 & 37 & 46.5 \\
Fenoterol powder $0.2 \mathrm{mg}$ & 26 & 29 & 29 & 39 \\
\hline Salbutamol aerosol $0.1 \mathrm{mg}$ & 368 & 264 & 36 & 45.5 \\
Salbutamol powder $0.2 \mathrm{mg}$ & 513 & 395 & 17 & 22 \\
Salbutamol powder $0.4 \mathrm{mg}$ & 1011 & 299 & 41 & 56 \\
\hline Terbutaline aerosol $0.25 \mathrm{mg}$ & 65 & 64 & 24 & 25.5 \\
\hline
\end{tabular}

TABLE II

Numbers of beta-2 agorist users, by age, with systemic steroid co-medication daring a 6-month observation period

\begin{tabular}{|c|c|c|c|c|}
\hline \multirow{4}{*}{$\begin{array}{l}\text { Fenoterol aerosol } 0.2 \mathrm{mg} \\
\text { Fenoterol powder } 0.2 \mathrm{mg}\end{array}$} & \multicolumn{2}{|c|}{$5-45$ Years } & \multicolumn{2}{|c|}{$>45$ Years } \\
\hline & N & With steroids & N & With steroids \\
\hline & 36 & $8(22 \%)$ & 27 & $15(55 \%)$ \\
\hline & 30 & $6(20 \%)$ & 14 & $8(57 \%)$ \\
\hline Salbutamal aerosol $0.1 \mathrm{mg}$ & 250 & $23(9 \%)$ & 175 & $54(31 \%)$ \\
\hline Salbutamol powder $0.2 \mathrm{mg}$ & 437 & $18(4 \%)$ & 152 & $32(21 \%)$ \\
\hline Salburamol powder $0.4 \mathrm{mg}$ & 764 & $64(8 \%)$ & 1012 & $229(23 \%)$ \\
\hline Terbutaline aerosol $0.25 \mathrm{mg}$ & 46 & $6(113 \%)$ & 29 & $13(45 \%)$ \\
\hline
\end{tabular}




\section{TABLE III}

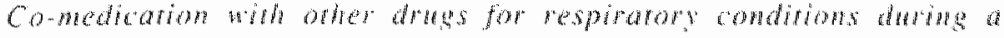

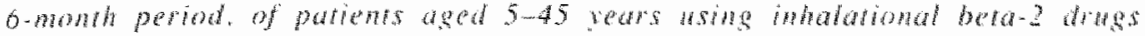

\begin{tabular}{|l|c|c|c|c|}
\hline & No. of respiratory drugs used as co-medication \\
\hline & $\mathrm{N}$ & None & $1-2$ & 3 or more \\
\hline Fenoterol aerosol $0.2 \mathrm{mg}$ & 36 & $13(36 \%)$ & $13(36 \%)$ & $10(28 \%)$ \\
Fenotarol powder $0.2 \mathrm{mg}$ & 30 & $19(63 \%)$ & $6(20 \%)$ & $5(17 \%)$ \\
\hline Salbutamol aerosol $0.1 \mathrm{mg}$ & 250 & $159(64 \%)$ & $65(26 \%)$ & $26(10 \%)$ \\
Salbutamol powder $0.2 \mathrm{mg}$ & 437 & $287(66 \%)$ & $112(26 \%)$ & $38(9 \%)$ \\
Salbutamol powder $0.4 \mathrm{mg}$ & 76.4 & $476(62 \%)$ & $200(26 \%)$ & $88(12 \%)$ \\
\hline Terbutaline aerosol $0.25 \mathrm{mg}$ & 46 & $19(41 \%)$ & $16(35 \%)$ & $11(24 \%)$ \\
\hline
\end{tabular}

TABLE IV

Co-medication with other drugs for respiratory condirons dwing a 6-month period. of pariens aged $>45$ years wing inhalational bera-2 atugs

\begin{tabular}{|l|c|c|c|c|}
\hline & \multicolumn{2}{|c|}{ No. of respiratory drugs used as co-medication } \\
\cline { 2 - 6 } & $\mathrm{N}$ & None & $1-2$ & 3 or more \\
\hline Fenoterol aerosol $0.2 \mathrm{mg}$ & 27 & $5(19 \%)$ & $5(19 \%)$ & $17(6.3 \%)$ \\
Fenoterol powder $0.2 \mathrm{mg}$ & 14 & $2(14 \%)$ & $6(43 \%)$ & $6(43 \%)$ \\
\hline Salbutamol aerosol $0.1 \mathrm{mg}$ & 175 & $71(41 \%)$ & $56(32 \%)$ & $48(27 \%)$ \\
Salbutamol powder $0.2 \mathrm{mg}$ & 152 & $75(49 \%)$ & $43(28 \%)$ & $34(22 \%)$ \\
\hline Salbutamol powder $0.4 \mathrm{mg}$ & 1012 & $380(38 \%)$ & $377(37 \%)$ & $255(25 \%)$ \\
\hline Terbutaline aerosol $0.25 \mathrm{mg}$ & 29 & $9(31 \%)$ & $8(28 \%)$ & $12(41 \%)$ \\
\hline
\end{tabular}




\section{TABLE V}

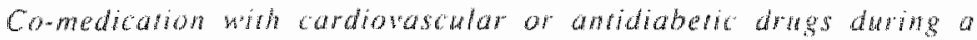
b-momh period. of patients aged $5-45$ years asimg inhalanonal bera-2 drags

\begin{tabular}{|l|c|c|c|}
\hline & $\mathrm{N}$ & $\begin{array}{c}\text { Users of } \\
\text { CardiovascularDrugs }\end{array}$ & $\begin{array}{c}\text { Users of } \\
\text { Antidiabenc Drugs }\end{array}$ \\
Fenoterol aerosol $0.2 \mathrm{mg}$ & 36 & $0(0 \%)$ & 1 \\
Fenoterol powder $0.2 \mathrm{mg}$ & 30 & $1(3 \%)$ & 0 \\
\hline Salbutamol aerosol $0.1 \mathrm{mg}$ & 250 & $7(3 \%)$ & 0 \\
Salbutamol powder $0.2 \mathrm{mg}$ & 437 & $3(1 \%)$ & 4 \\
Sallbutamol powder $0.4 \mathrm{mg}$ & 764 & $19(2 \%)$ & 0 \\
\hline Terbutaline aerosol $0.25 \mathrm{mg}$ & 46 & $0(0 \%)$ & 0 \\
\hline
\end{tabular}

TABLE VI

Comedication with cardiowasmala or antidiabetic drugs durng a 6-month period, of pariens aged $>45$ years wing iwhatarional bera-2 drags

\begin{tabular}{|l|c|c|c|}
\hline & $\mathrm{N}$ & $\begin{array}{c}\text { Users of } \\
\text { CardiovascularDrugs }\end{array}$ & $\begin{array}{c}\text { Users of } \\
\text { Antidiaberic Drugs }\end{array}$ \\
\hline Fenoterol aerosol $0.2 \mathrm{mg}$ & 27 & $8(30 \%)$ & 0 \\
Fenoterol powder $0.2 \mathrm{mg}$ & 14 & $7(50 \%)$ & 2 \\
\hline Salbutamol aerosol $0.1 \mathrm{mg}$ & 175 & $65(37 \%)$ & 5 \\
Salbutamol powder $0.2 \mathrm{mg}$ & 152 & $63(41 \%)$ & 40 \\
Salbutamol powder $0.4 \mathrm{mg}$ & 1012 & $398(39 \%)$ & 1 \\
\hline Terbutaline acosol $0.25 \mathrm{mg}$ & 29 & $11(38 \%)$ & 9 \\
\hline
\end{tabular}

The degree of co-medication with systemic corticosteroids is shown in Table II. This group of drugs is analysed also separately because it can be considered to be used by patients with more severe forms of asthma. In the younger age group. the use of systemic corticosteroids was highest in the group of fenoterol aerosol 
recipients: $22 \%$, and nearly as high $(20 \%)$ for the fenoterol dry powder users (Table 11). In contrast, less than $10 \%$ of the younger recipients of different forms of salbutamol had also received systemic steroids. Terbutaline was intermediate. Similar differences were found in the older age group (Table ll).

Cardiovascular and diaberes co-medication was not markedly different between the asthma drug groups (Tables $V$ and VI). It is low in the younger group but considerable in the older group.

In conclusion, the data show that inhalational fenoterol and terbutaline are channeled irto use in more patients with severe asthma than inhaled salbutamol. In contrast, the users of inhalational fenoterol, terbutaline and salbutamol do not have different patterns of co-medication with cardiovascular or diabetes drugs.

Compared to inhatational salbutamol, in The Netherlands inhalational terbutaline and especially fenoterol are dispensed to patients with more severe forms of asthma. Unless recognized, this channeling can be expected to result in allocation bias in observational studies. In turn, this can lead to unjustified conclusions about the individual drugs' differential therapeutic effects or propensities to cause adverse reactions.

\section{Acknowledgement}

The authors acknowledge grant support from Boehringer-Ingelheim GmbH.

\section{References}

1 Jackson RJ, Sears MR, Beagtehole R, Rea HH. International trends, in asthma mortality: 1970 to 1985. Chest 1988:94:914-18.

2 Burney PGI. Asthma mortality in England and Wales: evidence for al further increase 1974-84. Lancel 1986: ii: 323-26.

3 Sly RM. Increases in deaths from asthma. Ann Allurgy 1984; 53:20-25.

4 Inman WH. Adelstein AM. Rise and fall of asthma mortality in England and Wales in relation to use of pressurized aterosols. Lancel 1969 ; ii: $279-85$.

5 Gandevia B. The changing patem of mortality from asthma in Australia. 2. Mortality and modern therapy. Med J Aust 1968; 2: 884-91.

6 Lanes SL, Walker AM. Do pressurized bronchodilator aerosols cause death among asthmatics? Am I Epidemiot 1987; 125: 755-60.

7 Jackson R, Beaglehole R, Rea HH. Sutherland DC. Mortality from asthma: a new epidemic in New Zealand. Br Med J $1982 ; 285: 771-74$.

8 Esdaile JM, Feinstein AR, Horwitz Rl. Reappraisal of the United Kingdom epidemic 
of fata asthma can general mortality data implicate a therapeutic agen? Arch Intern Med 1987: 147: 54349 .

9 Robin ED Death from bronchial asthma. Chest 1988:93: 614-18.

10 Crenberg MJ. Isoprenaline in myocardial faijure (Letter). Lancer 1965: it: 442-43.

11 Stolley PD. Schinar R. Association between asthma mortality and isopreterenol aerosols: a review. Prev Med 1978: 7: 319-78.

12 Collins IM. MCDewit DG. Shanks RG. Swanton JG. The cardio-1oxicity of isoprenaline during hypoxia. Br J Pharm 1969: 36: 35-39.

13 Crane J. Flat $A$. Jackson $R$ et al. Prescribed fenoterol and dean from asthma in New Zealand, 1981-83: case-control study. Lancet 1989: 1: 917-22.

14. Inman WHW ced Moniloring for drug safery. Lancaster: MTP Press 1986.

15 Sacken DL. Shannon HS. Browman GW. Fenoterol and fatal asmma. Lancer 1990: i: $45-46$.

16 ODonnell TV, Rhea HH, Holst PE, Sears MR. Fenoterol and fatal asthma. Lancet 1989: i: 1070-71.

17 Buist AS. Bumey PG. Feinstein AR et al. Fenoterol and fatal asthma. Lancet 1989 : i: 1071 .

18 Petri H, Naus J, Urquhat J. Channeling of aerosol beta agonists and the interpretation of a concomitant adverse event. J Clin Res Drug Dev 1989; 3 (abstr): 224.

19. Petri H. Unquart J. Channeling bias in the interpretation of drugeffects. Statist Med fill presst.

20 Urquhard I. Two cheers for NSAIDs. Gut 1986: 27: 1287-91.

21 Newhouse MT. Dolovich MB. Control of asthma by aerosols. N Engl J Med 1986: 315: 870-74.

22 Sherter $\mathrm{CB}$ er al. Chronic Obstuctive Pulmonary Disease. In: George RB. Lighi RW, Matthay RA leds). Chest Medicine. New York, Churchill Liwingstone 1983: $229-68$.

23 Nordic Council on Medicines. Nordic Statistics on Medicines 1981-1983. Part II. Nordic Drug Index with Classification and Defined Daily Doses. Uppsala 1985.

Correspondence should be addressed to:

H. Pertri, M.D.

Vakgroep Epidemiologie. Rijkstuniversiteit Limburg Postbus 616.6200 MD Maastricht

The Netherlands 


\title{
Channeling of antidepressant drugs to patients with cardiovascular disease
}

\author{
Hans Petri ${ }^{1}$, Rob Heerdink ${ }^{2}$, Hubert G. Leufkens², Fons Kessels ${ }^{1}$ \\ and John Urquhart'
}

\author{
'Department of Epideniology. University of Limburg. Madstrich, and Deparment of \\ Phamacoepidemiology, University of Urech, Unech. The Notherhats
}

(Received 9 September 1991, accepted 14 Oclober 1991)

\begin{abstract}
Summary
Antidepressant drugs differ in their propensity to cause cardiac side-effects. Clatimed advantages of a drug may channel it to patients with special pre-existing morbidity, with the consequence that patient characteristics may be confounded with drug effects. We measured the relative usage of the various antidepressant drugs in patients with and without cardiovascular disease, particularly to learn whether antidepressant drugs without cardiae side-effects were more likely to be prescribed for patients with concomitant cardiovascular conditions. Our primary data were the drug-dispensing records from Dutch community pharmacies, covering $\$ 173$ anonymized recipients of antidepressant drugs in a 6 -month period. We interpreted as marker of cardiovascular disease the concomitan prescribing of major cardiovascular drugs, such as cardiac gycosides, beta blockers, calcium anta. gonists and the like. The diferences in the percentage of recipients of antidepressant drugs concomitantly prescribed major cardiac agents were considerable. At the high end were mianserin (36\%) and doxepin (35\%); at the low end were fluoxetine $(13 \%)$ and clompramine (18\%). When the deitu were stratified for age and sex. however, no significan residual differences remained with respect to cardiovascular co-medication. Thus, channeling occurs in some drugs, but apparently partly via the indirect way of age/sex differences of the recipients of the drugs.
\end{abstract}

Key words: Pharmacoepidemiology; Antidepressant drugs; Mental depression; Cardide disease; Adverse drug reactions

Correspondence: Hans Perri, M.D., Vakgroep Epideniologie, Rijksumiversiteit Limburg, Postbus 616, 6200 MD Maastricht, The Netherlands. 


\section{Introduction}

Tricyclic antidepressant (TCA) drugs have significant cardiovascular effects. The effects can be classified as conductivity disturbances, arrhythmias and orthostatic hypotension ${ }^{1.2}$. In therapeutic dosages these effects are considered to be a problem only with persons with actual cardiac disease $\mathrm{e}^{2,3}$, but overdosage with TCA drugs can induce life-threatening arrhythmias ${ }^{2,46}$. The newer, non-TCAs form a heterogeneous group of drugs; some are considered to be more safe with respect to the cardiovascular system ${ }^{1,2,4.7}$.

Cardiovascular disease is quite common in the age group of users of antidepressants and thus a problem of therapeutic choice will arise frequently. The antidepressants available differ in their labelling as concerns use in patients with cardiovascular disease. Thus, selective prescribing of certain antidepressants to groups of patients treated for cardiovascular disease can be expected, but it is not known to what extent this happens.

Channeling occurs when drugs with similar therapeutic indications are prescribed to groups of patients with different health status ${ }^{8,9}$ (Fig. 1). Channeling can occur due to differences in labelled characteristics of drugs, but also as a consequence of less obvious factors, such as time of introduction or different promotion of new products. Knowledge about channeling is important in the interpretation of adverse reactions, to a void confusion between problems attributable to patients' concomitant diseases or disease-severity and problems attributable to a particular drug.

The use of cardiovascular drugs is a marker for conditions that may make patients vunerable to cardiotoxic effects of antidepressant drugs. Also, cardiac events will occur with a relatively high incidence in users of cardiac drugs, independently of concurrent antidepressant medication. Channeling of certain antidepressants to these patients may lead to an artificial association of cardiac events to antidepressant use.

The Farmacotherapeutisch Kompas published by the public insurers is the reference book on prescription drugs most consulted by Dutch physicians. In the 1990 edition for most antidepressant drugs, a recent myocardial infarction is listed as an absolute contraindication and physicians are advised to refrain from using antidepressant drugs in a variety of conditions, including cardiovascular disease in genera ${ }^{10}$. For four drugs, mianserine, fluvoxamine, fluotexine and trazodone, no restrictions in the cardiovascular field are given. It is not known whether these drugs are more likely to be the prescribed antidepressant in patients with serious cardiovascullar problems, so this is what we sought to learn by comparing the use 


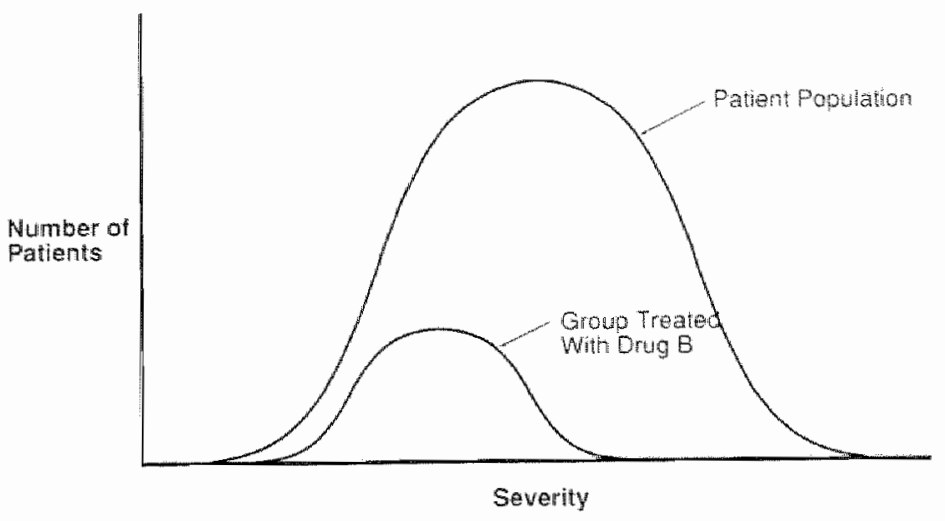

Fig. 1. Chamneling of a drug to a subgroup atypical of the general patient population.

of cardiovascular drugs in people who are treated with one of the antidepressant agents available in The Netherlands.

\section{Methods}

To be compared are age, sex, and use of cardiovascular drugs in the groups which had received one of the antidepressant drugs available in The Netherlands. The data source is a 12-phamacy database covering all medications dispensed in the year 1989 and the first 6 months of 1990. This reference population encompasses a population of approximately 130000 patients. The source pharmacies are spread over the country.

Patients' drug histories and data relating to the prescribing physicians were anonymized before leaving the pharmacy. In our database all prescriptions dispensed to each patient have a unique code number to maintain separate but anonymous identity of each patient's prescription drug history.

As antidepressants are selected the drugs in category N06AA-AE (all non-MAO inhibitor antidepressants) of the ATC Index of the World Health Organization". All drugs in this class available in The Netherlands as products with a single active substance are included.

For each antidepressant drug the following is determined: 
- The number of recipients of the drug, their sex distribution and median age

- The number of recipients who were prescribed and dispensed cardiovascular medication

In Table 1 , an overview is given of the number of recipients of each antidepressant; the numbers cannot be added because some persons received more than one antidepressant. To simplify, and in order to compare individual drugs, in the other tables the data are for persons who received only one of the listed antidepressants: results are given for drugs that were dispensed to at least 20 persons, i.e. for the 10 largest groups.

For each of these 10 groups of recipients of antidepressants, the presence of cardiovascular co-medication is compared with the other nine groups of recipients of antidepressants. Ten odds ratios ad/be are calculated, with

(a) recipients of the specific antidepressant who had cardiovascular co-medication

\section{TABLE 1}

Use of antidepressant drugs, sex distribution and age

\begin{tabular}{|c|c|c|c|}
\hline & $\begin{array}{l}\text { Users } \\
\text { (number) }\end{array}$ & $\begin{array}{l}\text { Female } \\
\text { (fraction) }\end{array}$ & $\begin{array}{l}\text { Age (yrs) } \\
\text { median }\end{array}$ \\
\hline (1) Amitriptyline & 348 & 0.66 & 53 \\
\hline (2) Clomipramine & 213 & 0.67 & 43 \\
\hline (3) Maprotiline & 191 & 0.71 & 54 \\
\hline (4) Fluvoxamine & 112 & 0.76 & 44.5 \\
\hline (5) Mianserine & 100 & 0.69 & 60 \\
\hline (6) Imipramine & 98 & 0.53 & 44 \\
\hline (7) Doxepin & 63 & 0.71 & 55 \\
\hline (8) Fluokeline & 52 & 0.58 & 49 \\
\hline (9) Dosulepine & 30 & 0.60 & 46.5 \\
\hline (10) Opipramol & 29 & 0.83 & 54 \\
\hline (11) Trazodone & 13 & 0.85 & 69 \\
\hline (12) Nortriplyline & 6 & 1.00 & 58 \\
\hline (13) Melitracene & 6 & 0.5 & 71.5 \\
\hline (14) Trimipramine & 3 & 0.8 & 60 \\
\hline (15) Desipamine & 2 & 0.5 & 60.5 \\
\hline (16) Dibenzepine & 0 & $-\ldots$ & - \\
\hline
\end{tabular}




\section{TABLE 2}

Age distriburion of users of antidepressant drugs

\begin{tabular}{lr} 
Age $(y r s)$ & Numb \\
\hline $0-14$ & 27 \\
$15-29$ & 94 \\
$30-44$ & 324 \\
$45-59$ & 331 \\
$60-7.4$ & 237 \\
$75 \rightarrow>$ & 160
\end{tabular}

(b) recipients of the specific antidepressant who had no cardiovascular co-medication

(c) recipients of other antidepressants who had cardiovascular medication

(d) recipients of other antidepressants who had no cardiovascular medication

Age and sex can be expected to be related with the use of both antidepressants and cardiovascular medication. Therefore, the odds ratios will also be determined stratified for age and sex with the Mantel-Haenszel procedure ${ }^{2}$. The age categories selected are the five highest groups of Table 2 . The youngest group is taken out and considered separately, as children are likely to have received the drugs for another indication than depression, i.e. enuresis.

The selected groups of cardiovascular drugs, with their ATC-code, are:

COIA cardiac glycosides

ColB anti-arrhythmics, classes I and III

$\mathrm{CO} 7$ beta blocking agents

C02DE calcium antagonists

C02EA converting enzyme blockers

C01DA anti-anginal vasodilators

C03 diuretic drugs

B0lAA oral anticoagulants (dicoumarol group)

B04A cholesterol- and triglyceride reducers

All calculations were done for a 6 -month time period (1.1 to 1.7 1990). This window was set to indicate concomitant use of the various types of drugs. A 6-month time window is long enough to see at least one dispensing in chronic medication, but not 
so long as to make it likely that agents were used in different periods, rather than concomitantly.

\section{Results}

The number of recipients of antidepressant drugs in the 6-month observation window is 1173 , i.e. about $1 \%$ of the covered population. A majority is female, 790 users, i.e. $67 \%$. A minority of 86 persons ( $7.3 \%$ ) had received more than one type of antidepressant drug. The number of recipients of the individual drugs are listed in Table I, together with the median age of the recipients. Amitriptyline is the drug most dispensed, followed by clomipramine and maprotiline. There were marked differences in age among the users of the different drugs. For the most used 10 drugs, the median age varied between 43 years (clomipramine) to 60 years (mianserine).

Table 2 gives the age distribution of the whole group of antidepressant drugs. Most of the drugs were dispensed to middle-aged or older persons. We considered separately the 27 users in the age group of $0-14$ years (Table 2), as use of the drugs in this age is more likely to be for enuresis than depression. Of these 27 persons, 24 had received imipramine, which is the only one of the selected drugs labelled also for enuresis. The other analyses were done with exclusion of this special younger group. This restriction to persons aged over 14 years hardly changes the value for the median age of the recipients of antidepressants, with the exception of imipramine ( 51.5 years in the restricted group, 44 years in the complete group as in Table 1).

Table 3 shows the degree of cardiovascular co-medication for recipients of the 10 most dispensed antidepressants. The data are for recipients of a single antidepressant aged over 14 years. The highest degree of cardiovascular co-medication is in the groups of users of mianserine (36\%) and doxepine (35\%), the lowest in the clomipramine (18\%) and fuoxetine $(13 \%)$ groups. The distribution of the presence of cardiovascular co-medication over the 10 groups is significantly uneven $(p=0.022$; Chi-square 19.37 df 9). While about two times more women had received antidepressants than men, the proportion within the sex groups that had cardiovascular comedication was not much different; in the group of drugs listed in Table 3 , $28 \%$ of women and $22 \%$ of men had cardiovascular co-medication.

For each of the antidepressants the degree of co-medication with cardiovascular drugs was also calculated as an uncorrected odds ratio, and stratified for age and 


\section{TABLE 3}

Cardiovascular co-medication with 10 most dispensed antidepressant drugs (users of a single antidepressant: 15 years and older)

\begin{tabular}{|c|c|c|c|}
\hline & \multirow{2}{*}{$\begin{array}{l}\text { No, of } \\
\text { users }\end{array}$} & \multicolumn{2}{|c|}{ (Cardiovascular co-medication) } \\
\hline & & any & none \\
\hline (1) Amitriptyline & 308 & $84(27 \%)$ & 224 \\
\hline (2) Clomipramine & 182 & $32(18 \%)$ & 150 \\
\hline (3) Maprotiline & 160 & $49(30 \%)$ & $\llbracket 12$ \\
\hline (4) Fluvoxamine & 94 & $21(22 \%)$ & 73 \\
\hline (5) Mianserine & 83 & $30(36 \%)$ & 53 \\
\hline (6) Imipramine & 68 & $17(25 \%)$ & 51 \\
\hline (7) Doxepin & 55 & $19(35 \%)$ & 36 \\
\hline (8) Fluoxetine & 38 & $5(13 \%)$ & 33 \\
\hline (9) Dosulepine & 23 & $5(22 \%)$ & 18 \\
\hline (10) Opipramol & 24 & $6(25 \%)$ & 18 \\
\hline
\end{tabular}

Chi square $=19.37$; df 9 ; wo trited $p=0.022$

sex, as described in the Methods section. Unadjusted odds ratios significantly different from unity were found for mianserin (OR 1.70) and clomipramine (OR 0.56) $(p<0.05)$. After correction for age and sex differences, however, none of the odds ratios were significantly differing from unity.

\section{Discussion}

The results show that usage of antidepressant drugs varies with age and cardiovascular co-medication. A simple comparison of the degree of cardiovascular comedication across the 10 largest groups of antidepressant recipients shows large differences. Two of the drugs showed significant channeling, when tested individually. After adjustment for age and sex differences however, no significant independent association remains between use of the different antidepressant drugs and cardiovascular medication. It can be concluded that there are marked differences between the antidepressants with respect to cardiovascular medication, but that no independent effect on the presence of cardiovascular medication can be shown. 
However, channeling occurs, in that the antidepressants are prescribed to groups of patients differing in age and sex distribution, and hence with a different degree of cardiovascular medication. Mianserine was the drug most channeled to patients with this type of medication; this group was also relatively old. This is in accordance with mianserin's relative freedom of cardiovascular side-effects and the lack of warnings with respect to this in medical literature ${ }^{13-15}$. At the same time, this channeling can be expected to lead to more cardiac events in the group of users of mianserin. In observational studies on drug effects the existing baseline differences between groups of users of specific antidepressants should be assessed. If these differences are not recognized, the studies may lead to wrong conclusions about the association of use of specific drugs and events in the groups of users of these drugs.

For fluwoxamine and fluoxetine, the other drugs without restrictions in the cardiovascular field, the degree of cardiovascular co-medication was much lower (Table 3). However, users of fluvoxamine and fluoxetine tend to be younger than recipients of mianserine. The two drugs were introduced on the Dutch market in 1985 and 1989, respectively; mianserine was introduced earlier, in 1982. Marketing for mianserine explicitly put emphasis on the tolerance of patients with cardiac discase for the drug ${ }^{16}$. "... no deleterious effect on the heart". For fluvoxamine and fluoxetine, cardiac safety has not been taken up as an explicit marketing item. Further, the recipients of these drugs were younger; the background for the age differences between the users of various antidepressants is not clear, but younger uisers can be expected to have less co-medication in the cardiovascular field. These results show that while several drugs may be suitable for use in patients with a pre-existing condition, not all of them are actually prescribed to a substantial degree for patients with this condition.

\section{Acknowledgement}

The authors acknowledge grant support from Duphar B.V. and Stada A.G.

\section{References}

1 Halper JP, Mann JJ, Cardiovascular effects of antidepressant medications. Br J Psychatry 1988, 153 (Suppl 3): $87 . .98$.

2 Rudorfer MV, Potter WZ. Antidepressants; a comparative review of the clinical pharmacology of the "newer" versus the "older" dngs. Drugs 1989; $37: 713$.738. 
3 Cassem N. Cardiowascular efrects of antidepressants. J Clin Phychiatry $1982: 43: 22-28$

4 Famer RDT, Pinder RM. Why do fatal overdose rates vary between antidepressants? Acta Psychiatr Scand 1989;80 (Suppl 354):25-35.

5 Stern TA, O'Gara PT, Mulley AG, Singer DE. Thibault GE. Complications after overdose with tricyclic antidepressants. Crit Care Med 1985: 13:672-674.

6 Cassidy SL. Henry J. Fatal toxicity of antidepressant drugs in overdose. Br Med J 1987; 295: $1021-1024$.

7 Burgess CD. Wadworth J, Montgomery S, Turner P. Cardiovascular effects of amilriptyline, mianserin, zimeldine and nofmensine in depressed patients. Postgrad Med J 1979; 55: 704-708.

8 Petri $H$, Urquhart J. Channeling bias in the interpretation of drug effects. Statist Med 1991: 10: $577-581$.

9 Petri $H$, Urquhart J, Herings R, Bakker A. Characteristics of patients prescribed three different beta-2 angonists: an example of the chameling phenomenon. Post Market Surveill 1991, 5: 57-66.

10 Van der Kuy A, red. Farmacotherapeutisch Kompas (Pharmacotherapeutic Compass). Amstelveen: Ziekenfondsraad, 1990.

11 WHO Collaborating Centre for Drug Statistics Methodology. ATC Index. Os\$l, 1990.

12 Kahn HA, Sempos CT. Statistical Methods in Epidemiology. Oxtord: Oxford Unversity Press. 1989.

13 Kopera $H$, Fluch $\mathbb{N}$, Harpe $H$, Klein W, Stulemeijer SM. Cardiovascular effects of mianserin a comparative study with amitriptyline and placebo in healthy subjects. In J Clin Pharmacol 1980; 18: 104 .

14 Coppen A, Kopera $\mathrm{H}$. Workshop on the clinical pharmacology and efficacy of miarserin. Br $\mathrm{J}$ Clin Pharmacol 1978; 915-995.

15 Burgess CD, Tumer $\mathrm{P}$, Wadsworth J. Cardiovascular responses 10 mianserin hydrochloride: a comparison with tricyclic antidepressant drugs. Br J Clin Pharmacol 1978; 5: 21S-25S.

16 Nederl Tijdschr Geneesk 1985; 129: 808-809 (insertion) (advertisement). 



\title{
Do prescribed drugs always follow the patients to hospital?
}

\author{
Pawhen A. W. Van Hesen Hans Petri and John Urgahant
}

\section{Introduction}

When patients are admitited to hospital, there should be a rational contmuty of the prescribed medications thay have beer taking as out patients prior to adnassiom. "Rational continuty" does not mean that all outpatient medication should necessarily be continued in hospital, bu that the outpatient medications should be care. fully evaluated at the tine of admission and rational choices made for in-hospital medication. To achieve this got of rational continthy, it is of great mpontance to have a complete list of the medications the patient has been taking, so that these medications are not stopped inadvertently; but only after proper medical consideration. Not only is it unsatisfactory that patients be inadyertently depriwed of needed drug actions, but there are some drugs ror which a sudden stop has been proved to be potentially dangerous, because of rebound effects [1].

For these reasons, the history taken at the time of hospital admission includes questions about the medications the patient has been taking. However, research has shown that patients are often unable to tell exacty which medications they have been taking $[2-41$. Even when they ane requested to bring all their medication, there is no guarantee of completeness [5]. Moreover, neither physicians nor medical reconds ave always able to giwe a proper and complete list of the drugs actually prescribed and taken by the patient $[25-11]$. Most of the orrors in physician recall and medical records are cron of omission, in which the record lails to show a drug that has been prescribed in the past and is still being taken by the patient $12357 \mathrm{H}$. This being the case, it is not surprising that Duthe of al. recently found that $29 \%$ tho of pationts taking major casdiovascular medications had these medications indvertently stopped when they were admitted 60 hospital for sungery $[12]$.
The aim of the rasearch was to mexsure the re liability with which oumpatient medications wre identified when patients are admutled to hospat in the Duteh situation. We recognise that there is a general feeling that the socalled medication bag brought to hospital by the petiont is fully" ane. liable, but we drubted that view. An underutiliged soures of information on patient sutpatient medication use is the conmunty pharmacy regralarly wisted by the putiont. This data is considered to be reasonaly valid $[8]$, allhough it may also show omishon and commission er" rors 161 . Th the Netherlands, in the case of heath inswance funds pationts, the administative requirement to designate a single community pharmatey for all reimbursed prescription drugs ensures a highly reliable and completo record of drug use. In this study, we ned the records of a Dutch community phatmaty as thas source of 1 eliable infomation on the out-patient medichions of patients admitted to hospital.

A series of steps were required to determine whether important errors did occur in therapeutic mangement as patients mate the trm sition from out patient to in-patient cate. Finst. we compared community-phammacy records and hospital pharmacy records of act patient. The discrepancies were clasisilfed by a panel of ex. perts as to their potential seriousmess. When we found what appeared to be serious discrepanciges, we consulted the patient"s medical record to ascertain, from the subsequent coutse of ewents, whether the stopping of medication had been in advertent of on purpose.

\section{Methods}

\section{Population}

Oul starting population consialed of all 5 at missions to hospital $\mathrm{H}$ between 1 Fobuary $198 \mathrm{~s}$ and 1 Mugst 1988 of inbabitante of the nomic.

\author{
Keywards \\ Data dispiday \\ Dregg therapy \\ Hospituals \\ Patient admision \\ Pharmacies, communmy \\ P.A.W. Won Hetsen. H. potrs \\ icorrespondence and Prof $\mathrm{Or}$ \\ W. Wrahart. Department of \\ Fipdeninlogy/Henth Cart \\ Research, Unwersity of Limburg. \\ P. B. Bo $616.6200 \mathrm{MD}$ \\ Maastricht, the Nethertards. \\ P.A. W. Wan Hessen ipresent \\ addresse TNO Instidute of \\ Preqentive Hoaluh Care \\ NPG TWO PO. Box 124 . \\ 2900 AC Leiden. \\ the Natherlardis.
}

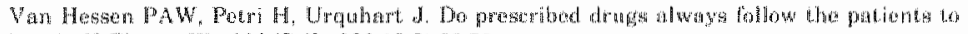

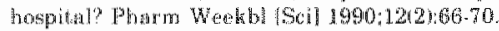

\begin{abstract}
The a

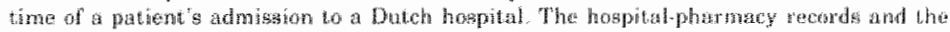

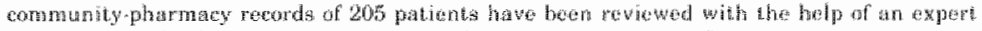

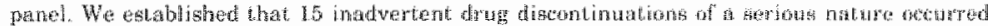

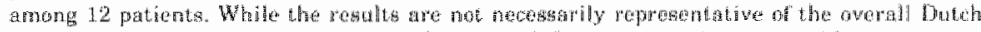

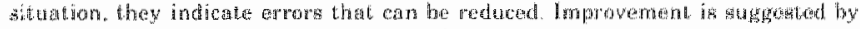

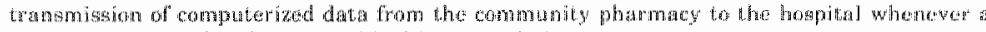
patiend is admitted and agrees with thig tratamission.
\end{abstract}

Acricepted 7 Frebruary 1990. 
pality M. M thes only one community pharmacy, wisted by the was majority of about $12,000 \mathrm{in}$. habiantas. Ahe game time, most hospleal admiasions of the inhabitanes of $\mathrm{M}$ are in $\mathrm{H}$, the nearat hoppital. H can be best described as a small reglonal hosplest. One patient could at. count for more that one admisgion.

At our disposat watata on 365 of these ad mistons, being those of patients who recerved ond or more medications from the hospital phar. macy during their stay in hospital. Of these, 325 were idertited in the records of the community phamacy at being aithor a health care in. starance patient or a privately insured patient and as having received at least one prescription druse from the community plarmacy in the 30 days prior to hospital admiggon. Privately in. sured patients were not otherwise included in the andysis; this tight writerion was used to diminish the lithelihood of indugion of privately in. sured patients who changed phamacy just be. fore hospital admigsion. Thus identilied, the patients whe numbered and treated anony. mously.

Among the 546 andmsions to $\mathrm{H}$, 181 patients did not receive medicatione while in hospital. Many of these patients were admitited for ahild. birtlin and as newborns. Mary of the others had brief stays for relatively rinor surgical pro. cedures, e.g tonsillectomy

Or the 325 patients who received prescription dpugs both as out-patients and in patients, 10 ware not further investigated, because they were admitted directly to the intensivenure unit, where medications are namaged apart from the hospitall pharmacy.

\section{Use of oul-patient medication}

The 315 remaining patients were judged on their use of out-patient medication at the mo. ment of admission to II according to the data from the community pharmacy. The judgment of present use ol out-petient medication was based on the most recent time of dispeneing of the drug and the legend durention of the preseription. In the enst of singledispensed druge, the legend durtion was defined as the number of dosage Foms dispersed, divided by the prescribed mum ber of dosage forms to be taken por day. In the case of serially rofilled dugs. present use was de termined with 14 days added to the legend da ration ans defined.

We excluded certain prescription drugs and other itins because of their seltevidenty minor rote in the petient s cara. Fxcluded medications. based on categories in the formulary of the Dutch health insurance funds ("Farmacotherapeutsoh Komplas wene:

- vehictes and indiferent dernatologics.

- bowl antinfoctive agents;

- cutaneous antipruritices:

-.. rubefacients etc:

- other dermatologic agents;

- diet and rood agents.

We also excluded item suder the eategory of "bardages and various dexices."

As a result, 110 patients were considered to be receiving no out patient medication of conse. quence at the time of ammisson, leaving 205 patients who were recetwing 709 drugs as out-pationt medication. fe a mean of 3.46 each. These 709 drugs were evaluated in respect of their continuation in the hospital.

\section{Contination of outpationt medication}

The 709 outpatient medications of 205 patients were compared, by a rather exten sive set of criveria, with the medications that were prescribed during the first two days of the patients stay in hospital. The criteria of con perison are described in the following paragraph.

Fach drug was identifted by its anatomical therapeutical chemical (ATC) code [13]. If the first thee lewels of the ATC code of the hospital medication comesponded to those of the out patient medication, the out-patient medication was judged to have been continued, even thongh a different drug of the same class may have been substituted. In addition, a 4 person group of pharmacologically innowledgeable people re. viewed other apparent substitutions, and judged the aut pationt medication to have been continued if the substitution was deemed therapeutically rational, even when fhere were diffenences in the first three levels of $\mathrm{A} \mathrm{I}^{\mathrm{C}} \mathrm{C}$ code. Examples of such judgments were drugs of the therapentic gub-groups "Synthetic agents and papaverne" (AOBA) and 'Belladonna and derivatives' ( $\mathrm{A03B}$ ) of the chef therapettic grotip 'Spasmolytics and anti-cholinergic drugs of the gastro-imtestimal mat" (AO3), which wore considered equivalent for the purposes of this study.

From this process, cases were selected that were considered as hawing one or more home drugs stopped the thme of hospital admission. These were next ewaluated with regard to thein potential serionsness.

\section{Interpretation of the potential seriousness of stopped madication}

Of each of the admissions where a medication appared to hate been stopped, an overview was made of the patient's are, gender, admiting speciality, all outuatient medications, and all hospital medications during the first two days of the hospital stay. These overviews were put be fore anel of 2 internists and 2 phamacists from other medical institutions in other parts of the country, and thes with no links to the hospital of to the community pharmacy. The panel members, meating nogether, were askod to griws their opinion on each discontinuation.

The "stops" were classived in 3 categories:

1 cessation of this outpatient madication will not cause problems with this patient:

2 cessation of this ontpatient medication will probably cause no problems, but problems can not be totally excluded:

3 cessation of this out patient medication should not have occurred, unless purposefully done on the advice of the attending physician.

From this point onward, we focused attention on "category 3 stops, in order to learm if they were arcidental or intented. A special category was created for stops of oral contraceptives, which were never dispensed in hospital. 
Furher asessment

For our thal judgment, the medical records of the patients wh "caterory 3 stops" were exmined. One of the records could not be remeved. A sample of 6 patients with oral contraceptive stops" wes analysed. The medical record was seanched for:

- adruiting diagnosis:

-.. use in the hospital of drugs brought in by the patients themselves;

-wat of the out patient medication after tho days of hosplital stay.

- delibenate cessation of out patient medications by a physician;

- indications of cessation of the out-patient mediotion pror to admission.

- type of irsuruance, as a check for the data in the phammacy.

For all drugs that still seemed to have been inatvertently stopped aften this examination of the medicd record, the data of the community phar" macy was reviewod to see whether the drugs were restated after the patient's discharge from the hospital.

\section{Results}

Based on our criteria for continuation of out patient medication, 143 of the 205 wsers of any out-patient medication had a total of 263 out patient medications that were provisionally re. Ereated as "stopped.

The pamel judged 68 'stops,' involving 41 cases, as belonging to category 3 . Thus, $26 \%$ of the original 263 "stops" were appraised as potentially hazardous if done accidentally. Oral contraceptives were 'stopped' 17 tines. The panel thought it most probable that their use was continued by the patients themselves during their hospital stay. They moted, however, that this practice had the potential problem of leading io faulty compliance and unwanted conception.

Examination of the medical records and post. discharge community phamacy data produced the following results on 67 'stops, one recond was unavailable Cor" nrew. 16 "Stopes" involved medi. cation that had already beer stopped prior to hospital admission. 5 'Stops' turmed out to be wrongly fudged, as the ditugs were brought in by the patients themselves and continued in the hospital. 3 'Stops' involved drugs that, while not administered during the first wo days, were re. sumed later. 26 Drugs we deliberately stopped by an atherding physician. 2 'Stops' could not be further judged because of ambiguous data.

"hlue remaining 1.5 stopped drugs, involving 12 parients, seemed inadvertent, $i$. no infor mation was found that could explain the sudden stop of theim use. Use of 9 of these was resumed after hospital discharge. Table 1 lists all 15 stopped druss, together with some salient characteristics of the patients.

In the case of 6 patients whose neoonds were examined regarding the in-hospital use of oral combaceptives, this use was mentioned in the medical records of 3 patients, whereas no infor mation on oral contraceptive use was found for the other 3. All 6 patients continued oral contra. ceptive use after discharge.

\section{Discussion}

\section{Wethodoloticat considerations}

By relying on written data, we have thee main uncertainhes to consider.

- we cannot axtude that the pationt simply did not lake drugs dispensed by the communty pharmacy;

- we camod be entrely centain fhat the at tending physician had deliberately stopped the drugs concerred withotyt making any written notation of it:

-it is also possible that the patients continuded taking drugs brought hom home whilst in hospital.

These thee points ane considered in turn in the following paragraphs.

For the first point, 10 of the 15 sertons onissions involved druge reflled in the communuty pharmacy befote the time of hospital admission. and 9 were refilled agam atter the patient re turned home. Timely refills are a generally de pendable indication of drug complistnce 111 .

The second point is a passible but unlikely basis for error. Certainly, a hospital achmission can be the ootasion to review the patients medical status and to nake changes in prosicribed drugs, but such changes would normally be docu mented when they inwolve discontinution of important (categrory 3') dncugs.

Fon the third point, the in hospital use of im. pottant medications brought from home is also possible, but constitutes a procedural enror of another kind, and is therefore demed unlikely.

It should be noted that our analysis did not in. clude patients who though taking ovitpationt medications, received no medications at all while in hospital. Becanse we used hospital pharmacy records as the starting point to identify admitted patients, we would have missed any such patients, who are probably relatively fow. Fiture studies of this problem might usefully begin with admited patients rather than with in hospital reciptents of proseription truige Future studies might atso focus on the chartuctereticas of the patients with important drug omisgions.

\section{Conclusions}

In general, the situation is lass than optimal. Athough at first sight, 263 of all 709 out-phentiont medications appeared to have been discontinued. only 68 of these were deemed of potential con. cern, and only 15 omisaions of potential concern appeared to have been inadvertently mads on hospital admission. Of the 205 atuble patients at risk of having any medication inad. vertenty stopped. 15 inadvertent omissions of a serious (caltegony $y^{*}$ ) nature occumed amongr 12 patients.

As we did not feel justifed in requiring the four experts to categorize the drugs of all 205 eralu able patients, we cannot say for cortain how many of the 205 patients we takjeg wategony 3 ' drugs, but certainly not all were. Thus, we can not exactly say what the likelihood is that a patient taling a category 3 ' drug as out-pationt medication had that drug indwertenty omited at hospitalization. fit occured in at least $B$ of of 
T. atole I

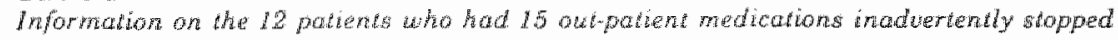

\begin{tabular}{|c|c|c|c|c|c|}
\hline Genter (Tmige & $\begin{array}{l}\text { Inadvertently } \\
\text { omituded drug }\end{array}$ & $\begin{array}{l}\text { Other drugs } \\
\text { conthned }\end{array}$ & $\begin{array}{l}\text { Pefills before } \\
\text { admission }\end{array}$ & $\begin{array}{l}\text { Contrinued after } \\
\text { discharge }\end{array}$ & $\begin{array}{l}\text { Adruizing } \\
\text { dagmosis }\end{array}$ \\
\hline$F 69$ & $\begin{array}{l}\text { Metoprolol } \\
\text { Gelokente } \\
\text { Digoxin } \\
\text { (Lanosing }\end{array}$ & $\begin{array}{l}\text { yes } \\
\text { yes }\end{array}$ & $\begin{array}{l}\text { yes } \\
\text { yes }\end{array}$ & $\begin{array}{l}\text { yes } \\
\text { yes }\end{array}$ & angina pectoris \\
\hline F/48 & $\begin{array}{l}\text { Furosemide } \\
\text { Fusidey } \\
\text { Fomotidire }\end{array}$ & yes & yes & no & depression \\
\hline$F / 40$ & $\begin{array}{l}\text { Famotidine } \\
\text { (Pepcidin }\end{array}$ & no & no & yes & Iumpectomy \\
\hline$M / 61$ & $\begin{array}{l}\text { Trimethoprim- } \\
\text { gulfarnethoxazole } \\
\text { (co-trimoxazol) }\end{array}$ & no & no & no & abdominal pain \\
\hline 167 & $\begin{array}{l}\text { Maprotiline } \\
\text { (Ludiomi } \\
\text { Perazine } \\
\text { (Taxilang }\end{array}$ & yes & yes & $\begin{array}{l}\text { no } \\
\text { yes }\end{array}$ & depression \\
\hline 1769 & $\begin{array}{l}\text { Manserin } \\
\text { (Tolvono) } \\
\text { Oxazepama } \\
\text { (Seregta) }\end{array}$ & $\begin{array}{l}\text { yes } \\
\text { yes }\end{array}$ & $\begin{array}{l}\text { yes } \\
\text { yes }\end{array}$ & $\begin{array}{l}\text { yes } \\
\text { yes }\end{array}$ & nausea womiting \\
\hline $1 / 82$ & $\begin{array}{l}\text { Furosiemide } \\
\text { (Fuside) }\end{array}$ & yes & yes & yes & "psetudo-dementia" \\
\hline$M / 31$ & $\begin{array}{c}\text { Doxycycline } \\
\text { (Unidox } 9)\end{array}$ & yes & no & no & herpes zoster \\
\hline$M / 47$ & $\begin{array}{c}\text { Doxycycline } \\
\text { (Unidox }\end{array}$ & no & no & no & $\begin{array}{l}\text { appendical } \\
\text { infitration }\end{array}$ \\
\hline F/81 & $\begin{array}{l}\text { Triamterenel } \\
\text { hydroehloro } \\
\text { thiazide }\end{array}$ & no & yes & $y e s$ & $\begin{array}{l}\text { sick sinus } \\
\text { syndrome }\end{array}$ \\
\hline D. 60 & $\begin{array}{l}\text { Furosemide } \\
\text { (Fusid } \\
\text { Disopyramide }\end{array}$ & yes & yes & yes & battered female \\
\hline & (Ritmolorines) & yes & yes & no & depression \\
\hline
\end{tabular}

patients, and doubtiess in a somewhat higher percentage. This funding does not support the opinion thatrug histories obtaned at the time of hogpital admission are alway accurate.

The "categry 3 " drug omission rate we found was appreciably lower" than the rate foum by Duthe et al. armong patients admithed for surgery in Glasgow [12], By limiting their forus to surgical patients, Duthie et al. had a much higher proportion of admissions for emergency surgery. For many reasons there is less likeli. hood of ascertaning a correct medication history at emergency surgery. In contrast, we included in our studies various kinds of admissions, the wast majority of which was elective rather han emergency. Also, our study did not include patients admiticd directy to the irtensivecare unit.

Neither is it considered advisable to allow patients to manage their own oral contraceptive dosing, without involvement of the hospital pharmacy, as probably has happened. It opens the possibility of missed doses and unrecognized drug interactions. Oral contraceptives are known to be susceptible to several interactions with other drugs [14].
It was beyond the scope of this study to attempt to assess the risks to patients created by these in. advertent omissions. We can say that mone of the 15 inadwertent omissions of "category 3 " drugs led to problems attributable to the omissions. Assessment of the risk of suddon cessation of pre. scription drug therapy is, in general, specific to drug, disedse, severity of the disfase, and patient characteristics.

\section{Opportunities for improvement}

While our results are not necessarily represen. tative of the owerall Dutch situation, they indi. cate errors that can be reduced, if not altogether avoided through provision of better quality in. formation to hospital staft about patients" outpatient medications. One approach would be the general use of some type of "medical passport" [15], in written form or as an electronic smart card" [16 17]. However, such approaches would require a nation-wide revision of current prac. tice. This seems hard to achieve as the fajlure of the medical pasisport in the past suggests [18].

A far simpler way to improve the quallity of in formation on patients' outpatient medication history is to make use of the information already 
avalable in community pharnacies. Pilot studies might usefully be undertaken in raking avaliable to hospitals at the thme of admission the salient parts of patients outpatient medication histories. With the widespread adoption of computerized records in community pharmacies, and the ncreasing use of facsimile transmission, swch communication could be organized to be done wh litte delay. It could even be avalable on an urgen basis for emengency admissions.

There is a certain issue about obtaining con. sent for communicating this information to the hospital physician, but that can reasonably be handled in the same mamer as information $\mathrm{ex}$ changes between the various physicians involved in the patients care. If the eirors we found prove to be representatiwe, it would seem only logical to thake medical advantage of information in com munity phammacies that presently has already administrative and research value [19].

\section{Acknowledgement}

"The authors thank the pharmacists of the com. munity pharmacy and the hospital phamacy, as well as the medical specialists in the hospital, the board of directors and the record office staff for making all the data avallable. The authors me indebted to L. Van Bortel, E. Gemmeke, Dw. J. Loman, J. Nans, Dr. P. De Smet and Di". P. Smits for their contributions to the medical phamacological discussions.

\section{References}

1 De Greft PA. De gevaren ran het photseling staken vala geneesmiddelen IDangers of sudden cessation of drug then apyj. Ned THidsch" Goneestod 1985;129:1034 5.

2 Price D, Cooke J, Singleton 5, Fely M. Doctors un. awareness of the drugs thein patients nre taking: a majol" couse of owerpresoribing? Br. Mew d 1986,292:99 100 .

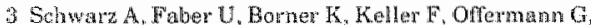
Moleahn $M$, Relisability of drug history in analysa users, Lancet $1984 ; 2 ; 1163-4$.

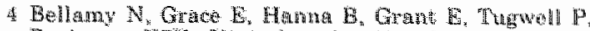

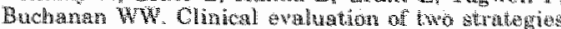

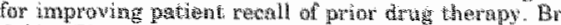

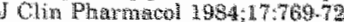

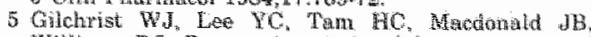

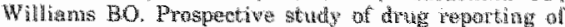

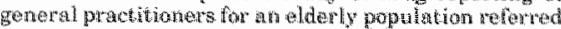

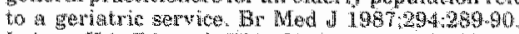

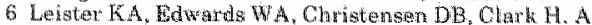

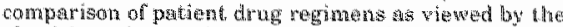

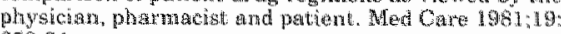

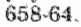

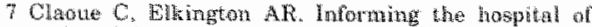

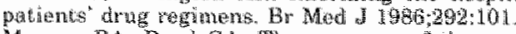

8. Honson. RA, Bond CA. Thus acuracy of the medical

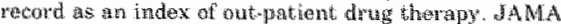
$1978,240.21824$

9) Jolnson RE, Azevedo D., Camphell WH Christensen

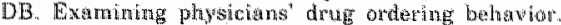
Mted Cara $1978 ; 16: 408$. 16

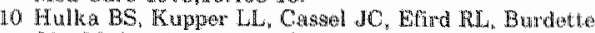

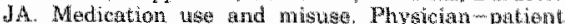
ascrepannies. J Chom Dis 1975;28,7-21.

1. Bond $\mathrm{CA}$, Monson R. Sustanted improvement in almg

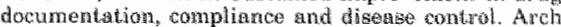
Intorm Mod 1984,144:1159-62.

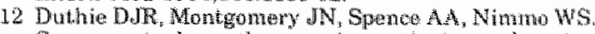
Conemremt drog therapy in pitiends undergoing

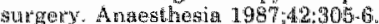

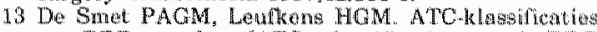

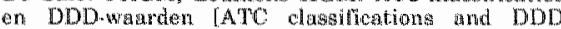

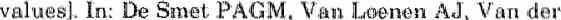
Doen E. ads. In Cormatorim Medicamontortim 1987 deel III. Aphen ad Rijn: Samem Stafink, 1987:300 32

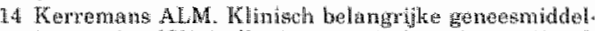

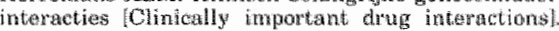

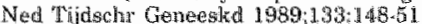

15 Dalmans JMEV. Mertens PB. Geneesnidalenmpas. poort - gelowik en toelicheing IDnts prsport wa. wa

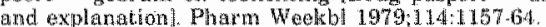

16 Jenkingon S. Medical cleat cards. Br Med a 1939299 ; 472 .

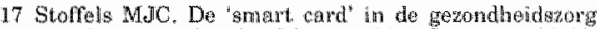

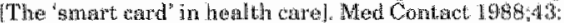
$405 \times 7$.

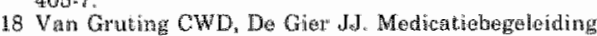
[Medication support]. Prat na Weetbl 1987:122;1057. 65.

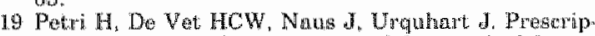
tiom sequernce analysis: a now sud lase nethod for as sessing eerain alverse reactions of preseription druge

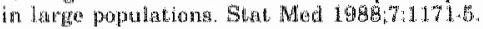





\title{
Comparison of questionnaire information and pharmacy data on drug use
}

\author{
Piet A. Wanden Brond, Hans Petri, Ensabeh Dortht R. Alexandra Goldbohm and \\ Sacha Van de Crommer
}

\section{Introduction}

In large-scale prospective epideriologic studies increased use is made of selfadminis. tered questionmaires to estmate exposure to various environmental factors, including prescription drugs. Selfadministered questionnaires las well as personal interviews an, however, subject to response errors.

Studies on the validity of questionnarede rived drug history information have been re vieked recently [1]. Mast studies focused on reproduction-related drug use, like oral contraceptives [2], estroger use [3] and preynancy related drug use 141. Very few studies have evalu. ated non-hormonal or non-pregnancy related medication [ $\left[\begin{array}{ll}5 & 6\end{array}\right]$

We studied the vallidity of questionnaire information on general drug wse. "This questionnaire was used in an ongoing large scale prospective cohort study on diet, other lifestyle factors isuch as lorg-term drug use) and the iradence of can cer in the Netherlands. The validity of the infor mation on drug use was investigated by com paring the questionnaire data with pharmacy records of dispensed drugs. We also analysed personal characteristies as potential determinants of the quality of questiontraite infomation, as has been done with regard to reporting of medical conditions [7]. Dutch pharmacy records are uniquely complete on the level of an individuct patient, due to insurance requirements. In 1986 , $67 \%$ of the Dutch population was emrolled in the health insurance fund scheme which require them to designate a single phamacy from which they receive all remborsed prescription a drugs $18 i$.

\section{Methods}

Cohort study

The prospective cohort study started in 1986 wh the baseline exposure measurement. The cohort $(\mathrm{n}=120,852)$ of 55.69 yegr old men and women originates from 204 muntcipal poptlation registries. Follow-up for cancer consists of record linkage lo cancer and patholony regigtios 19. The baseline exposure measurement imwolved completing at selraminstered questionnaire on diet, medical history, history of longr term drug use, smoking, occupstion and varigus other factons. The question on drug history was open-ended, asking for drags that had been taken for a period of at leasi 6 months at any time in the past. The generic or trade name of the drug was asked for, and for woln drug the therapeutic indication and the calendar period of usage in years. The space on the questionmaires allowed for 4 drugs to be mentioned.

\section{Vatidation study}

In the municipality where the validation study was conducted, 239 subjects participated in the baseline measurement. The town (with 14,000 imhabitants) is served by 1 pharmacy, which keeps records on all dispensed drugs, patient by patient. There are no other pharmacies within w radius of $5 \mathrm{~km}$. Because the patients in the health insurance fund scheme wre required to designate a single pharmacy for all neimbursed drugs, they are known to their designated phar macy, whether they use drugs or not. Whereas the colvor questionnare was completed in September-October 1986 , the computerizad foc

\section{Keywords}

Drug utitization

Epidenaiologric nethods

Neoplasm

Pharmacoepidemiology

Pharmacy records

Questionnaires

Validizy

P.A. Wan den Brandi

(correspondence H. Perri. E Dorantand $\mathrm{S}$ Van de Cromurnert. Department of Epidemiology, Uanereity of Limburg, P.O. Box 616, 62000 MD Maastricht the Nevherlands.

R.A. Golcbohm Departirnent of Hurman Nutrition, TNOCKO Tasicolagy and Nutrition Institute. P.O. Riox 360,3700 Ad Zeist, the Netherlands.

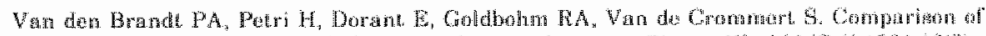

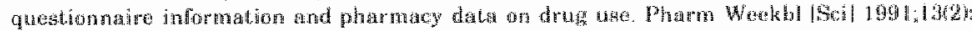
91.69

\footnotetext{
Abstract

Information on chronic dridy use at any time in the past was collectod with a

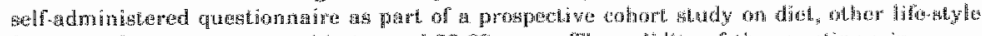

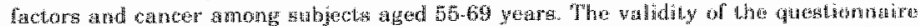

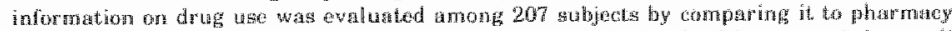
reconds of dispenged drtigs. The compurison could be mave for the 25 year poriced preceding

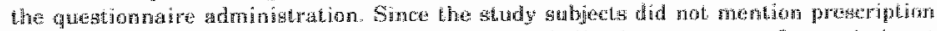
drugs that were not dispensed by their pharmacy, indicating no orrors of comomistion, the

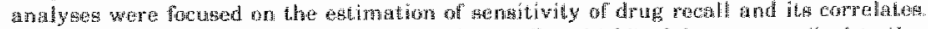

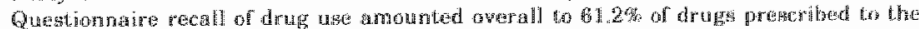

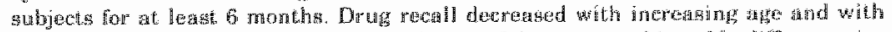
incressing number of preseribed chronic ube of drugs per subject. No ditherence in recall was

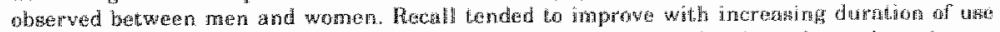

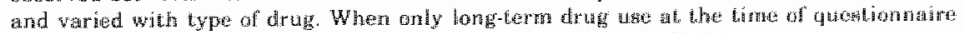

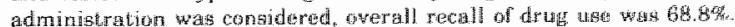

Accepted 22, Hanuary 1991. 
Table 1

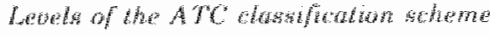

\begin{tabular}{|c|c|c|}
\hline 1.vent & Wemo & Fxample \\
\hline 1 & and torne level & central nervous system \\
\hline 2 & therapeutic main gromp & psycholentess \\
\hline 3 & therapeutic subgroup & tranquillizers \\
\hline 4 & chemeal math group & betzodiazepireses \\
\hline 5 & chemical entity & diazepam \\
\hline
\end{tabular}

ortis of the phatmacy were only awalable from April 1984 onwards. This study is therefore lim. ited to drug recall from the period Aprill 1984 th til Seplember 1986

Of the 239 cohort members in the study town 207 subjocts 193 men, 114 women were al registered in the phamacy. The remaning 32 stabecto woro either living in a nearby willage, which is served by another phamacy, or were privulely insured and had not used drugse from the study phamacy. The phamacy records tee. presenting drags dispenged to the 207 subjects were selected from the computerized data base. There were 138 (67\%) health insulance fund palients and $69(33 \%$ ) privately insured pationts among the 20 subjects, as observed in September 1986. The 69 privately insured pationts could remain in the study population since the andysis could be concentrated on sensithity of necall hee Siatistical analysist. The validation sudy was focused on dungs for systemic use; local applications for skin, ear, eye and mouth were therefore excluded from consider. ation. Also, homoeopathic drugs and vitamins and mineril supplements were excluded as these items may not be perceived as drugs by the sub. jects.

Next. the proseribed dosages and dispensing

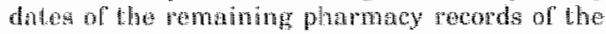
207 sabjects were uged to construct drug histories for each atubed. The dumation of use was deterninod by dividing the number of dispensed arose by the number of prescribed doses per day. When a prescription for the same drug was disponsed within 30 days of the calculated whend of the previous prescription, drug use was comsidered to be continuous. Long-term deug use whs dolined as continuous use of a drug aver a

Tablle 2

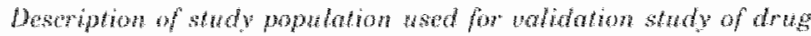
rembl

\begin{tabular}{|c|c|c|}
\hline Chandecteristic & Numbar of subjects & $\begin{array}{l}\text { Long-term } \\
\text { drug users }(\%)\end{array}$ \\
\hline \multicolumn{3}{|l|}{ Genden. } \\
\hline - Men & 98 & $36(38.7)$ \\
\hline women & 114 & $51(44.7)$ \\
\hline \multicolumn{3}{|l|}{ Age (years) } \\
\hline$-5 \times 59$ & 85 & $31(36.5)$ \\
\hline-60.64 & 71 & $32(45.1)$ \\
\hline 65.69 & 5.1 & $24(47.1)$ \\
\hline
\end{tabular}

period of at least 180 days. The conot quesionnare also asked the subjects to list drugs that bod hean taken for at least o months. "lhese questionaine responses were compared to the pharmary records of the 207 subjects.

The questionnaire information on drtig types, (s) wall as the phamacy data were classified ac conding to the Anatomic Therapeutic Chemical (ATC) classfication scheme 110$]$. Wh this hier. archical scheme, drugs are classified on five levels defined by anatomic, therapeutic and chemical characteristics of the drug and the ind cation for which it is used. The five lewels are amatomic main group, therapatic main and sub group, chemical main and subgroup. The rirst, most weneral, level nepregents classification of drugs into anatomic gromps, bi. the site at which treatment is directed. The fofth and most specilic level is defined by the chenical enticy or struc ture of the drug. An example of this hielarehy is given in Table 1 :

\section{Statisticat analyas}

The accuracy of drug refall obtained by questionnaive was measured by assesging the degree to which drugs, which thad been chronically used acconding to the phamacy data, ware correctly recalled by the respondents. No prescription chugr was listed for the period 1984.1986 by respondents that was not dispensed (6. no errors of commission occured). Therefore, the analysis rurther concentrated on emors of omission and the sensitivity of the drug recallecthon. In est: mating these sensitivity rates, agrement on the individual drug level (i.e the fifth and most detailed level of the ATC classification code) was required.

The analyses were stratified according to warious factors, to determine what influence these might have on the sensitivity rates. "These fac* tors include: gender, age, number of preseribed drugs per subject, duration of use and type of drute. Separate analyses were carried out fon arugs that were in use at the limo the question. maine was admintstered in the cohort

While in the analyes mentioned above figree ment on individual drug lavel was required, wa also estimaled the sensitivity rates on a legel of move general classes of medication as defined by the ATC classification code.

\section{Results}

Of the 207 respondentes who were incluted in the analysis, the phamacy records showed that 186 ware recipients of one an more prescabed drugs in the period April 1984 to September 1986. A total of 87 subjects $(36$ men, 51 women) wore defined as long term drug users (ite at least 180 days of continuous prescription, based on the pharmacy records. "Thus, 42 of of the respon dents were longterm drug users. As can be seen from Table 2, the proportion of long-term drug users is greater anong women than men $(44.7$ and $38.7 \%$, respectively) and increases with age. The 87 subjects had been prescribed 242 drugs for at least 6 months in the period 19841986 . Table 3 shows longterm drug use, stratified by type of drug. Most drugs used are for cardio. 
Table 3

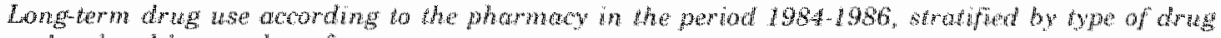
and ordered by number of wasers

\begin{tabular}{|c|c|c|}
\hline Type of $\mathrm{drug}^{\mathrm{s}}$ & 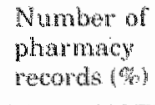 & $\begin{array}{l}\text { Number of users } \\
\text { (of of at longerm } \\
\text { drug users? }\end{array}$ \\
\hline Cardiowascular system & $138(57.0)$ & $62(7.3)$ \\
\hline Central nerwous system & $43(17.8)$ & $30<84.5)$ \\
\hline Alimentany tract and metabolism & $25(10.3)$ & $16(18,4)$ \\
\hline Blood and blood-torming organs & $11(4.6)$ & $11(12.6)$ \\
\hline Respiratomy system & $8(3)$ & $5(5.3)$ \\
\hline Systemach homonal preparations, excluding sex hormones & $4(1.7)$ & $3(3.5)$ \\
\hline Musculoskeletal system, genitomurinary systern and sex & & \\
\hline $\begin{array}{l}\text { hormones } \\
\text { Menopausal hommones, urology drugs }\end{array}$ & $\begin{array}{l}5(2.1) \\
2(0.8)\end{array}$ & $\begin{array}{l}3(3,5) \\
2(2,3)\end{array}$ \\
\hline General anti-infectives, systentic & $1(0.4)$ & $1(1.2)$ \\
\hline Antineoplastic and immuno-suppressive dnugs & $2(0.8)$ & $1: 1.2)$ \\
\hline Other: & $3(1.2)$ & $3(3.5)$ \\
\hline
\end{tabular}

* Drugs categorized according to hrst level of ATC classification scheme [Lok sealso Table 1 .

wascular conditions, followed by drugs indicated for central nervous system disorders, alimentary tract conditions, and haematologic conditions. Together, these categories comprise almost $90 \%$ of drugs taken chronically by the subjets.

Of the 242 chrorically used drugs, 148 were we. ported in the questionnaire, when agreement on the fifth (most detailed) level of the ATC code was required. The oserall sensitivity, in. percen. tage of pharmacymeconded drugs reponted in the questionaine, was therefore $61.2 \%$. Table 4 pre

Tables 4

Questonmaire recall of long-term drag use companed to pharmacy reats, whatified by selected charateristies

\begin{tabular}{|c|c|c|}
\hline Chavacteristic & $\begin{array}{l}\text { Number of } \\
\text { phammacy } \\
\text { records }\end{array}$ & $\begin{array}{l}\text { Number or } \\
\text { questionmaire } \\
\text { responses } \\
\text { (\% recall) }\end{array}$ \\
\hline All & $24: 2$ & $148(61.2)$ \\
\hline \multicolumn{3}{|l|}{ Gender } \\
\hline -..' men & 104 & $64(61.5)$ \\
\hline women & 1.38 & $84(60.9)$ \\
\hline \multicolumn{3}{|l|}{ Agen (years) } \\
\hline-5059 & 72 & $47(65.3)$ \\
\hline-60.64 & 93 & $56(60.2)$ \\
\hline-65.69 & 77 & $45(58.4)$ \\
\hline \multicolumn{3}{|l|}{ Duration of wase (months) } \\
\hline$-6-1.9$ & 100 & $59(59.0)$ \\
\hline-12.239 & 76 & $47(61.8)$ \\
\hline$-2 \geqslant 24$ & 66 & $42(63.6)$ \\
\hline \multicolumn{3}{|l|}{ Number of prescribed drugs } \\
\hline-1 & 24 & 1700.81 \\
\hline-2 & 50 & $32(64.0)$ \\
\hline$\cdots \geq 3$ & 168 & $99(58.9)$ \\
\hline \multicolumn{3}{|l|}{ Type of drug } \\
\hline alinentary tract & 25 & $12(48.0)$ \\
\hline - cardiowscular system & 1.38 & $91(65.9)$ \\
\hline - cenfral nervous system & 43 & $231.53 .5)$ \\
\hline- other & 36 & $22(61.1)$ \\
\hline
\end{tabular}

sents the sensitivity of drug recall stratined by warous factors. "lable 4 shows thet gender" was not related to drug recall: the sensititity thes were $61.5 \%$ and $60.9 \%$ for men and women, respectively. With increasing age, fecall do creased slightly from $65.3 \%$ among $55-50 y$ year ald people to $60.2 \%$ among 60-64.year ald people and 58.4 o fo 65.69 year old subjects. Drug re call was somewhat increased when the duration of use was longer: recall was $590 \%, 61.8 \%$ and $6 \% .6 \%$ for druge used 6.11.9, 12.23.9 and 24 monthe or longen, respedively.

Whers a statification was made on the number of chronically used drugs per subject, recall per drug decreased from $70.8 \%$ lon subjects using one drug to 64.0\% when using two drugs and 58,9 . when using the druge or more. With respect to the type of drug, it was fond that cardiovascular

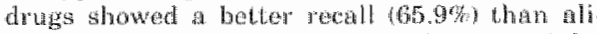
mentary irace drugs $\{48.0 \%$ or drugs used for central newous aysem disonders $(53.5 \%)$ other drugs were not Beparately considered because they were too low nin namber.

As the devensed recall with imatasing age wight bo due to the fact that whe sublects wo move drugs or vice versa, we also conducted analyses stratified by age and the number of pre. scribed drugs. Whon the perentage vecall is con sidered lor each of the cells (Table 5), where 19 no longer a clear trend whtl eithen of the two rac lors, probaby due to small numbers. Subjecte from the youngegt age group seem to recall dintog somewhat bether, independent of the nurbber of drugs being used. Also, in tivo age groups bub jects using at least three drugh show en lower re eall than subjects wing one drug. Thus, the of fects of both stratiffication factors geem independeret of each othes"

Table 6 shows the percentage recall per type of drug, stratified by gender, age, duration of wse and number of presstibed drugh. For dhis calea lation the two categories of druge taed for the at mentary tract and central nerwous aystem dis ordens were combined in order to awoll very 
Tubles

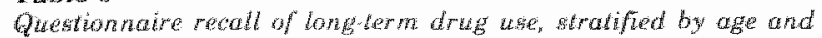
number of presseribed dregs

\begin{tabular}{|c|c|c|c|}
\hline A.ge (yodrots & $\begin{array}{l}\text { Number of } \\
\text { preferiben } \\
\text { druge }\end{array}$ & $\begin{array}{l}\text { Wumber of } \\
\text { pharmacy } \\
\text { jecondo }\end{array}$ & $\begin{array}{l}\text { Namber of } \\
\text { questioname } \\
\text { responstes } \\
\text { (o recall }\end{array}$ \\
\hline \multirow[t]{3}{*}{ 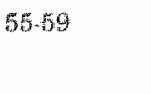 } & 1 & 10 & $9(90.0)$ \\
\hline & 2 & 26 & $12(500)$ \\
\hline & 23 & 36 & $25(69.4)$ \\
\hline \multirow[t]{3}{*}{$60 \cdot 84$} & 1 & 8 & 450.0 \\
\hline & 2 & 16 & $15(938)$ \\
\hline & $\geqslant 3$ & $B 9$ & $37(53.6)$ \\
\hline \multirow[t]{3}{*}{$65 \cdot 69$} & i & 6 & 4: $(68.7)$ \\
\hline & 2 & 8 & 4. 6000 \\
\hline & $\geq 3$ & 63 & $37(58.7)$ \\
\hline
\end{tabular}

smal numbers per cell and thus unstable esti. mates of recall. Alsn, the overall recall percen. tages for these towo groups were relatively close to each other, as was shown in Table 4 . As cam be aen from 'Table 6 , the percentage recall for cardiovascular drugs is consistently higher than for other types of drugs. For cardiovascular drugs, the trends in vectll. according to the various levels of the stratification factors, are similar to what was observed for owerall long term drug use (Table 4). For alimentary tract or central nervous syatem drugs and oubr drugs the trends are less clear, which may lso be due to the small number of observations per cell.
The recall might be low when drugs are mot actually used at the time of the basel ine ques tomnaire. To evaluate this possibility, we also analyzed the quality of reporting of current long term drug use (Table 7 . Current we in this situ. ation means longterm drug use at the time of the questiontaire baseline measurement in the cohort study (September 1986). Among the total gutu of 87 longterm drug usets, 69 were chron: cally using drugs at the cime of the baseline measuremert. On a werage these participants ased 1.9 drugs ahronically per subject. Table? shows that reporting of current long-term drug use is somewhat better than reporting of all long term drug use in the period 1984-1986. Ovendil, $68.8 \%$ of current long-term drug use was cor rectly reported (analysis on the chemical entity leval), compared to $61.2 \%$ among all longterm drug users.

The downward trend in recall with increasing number of drugs and with increasing age among current users is comparable to the trend among all long term drug users. Gender has no substantilal effect on drug reporting in this group. Where was no consistent trend in drug reporting with duration of use in thisg group. Again, candiovas cular-oriented drugs were the type of drugs that showed the highest degrae of reporting $(76.6 \%$, followed by allmentary tract drugs $(64.7 \%)$. Re porting of alimentary tract drugs is stbstantially improved when current use instead of all long. term drug use in the peniod $1984-1986$ is con. sidered.

Finally, sensitivity rates were determined when agreenent on a less detailed level of the

Table 6

Questionnawe recall of long term drug use per ype of drag, stratified by selented characteristics

\begin{tabular}{|c|c|c|c|c|c|c|}
\hline \multirow[t]{3}{*}{ Characteristic } & \multicolumn{6}{|c|}{ Type of drug } \\
\hline & \multicolumn{2}{|c|}{$\begin{array}{l}\text { alimeritery trat } \\
\text { centeal nervous system }\end{array}$} & \multicolumn{2}{|c|}{ candiowascular systuen } & \multicolumn{2}{|l|}{ wher her } \\
\hline & $\begin{array}{l}\text { Thmber of } \\
\text { pharmacy } \\
\text { records }\end{array}$ & recall $(\%)$ & $\begin{array}{l}\text { number of } \\
\text { pharmacy } \\
\text { necoteds }\end{array}$ & recall $(\%)$ & $\begin{array}{l}\text { number or } \\
\text { pharmacy } \\
\text { records }\end{array}$ & recall $(\%)$ \\
\hline All & 68 & 51.5 & 138 & 659 & 36 & 61.1 \\
\hline \multicolumn{7}{|l|}{ Gender } \\
\hline mert & 91 & 54.8 & 57 & 68.4 & 16 & 50.0 \\
\hline -... women & 37 & 48.6 & 81 & 64.2 & 20 & 70.0 \\
\hline \multicolumn{7}{|l|}{ Age (youts) } \\
\hline$-55-59$ & 25 & 56.0 & 38 & $\forall 1.1$ & 9 & 66.7 \\
\hline$-60 \cdot 64$ & 22 & 45.5 & 59 & 64.4 & 12 & 66.7 \\
\hline 6569 & 21 & 524 & 41 & 63.4 & 15 & 53.3 \\
\hline \multicolumn{7}{|l|}{$\begin{array}{l}\text { Duration of use } \\
\text { (months }\end{array}$} \\
\hline$\therefore \quad 6-11.9$ & 26 & 46.2 & 5.3 & 62.3 & 21 & 66.7 \\
\hline-12.23 .9 & 14 & 57.1 & 53 & 66.0 & 9 & 44.4 \\
\hline$-\geq 24$ & 28 & 53.6 & 32 & 71.9 & 6 & 666.7 \\
\hline \multicolumn{7}{|l|}{$\begin{array}{l}\text { Number of prescribed } \\
\text { drugs }\end{array}$} \\
\hline$\cdots 1$ & 9 & 学筩.8 & 11 & 72.7 & 4 & 50.0 \\
\hline--2 & 14 & 57.1 & 25 & 60.0 & 11 & 81.8 \\
\hline$\geq 3$ & 45 & 44.4 & 102 & 66.7 & 21 & 52.4 \\
\hline
\end{tabular}




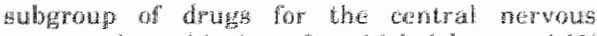

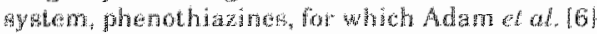
renorted low agrement betwen guestonare

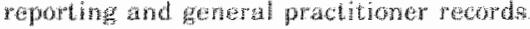

It ins unclear why recall of alimentary tract drage whe relatively por in our sudy population

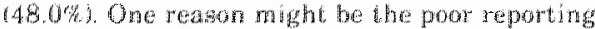
of prescriptions for weight loses none of the three prescriptions were reponted by respondents. Ex. duding this subgroup, the percentage recall would be $54.5 \%$ fro almentsuy tract drugh. Un. fortumately, no other investgatorg have lonked at this group of "arugs. A considerable improvement in drug reporting of this group was ob. berved when only current longtem hise was

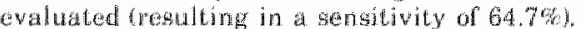

The guctionnaine contained an open-ended question on drug use. While a chosed question on drug the would load to a congiderable number of alserositives tin terms of exposure as found by Paganimi-Hon and Rosas $[5]$, an open-ended question would generally have very high specificity. which alan sesens to apply to occupational expostres 111\%. Thus, it aems that openendod questions may lead to less latse-positives but Wha also reduce the true postive rute or sensiWivity I 21. The seriousness of the consequerees of ebther an wevated falsepositive rate or an elevated false-negative bute depends on the purpose of the study.

Whereas rverall 61.2 of all long-term drug use was correcty reported by the respondents, roporting was better when drugs were used an the time of baseline mosumement in the cohort. The length of elupsed time since drugs were taken therofore may be an important determinant of recall. In occupational sethags, a do creased recall of expliew exposures such as work assignments has also been noted [1.1.

\section{Conclusion}

Tho sensitivity of dug recall as measured by a

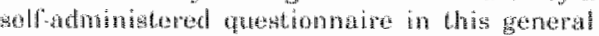
popolation cohorl. oompared to pharmacy rec.

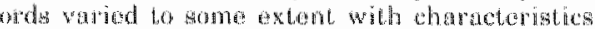
was are, duration of ase and number of preseribed

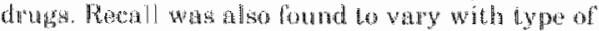
drug, with cardingseutan drugs showing the highost songitivy. When rectll sas andysed with regard to thesspente man groups, rather ditan on ehemical ontify lovel, recall was im

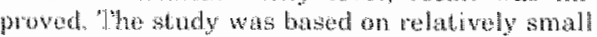
numbers and was atso limiled by the 30 month perive al coverage by the phamacy; atudy com prising a longer obsorwathon period is warranted to fur the ox tuate the infuence of duration of tase as a determinant of wecall. The aeterminants of druis recall quality were quite comparable to

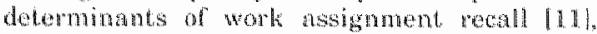
wheres los similarity wa noted wh sidudes on reall of medica cond tions [7]. Whether this is due to the diflerence in question style lopenended versus closed quentionsing intervew seting Gquestomane, telephone on personal. interyew and whether deteminants of recall are different fon ather exposure types regrites further mest. gation

This study indicates that $60.70 \%$, depending on

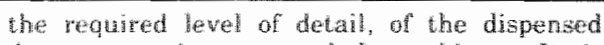
dragges are also reported by subjecis. It is interesting to note that this sensitivity lewel is comparable to the levels of comphare that are observed in many elnical trials on dregs. White meansurement of conpliance by questionnaire or interview is influenced both by the subjects" memony and his thue compliance, compliance mexsunements using an alectronic monitoring derice (MEMS) also indicate levels of $70 \%$ (13).

"Thus, whis there is undoubtedy underreport ing of the drug use in our questionnare the dispensing of drugs may pof necessarily imply then they are gilways used, althotugh regular rew fills of dug for long term use suggest a nertain degree of compliance. This underreporting and is postible relationship to compliance be haviour, as woll as quantiluation of both compannents warrant furher investigation.

\section{Acknowledgement}

This study was supported by the Dutch Cancer Society. We would like to thank the participants in this study, . Naus for prowding the phanacy reconds, $G$. Franssem, M. Bethlehem and P. Worax for their assistance, and U. Urquhart for useful comments on this manuscript.

\section{References}

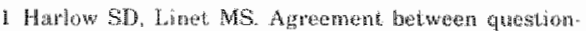

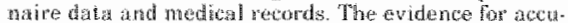
racy of recill, Am of pidentol $1989,129223-48$.

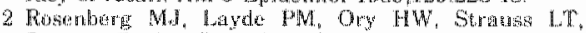
Bourno Tooks of Rubin Gl Apreement beween

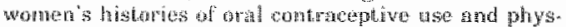

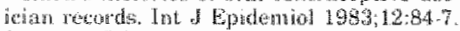

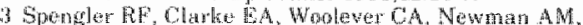

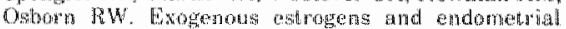
cuncer a casecothol study and assesement ol potem.

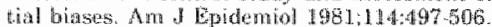

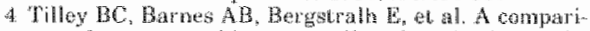

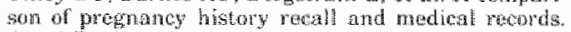

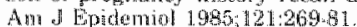

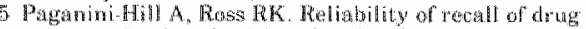

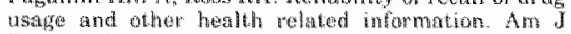

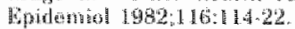

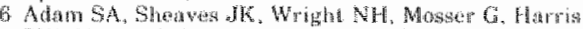

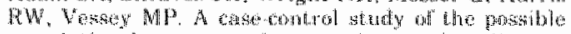

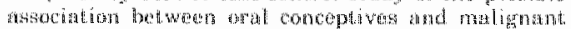
motanoma Br Hancer 1981) $44: 45 \cdot 50$

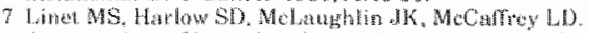

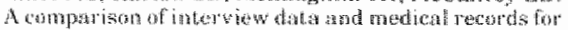

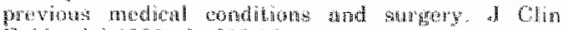
Fpidemol 1969-12:1207-13

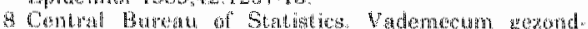

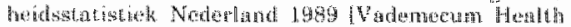

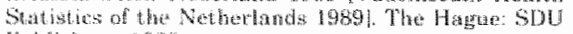

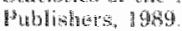

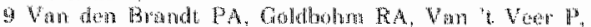

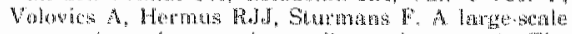

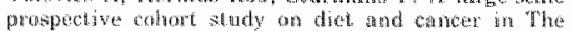

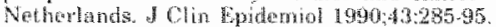

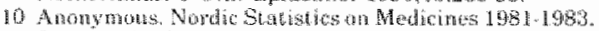

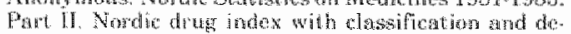
fined taily doses. Uppsalut Nordic Coumel on Medi aides, 1985

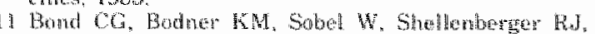

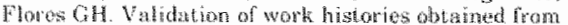

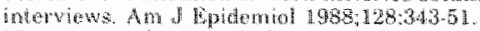

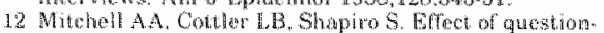

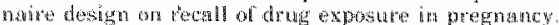

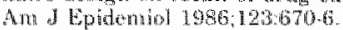

13 Gramer $\mathbb{K}$. Mation RH, prevey ML, Scheyer $\mathrm{RD}$,

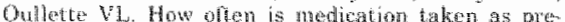

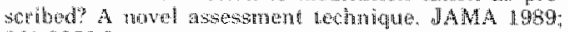
26020273 
studies on effects of industrial exposure, observational studies on effects of drugs are more likely to rase interpretation problems, especially if large, but incomplete databases are used, because the former involves mainly healthy workers and the latter involves mainly the sick and/or the elderly.

We thimk that for studies on channeling and prescribing practices in general, the prescription drug history will remain to be valuable as a separate source of information. In tuture, however, many studies will probably use computerized drug records, while additional information is collected from other records and from questionnaires or interviews. In this case, computerized records on drugs dispensed may be used as a source from which recipients of specific drugs are identified, e.g. for cohort tracing. Additional information on health status and relevant determinants are to be collected from records in general practice or in hospitals and by interviews. ${ }^{6}$

As concerns the availability of basic data, the health care insurers seems to be the most promising source. Data from comprehensive regional insurance schemes (e.g. Saskatchewan ) or, in the U.S., regional ones that cover subgroups in the population have been succesfully used for studies on drug effects. 8.9

In the Netherlands, the main insurers (ziekenfonds) have recorded information on many procedures in individual persons; these data were audited to control the degree of use of certain procedures. Data on reimbursment of drugs were, however, not filed on the level of the insured individual. This is changing now together with the introduction of a new auditing scheme in which data on the drugs that were dispensed are sent from the pharmacy to the ziekenfonds. Advantage should be taken of the availability of data on drugs dispensed and procedures, indications for procedures, and other diseaserelated information in one organization.

One of the conclusions of chapter 9 was that, in order to prevent mistakes with medication, it seems worthwile to transmit a drug history from the community pharmacy to the hospital whenever a patient is admitted. One of the prerequisites for such a procedure is that the drug history is reasonably complete, and this can only be achieved if the patient relies on one pharmacy. The ziekenfonds require that their clients choose a general practitioner and a dentist for their medical and dental care, and that they pationice une phamacy from which relmbursed arugs are to be obtained. This linkage of patients to caregivers facilitates health care tailored to the individual, with insight into his or her history. Periodically, the designated pharmacy system has been challenged on economical or political grounds. Its value as a source of integrated drug information should not be overlooked in this discussion.

A combination of health insurance regulations and practice of pharmacy in the Netherlands made possible the studies presented in this thesis. General practice in the Netherlands also has gained much from the fact that individual persons register with one family plysician. The patient file in general practice is of potential value for epidemiological studies because of this patient-doctor linkage, which helps to get a good medical history; use of computers will stimulate the use of this potential. We hope that, both for patient care itself and for its value for research, the linkage of individual patients to individual professionals in health care will renain. This linkage and the use of computers in various areas of health care will also enable a more instructive flow of information to and fro among the insurer, the pharmacist, and the practicing physician. 


\section{References}

1. (anonymous). FDA reforns - US implications. Scrip 1991: no. 1671: 18-20

2. (anonymous). FDA reforms: appause and opposition. Scrip 1991; no, 1672; 16-17

3. Bergman U. Pharmaco-epidemiological perspectives. Pharm Weekbl [Sci] 1989; 11: 151-154

4. Connell FA, Diehr $\mathbb{P}$, Hart $\mathbb{L G}$. The use of large dlata bases in health care studies. Ann Rev Public Health $1987 ; 8: 51-74$

5. Hasman A. Medical applications of computers: an overview. Int J Biomed Comput 1987; 20: 239-51

6. Leufkens HG, Ruter EM, Ameling CB, Hekster YA, Bakker A. Linkage of pharmacy dat on heavy users of nonsteroidal anti-inflammatory drugs to information from general practitioners. J Pharmacoepidemiol 1991; 2: 67-77

7. Strand LM, West R. Health data bases in Saskatchewan. In: Strom BL,ed. Pharmacoepidemiology. New York: Churchill Livingstone, 1989

8. Jick H, Madsen S, Nudelman PM, Perera DR, Stergachis A. Postmarketing follow-up at Group Health Cooperative of Puget Sound. Pharmacotherapy 1984; 4: 99-100

9. Friedman GD. Kaiser permanente medical care program: Northern California and other regions. In: Strom BL,ed. Pharmacoepidemiology. New York: Churchill Livingstone, 1989 

New drugs are registered for use in the general population after an elaborate process of development, toxicological studies, and randomized controlled trials. New knowledge about wanted and umwanted effects is also gained after the introduction of a drug for use in the general population. Pharmacoepidemiology is the study of characteristics of groups of recipients of specific drugs and of the effects of drugs in large populations.

Chapter 1 describes the structure of this thesis. Studies were done on different subjects, common for these studies is the analysis of drug histories of relatively large numbers of persons.

Chapter 2 provides an overview of the types of studies in phamacoepidemiology. A description is given of the various approaches in relation to the type and frequency of the problems to be studied. The many interpretation problems in observational studies on drug effects are reviewed. Whereas the availability of large databases with healthrelated information is now changing the field of pharmacoepidemiology, it is concluded that many of the interpretational problems will remain or may even worsen.

One of the issues is the quality of the data on drug exposure in pharmacoepidemiological studies. Our work centers on methods for ascertaining drug use and on methods to interpret drug histories of large groups of patients.

Chapter 3 describes the exposition data of our studies, Dutch pharmacy data, in relation to other types of information on drug dispense and drug use(questionnaires, pill counts, external monitoring, biological monitoring). The use of these pharmacy data for research purposes is described.

On account of insurance regulations, the majority of Dutch population have to choose one pharmacy from which all reimbursed drugs are to be obtained. Moreover, pharmacies in the Netherlands tend to be large and the majority keep patient drug histories on computer file. These circumstances make it possible to gather large numbers of complete or nearly-complete outpatient prescription drug histories from the general population. Patient anonymity is maintained as the histories leave the pharmacy with information on age and gender, but without name or address.

In chapter 4 the approach of prescription sequence analysis is presented. This method is applied for drugs with a possible side-effect that could lead to a condition for which specific drug therapy is available. If such side-effects indeed occur with any appreciable incidence, they would be revealed by a characteristic sequence of prescriptions in patients' drug histories. The technique is to be used to assess the risk of certain drugs in situations where an urgent need arises to obtain information about. the plausibility of reports of an adverse drug reaction.

An analysis was made of computerized drug histories of users of the antimigraine/anti-vertigo drug flunarizine, after the publication of case-reports suggesting that the drug might cause mental depression and parkinsonism. We selected the drug histories from patients who had received both flunarizine and an anti-depressant drug at some time in the available history. The initiation (i.e. "start") of antidepressant therapy was considered as to be a marker of the occurrence of mental depression. The occurrence of these starts were compared in the periods before, during and long after the dispensing of flumarizine. In the largest of our two studies (chapter $4 b$ ) the incidence of antidepressant starts was slightly higher during flunarizine use than before or long after. Consequently, the possibility that flumarizine induces drug-treated mental depression cannot be excluded, although the association found could be explained by alternative mechanisms.

An additional finding was that a remarkably large proportion of the recipients of flunarizine had received an antidepressant drug at some time during the available drug history. Therefore, it appears that flunarizine is prescribed to a group of patients for whom antidepressant drugs are frequently prescribed, presumably indicative of an 
unusual prevalence of depression oir depression-like symptoms in these patients. This kind of knowledge on the background of drug-treated persons should be relevant for other types of studies which try to distinguish a drug effect from a condition already present in the persons studied.

Chapter 5 describes an analysis of patients' drug histories that include inhaled steroids and topical oral anticandida medication. The use of inhalled steroids (A) can induce oral candidiasis, and we considered the dispensing of topical oral anticandida medication (B) to be a marker of oral candidiasis. Thus, A can cause oral candidiasis, while $B$ is a therapy for this condition. The approach of prescription sequence analysis of chapter 4 was used here, with modifications. In this analysis a positive association, though not a strong one, was found between exposure to inhaled steroids and start of anticandida drugs.

In chapter 6 the concept of channeling is presented. This phenomenon occurs when drugs with similar therapeutic indications are prescribed to groups of patients with a different health status or prognostic characteristics. Time of introduction or specific marketing claims may result in channeling of a new drug to a group of patients different firom the users of pharmacologically related drugs. A late-entry drug is more likely to be given to patients who have not responded satisfactorily to therapy with an established, early-entry drug. The claim that a drug causes few side-effects may lead to selective prescribing to patients with pre-existing morbidity. Consequently, more problems may be observed in a group of patients that is treated with a drug that should cause few problems. If chameling is not recognized, confounding by indication may be introduced in observational studies on drug effects.

Chapter 7 describes how three asthma drugs in one pharmacologic class, the beta-2 agonist class, are channeled to patients with a different severity of asthma, as expressed by concomitant medication. The drug histories of recipients of the inhalational beta-2 agonists salbutamol, fenoterol and terbutaline were compared for markers of severe or difficult-to-treat asthma, diabetes and cardiovascular conditions. We considered the use of systemic corticosteroids by asthmatics to be such a marker of severe or difficult-totreat asthma. In a database covering the medication of 121,000 persons the drug histories af recipients of one of the three inhalational beta- 2 agonists were retrieved and andyzed. We found 2-2.5 times more co-medication with systemic steroid drugs in the group of recipients of fenoterol than in the recipients of salbutamol. Terbutaline recipients were intermediate. Also, the proportion with one or more other asthma drugs was highest among fenoterol recipients and lowest among salbutamol recipients; terbutaline was again intermediate in this respect. Therefore, it appears that Dutch physicians prescribe terbutaline and fenoterol to patients with more severe forms of asthma than salbutamol.

In Chapter 8 a study on the channeling of antidepressant drugs is presented. The labelling of most of these drugs set various restrictions with respect to prescribing to patients with cardiovascular co-norbidity; for some of the antidepressants no such restrictions are given. Our question was whether these differences in labelling were reflected in selective prescription of certain antidepressants to persons with cardiovascular conditions.

The primary data were extracted from a drug database covering a population of approximately 130,000 persons, of whom 1173 had received an antidepressant within a six month time frame. As a marker of cardiovascular disease we considered medication with one or more cardiovascular drugs. The recipients of the various antidepressant drugs differed considerably with respect to the dispensed medication for cardiovascular conditions. Relatively high in this respect were recipients of mianserin $(36 \%)$ and 
doxepin (35\%); at the low end were fluoxetine (13\%) and clomipramine (18\%). However, the groups of recipients of the antidepressants varied considerably as to age and sex and after stratification for these two variables no significant residual differences remained with respect to cardiovascular comedication. Apparently, channeling occurs with some drugs, but partly via the indirect way of age/sex differences of the recipients of antidepressants.

The results of the analysis show that the antidepressants that are specifically suited for persons with pre-existing cardiovascular conditions are not all used to the same extent by these patients. It is discussed how time of introduction and marketing activities may have had a role in these differences.

The work presented in chapter 9 was inspired by literature reports on a problem of unintended cessation of medication in patients who are admitted to hospital. In view of this, we studied the continuity of medication of a group of patients admitted to a Dutch hospital. Outpatient drug histories from the only pharmacy in one of the towns in the hospital's catchment area were matched to records of drugs dispensed to patients during their stay in the near-by hospital. The hospital and community pharmacy records of 205 patients were reviewed with the help of an expert panel. The discrepancies were classified by this panel as to their potential seriousness. When we found what appeared to be serious discrepancies, we consulted the patient's medical record to ascertain, from the subsequent course of events, whether the stopping of medication had been inadvertent or purposeful. The panel judged 68 "stops", involving 41 patients, as potentially hazardous if done accidentally. Examination of the medical records led to the conclusion that 15 inadvertent drug discontinuations of a more serious nature occurred, involving 12 patients.

The results are not necessarily representative of the overall Dutch situation, but they indicate that there are errors that can be reduced. Improvement is suggested by transmission of computerized data from the community pharmacy to the hospital whenever a patient is admitted.

Chapter 10 describes a study on the validity of information from a patient questionnaire on chronic use of drugs. This questionnaire was used in a large-scale prospective cohort study on diet, other lifestyle factors (such as long-term drug use) and the incidence of cancer. The validity of the information on drug use was investigated by comparing the questionnaire data with pharmacy records on dispensed drugs. The validation study was conducted in a municipality served by one pharmacy for the persons who had returned the questionnaire.

All drugs mentioned in the questionnaire to be used at the moment of the baseline measurement were traceable in the pharmacy record. Since there were no errors of commission, i.e. drugs mentioned but not dispensed in the pharmacy, the analyses were focussed on errors of omission, drugs dispensed but not mentioned in the questionnaire. Of the 207 cohort members 69 chronically received drugs at the time of the baseline measurement. On average, these participants received 1.9 drugs for at least 6 months. Overall, $68.8 \%$ of current long-term use was correctly reported. Drugs chronically dispensed but whose use ceased before the baseline measurement were reported less adequately.

In conclusion, the open-ended question on drug use had a high specificity but a rather low sensitivity, i.e. the absence of false positive answers is accompanied by defaults in the reporting of drugs that were dispensed to the cohort members. Relevant for other studies in pharmacoepidemiology is the high reliability of pharmacy data when a history of the drugs received by individuals is required. 
The epilogue gives an overview of the work presented in this thesis and some of its implications. The opportunities for future studies are discussed, especially for the field of record linkage. It is concluded that the prescription drug history has a value in research both as a separate source of information and in combination with other healthrelated data. The value of longer drug histories, as could be built up in pharmacies or by insurers, is emphasized for surveys of changes of pharmacotherapeutic practices and for studies on long-term effects of drugs.

Reliable prescription drug histories are a cornerstone of pharmacoepidemiology. Practices in Dutch health care and regulations of insurers have stimulated the adherence of patients to one pharmacy, analogous to the adoption by patients of a general practitioner and a dentist. This linkage of individual patients to individual professionals in health care has advantages both for patient care and for research purposes; for these reasons its continued existence is advocated. 
De toelating van nieuwe geneesmiddelen gebeurt na een uitgebreid proces vam ontwikkeling, toxicologische studies en een zg. klinusche trial. Nieuwe kennis over gewenste en ongewenste werkingen wordt vak ook nog verkregen na introductie van een middel voor gebruik in de algemene bevolking. Farmaco-epidemiologie is de studie van kenmerken van gebruikers van geneesmiddelen en van de effecten van deze mididelen in de bevolking.

Hoofdstuk 1 beschrijft de opzet wan het proefschrift. Studies over verschillende onderwerpen worden gepresenteerd in dit proefschrift, gemeenschappelijk is de analyse van medicatiegeschiedenissen van een relatief groot aantal mensen.

Hoofdstuk 2 is een algemene inleiding over onderzoek op het terrein van de farmaco-epidemüologie. Verschillende benaderingen worden besehreven, in relatie met. het type en de frequentie van het te onderzoeken probleem. De vele interpretieproblemen bij observationeel onderzoek naar effecten van geneesmiddelen komen aan de orde. De toenemende beschikbaarheid van grote geauromatiseerde databestanden heeft de mogelijkheden voor populatiegericht onderzoek naar effecten van geneesmiddelen vergroot; wel is het zo dat veel interpretatieproblemen zullen blijven of zelfs kunnen toenemen.

Het is belangrijk in farmaco-epidemiologisch onderzoek dat gegevens net betrekking tot het gebruik van geneesmiddelen volledig zijn. Centraal in ons werk staat de methodiek van het verzamelen en interpreteren van medicatiegeschiedenissen van grote groepien patiënten.

Hoofdstuk 3 beschrijft het voor ons onderzoek gebruikte materiaal, gegevens zoals bewaard in apotheken met een geautomatiseerd databeheer, in vergeiijking met andere types informatie over gebruik van geneesmiddelen: patiënt-vragenlijsten, tellingen van niet gebruikte medicatie, externe monitoring en biologische monitoring. De toepassing van de apotheekgegevens voor onderzoek wordt beschreven.

Als gevolg van regels van de ziekenfondsen moet een meerderheid van de bevolking in Nederland een vaste apotheek uitkiezen. Verder is het zo dat de apotheken in Nederland relatief groot zijn en meestal de medicatiegeschiedenis van patiënten in een computerbestand bewaren. Door deze omstandigheden is het mogelijk grote aantallen bijna volledige of volledige medicatiegeschiedenissen te verzamelen. De anonimiteit van patiënten wordt beschermol cloordat de medicatiegeschiedenissen de apotheek verlaten met informatie over leeftijd en sekse, maar zonder naam of adres van de patient.

Hoofdsuk 4 geeft een beschrijving van de benadering van prescriptie-sequentie analyse. Deze methode is toe te passen voor bijwerkingen van geneesmiddelen die leiden tot een toestand waarvoor specifieke medicamentewze therapie beschikbaar is. Als een dergelijke bijwerking optreedt moet dit zijn weerslag hebben in de medicatiegeschiedenis van patienten. De benadering is bedoeld om, als casuistische meldingen daartoe aanleiding geven, op korte termijn het mogelijke risico van een middel te onderzoeken. Naar aanleiding van meldingen over depressie en parkinsonisme na gebruik van flunarizine, een middel voorgeschreven bij migraine en duizeligheid, analyseerden we medicatiegeschiedenissen van ontvangers van dit middel. Uit geautomatiseerde apotheekbestanden selecteerden we de medicatiegeschiedenissen van personen die zowel flunarizine als een antidepressivum hadden ontwangen. De eerste aflevering (d.i. de "start") van een periode van therapie met een antidepressivum is beschouwd als indicatie van het optreden van medicamenteus behandelde depressie. Het optreden van deze starts is vergeleken in de periodes voor, tijdens, en lang na het afleveren van flunarizine. In de anallyse die de meeste gegevens omvatte (hoofdlstuk 4b) was de incidentie van starts van therapie met antidepressiva tijdens gebruik van flunarizine enigszins hoger dan in de periodes voor of lang na gebruik van flunarizine. 
Op grond wan dit resultaat kan niet worden uitgesloten dat gebruik van flunarizine medicamenteus behandelde depressie induceert, al is de associatie met andere mechanismen te verklaren.

Een ander resultaat van dit onderzoek was dat een opmerkelijk groot deel van de ontvangers van flumarizine in de periode die bestreken werd door de medicatiegeschiedenissen ook ooit cen antidepressivum had ontvangen. Kennelijk wordt flunarizine voorgeschreven aan een groep patiënten met een grote consumptie van antidepresiva, wat suggereert dat depressie of depressie-achtige verschijnselen in deze groep patienten op rume schaal wook komt. Dit soort kennis over de achtergrond van personen lijkt relevant voor vele soorten onderzoek waarbij een effect wan een geneesmiddel onderscheiden moet worden van een al bestaande toestand bij patiènten.

Hoofdstuk 5 beschrujft een analyse van patiênt-medicatiegeschiedenissen die afleveringen omvatten wan inhalatiesteroiden en medicatie tegen candida-infecties in de mond. Het gebruik wan inhalatiesteroiden (A) kan orale candida-infecties (B) induceren. We beschouwden een aflevering van lokale orale candidamedicatie als indicatie vam het optreden wan een candida-infectie in de mond. Met andere woorden, A kan de lokale candida-infectie veroorzaken, $\mathrm{B}$ is de therapie ertegen.

De in hoofdstuk 4 voorgestelde methode van prescriptie-sequentie analyse is met enkele modificaties hier toegepast. In deze analyse is een positief, hoewel niet sterk, verband gevonden tussen het gebruik van inhalatiesteroiden en de start van medicatie met een anti-candidamiddel.

In hoofdsitk 6 wordt het concept "channeling" (leiden, sturen) geintroduceerd. Dit verschijnsel treedt op als geneesmiddelen met eenzelfde therapeutische indicatie worden woorgeschreven aan groepen patiënten die verschillen wat betreft gezondheid of prognostische eigenschappen. Het tijdstip van introductie of specifieke promotionele activiteiten van de fabrikant kunnen resulteren in channeling wan een nieuw middel nar een groep patiënten die verschilt van de gebruikers van farmacologisch verwante middelen. Een later geintroduceerd middel zal met name ook worden voorgeschreven aan mensen waarbij therapie met een ouder, gevestigd middel geen sukses was. Een bewering dat een middel weinig bijwerkingen heeft kan leiden tot het selektief voorschrijven ervan aan patiënten met veel morbiditeit in de voorgeschiedenis. Als gevolg hiervan kunnen meer problemen worden gezien in de groep patiënten die wordt behandeld met een middel dat juist weinig problemen zou moeten veroorzaken. Als chameling niet wordt onderkend kan vertekening van de resultaten optreden in observationeel onderzoek naar effecten van geneesmiddelen.

Hoofdsuk 7 laat zien dat drie farmacologisch verwante astmamiddelen worden voorgeschreven aan groepen patiënten met een verschillende graad van ernst van astma, zoals deze tot uiting komt in comedicatie. De medicatiegeschiedenissen van ontvangers van te inhaleren vormen van salbutamol, fenoterol en terbutaline zijn vergeleken wat betreft indicaties voor de aanwezigheid van ernstige of moeilijk te behandelen astma, diabetes en cardiovasculaire aandoeningen. We beschouwden het gebruik van systemische glucocorticosteroiden als zo'n indicatie voor de aanwezigheid van ernstige of moeilijk te behandelen astma. In een databestand dat de medicatie van 121.000 personen onvatte, zijn de medicatiegeschiedenissen van de ontvangers van salbutamol, fenoterol en terbutaline geselecteerd en geanalyseerd. Bij de groep ontvangers van fenoterol vonden we, in vergelijking met de ontvangers wan salbutamol, 2-2,5 maal vaker comedicatie met systemische steroiden. Ontwangers van terbutaline hadden wat dit betreft een tussenpositie. Ook het aantal patiënten met én of meer andere astmamiddelen was het hoogst voor fenoterol en het laagst voor salbutamol.

Terbutaline had hier weer een tussempositie. Concluderend lijkt het erop dat artsen in 
Nederland fenoterol en terbutaline, in vergeliking met salbutamol, aan patienten met meer ernstige vormen van astma voorschrijven.

In hoofdsuk $\$$ wordt een onderzoek naar chanding van antidepressiva gepresenteerd. De bijsluiter van de meeste middelen in deze groep stelt beperkingen ten aanzien van de toepassing bij patiënten met een cardiovasculaire aandoening; bij enkele antidepressiva was er geen sprake van een contra-indicatie op dit terrein. Onze vraag was of deze verschillen in de bijsluiter samenhangen met de mate waarin de verschillende antidepressiva worden voorgeschreven aan patiënten met een cardiovasculaire aandoening.

De gegevens waren afkomstig uit een medicatie-databestand dat een bevolking van 130.000 mensen bestrijkt; 1173 personen hadden in een tijdspanne van zes maanden een antidepressivum ontvangen. Afgifte van eén of meer cardiovasculaire middelen is beschouwd als indicatie voor de aanwezigheid van een cardiovasculaire aandoening. De groepen ontvangers van diverse antidepressiva verschilden sterk wat betreft de mate van comedicatie in verband met cardiovasculaire aandoeningen. Deze medicatie was afgeleverd aan een relatief groot deel van de groep ontvangers van mianserine $(36 \%)$ en doxepine (35\%); relatief klein was dit aandeel bij de ontvangers van fluoxetine (13\%) en clomipramine (18\%). Er moet worden opgemerkt dat de groepen ontwangers van de diverse antidepressiva sterk verschilden wat betreft de verdeling van leeftijd en sekse, en na stratificering voor deze variabelen waren er geen residuele significante verschillen wat betreft cardiovasculaire comedicatie. Er was bij enkele middelen sprake van channeling, maar kennelijk gedeeltelijk indirect, via verschillen in leeftijd en sekse van de ontvangers van de antidepressiva.

De analyse laat zien dat antidepressiva die geschikt zijn voor patiënten met een aanwezige cardiovasculaire aandoening toch niet relatief valk worden voorgeschreven aan deze groep patienten. Besproken wordt hoe het tijdstip van introductie en promotionele activiteiten van de fabrikant een rol kunmen hebben bij het ontstaan van de gevonden verschillen.

Hoofdsuk 9 beschrijft een onderzoek dat gedaan is naar aanleiding van publicaties over onbedoeld stoppen van het gebruik van geneesmiddelen bij opname in het ziekenhuis. In dit kader onderzochten we de continuïteit van medicatie bij een groep in het ziekenhuis opgenomen patiënten. Medicatiegeschiedenissen afkomstig van de enige apotheek in een dorp in het verzorgingsgebied van het ziekenlwis werden vergeleken met gegevens over tijdens het ziekenhuisverbliff afgeleverde medicatie. De gegevens van de openbare en de ziekenhuisapotheek werden voor 205 patienten vergeleken door een panel van deskundigen op het terrein van farmacotherapie. Discrepanties werden door het panel ingedeeld op grond van de potentièle mate van ernst. Als de discrepanties ernstig leken gingen we in medisch dossier na of de medicatie bij de opname bewust was afgebroken. Het panel beoordeelde 68 "stops", die 41 patiênten betroffen, als potentieel riskant als deze stops het gevolg zouden zijn van een vergissing. Bestudering van de medische dossiers leidde tot de conclusie dat 15 afbrekingen niet bedoeld waren; hierbij waren 12 patiënten betrokken.

Deze bevindingen zijn niet noodzakelijkerwijs representatief voor de gang wan zaken bij opname in het ziekenhuis in het algemeen, wel is er de suggestie dat er vermijdbare fouten worden gemaakt. Overdracht van gegevens van de openbare apotheek naar het ziekenhuis langs elektronische weg wordt gesuggereerd om de anamnese bij opname van patiënten te ondersteunen.

Hoofdstuk 10 beschrijft een onderzoek naar de kwalliteit van informatie verkregen met een schriftelijke vraag over chronisch gebrulk wan geneesniddelen. De vaag was onderdeel van een vragenlijst die gebruikt is in het kader van een groot prospectief 
onderzoek naar de invloed van voedingsgewoonten en andere met leefstijl samenhangende factoren (zoals chronisch gebruik van geneesmiddelen) op het optreden van kanker. De betrouwbaarheid van de informatie over geneesmiddelgebruik uit de vragenlijst werd onderzocht door de gegevens van de vragenlijst te vergelijken met in de apotheek bewaarde informatie over afgelewerde medicatie. De vergelijking werd uitgevoerd in een gemeente met éen apotheek voor personen die de vragenlijst ingevuld hadden teruggestuurd.

Alle geneesniddelen waarvan in de vragenlijst was opgevoerd dat ze werden gebruikt op het moment van de enquête waren ook geregistreerd in het historisch bestand van de apotheek. Omdat er in de vragenlijsten geen middelen waren opgevoerd die niet waren afgeleverd in de apotheek, hebben we het apotheekbestand als referentie beschouwd en geanalyseerd hoe volledig er was geantwoord op de viaag naar chronisch gebruikte geneesmiddelen. Van de 207 leden van het cohort ontvingen er 69 chronisch medicatie toen de enquête werd uitgevoerd. Gemiddeld ontvingen deze 69 personen 1,9 middelen op chronische basis, d.i. gedurende een periode van minstens zes maanden. Van deze afgeleverde middelen is $68,8 \%$ ( 88 van 128 ) in de antwoorden van de vragenlijst terug te vinden. De middelen die wel op chronische basis waren afgeleverd, maar waarbij dit was opgehouden ruim voor de enquête, werden relatief minder frequent opgevoerd in de vragenljist.

De conclusie was dat de open vraag over gebruik van geneesmiddelen een hoge specificiteit maar een lage sensitiviteit had, d.w.z. de afwezigheid van fout-positieve antwoorden ging samen met lacunes in het opgeven van de middelen die waren afgeleverd aan de leden van het cohort. Belangrijk in verband met onderzoek op het terrein van de farmaco-epidemiologie is hier de hoge betrouwbaarheid van de individuele medicatiegeschiedenis zoals deze in de apotheek wordt bewaard.

In de epiloog komen de methoden en enkele implicaties van de resultaten van het werk voor dit proefschrift aan de orde. Benaderingen voor nieuw onderzoek worden besproken, met name het koppelen van verschillende informatiebestanden in de gezondheidszorg, de $\mathrm{zg}$. record linkage. De conclusie is dat patiëntmedicatiegeschiedenissen informatieve waarde hebben in geissoleerde vorm en in combinatie met andere gezondheidsgebonden gegevens. In apotheken en bij verzekeraars zijn in principe langere medicatiegeschjedenissen op te bouwen, deze hebben warde in het kader van de bestudering van veranderend therapiebeleid en voor onderzoek naar lange-termijn effecten van geneesmiddelen.

Betrouwbare medicatiegeschiedenissen zijn een hoeksteen van de farmacoepidemiologie. De ziekenfondsen, en de gezondheidszorg in het algemeen in Nederland, hebben bevorderd dat patiënten én apotheek bezoeken, analoog aan de inschrijving bij een huisarts en een tandarts. Deze verbinding tussen individuele patiënten en individuele hulpverleners in de gezondheidszorg heeft voordelen in het kader van de zorg en ook woor onderzoek; het blijven bestaan van deze verbinding wordt bepleit. 


\section{Articles}

The articles marked with an asterisk $\left({ }^{*}\right)$ are reproduced in this thesis

Petri $H$, Arends BG, Van Baak MA. The effect of verapamil on cardiovascular and metabolic responses to exercise. Eur J Appl Physiol 55: 499-502 (1986)

Van Baak M, Boehm RO, Petri H, Mooy JM, Rahn K-H. Comparison ofthe metabolic effects of propanolol and verapamil during exercise in hypertensive patients. $J$ Hypertension: S183-S185 (1986)

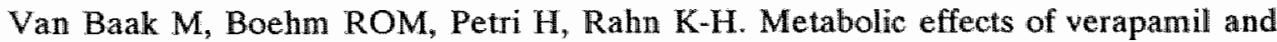
propranolol during submaximal endurance exercise in patients with essential hypertension. Int J Sports Med 8: 270-274 (1987)

Petri H, De Vet HCW, Sturmans F. Farmaco-epidemiologie: een retrospectieve bijdrage aan veiligheid? [Pharmaco-epidemiology: a retrospective contribution to safety?] Pharm Weekbl 122: 145-149 (1987)

* Petri H, De Vet HCW, Naus J, Urquhart J. Prescription sequence analysis: a new and fast method for assessing certain adverse reactions of prescription drugs in large populations. Statist Med 7: 1171-1175 (1988)

Petri H, Touw D. De bijwerking betrapt: de medicatiegeschiedenis als indicator van een mogelijke bijwerking [An ADR caught: the drug history as an indicator of a possible adverse drug reaction] Pharm Weekbl 124: $923-925$ (1989)

* Petri H, Leufkens H, Naus J, Silkens R, van Hessen P, Urquhart J. Rapid method for estimating the risk of acutely controversial side effects of prescription drugs. $J$ Clin Epidemiol 43: 433-439 (1990)

* Van Hessen P, Petri H, Urquhart J. Do prescribed drugs always follow the patients to hospital? Pharm Weekbl Sci Ed 12: 66-70 (1990)

* Petri $\mathrm{H}$, Urquhart $\mathrm{J}$. Channeling bias in the interpretation of drug effects. Statist Med 10: $577-581$ (1991)

* Petri $H_{*}$ Urquhart J, Herings R, Bakker A. Characteristics of patients prescribed three different inhalational beta- 2 agonists: an example of the channeling phenomenon. Post Market Surveill 5: 57-65 (1991)

* Petri H, Kessels F, Kamakura T. Markers of adverse drug reactions in medication histories: an analysis of inhaled steroid utilization. Pharm Weekbl Sci Ed 13: 97-101 (1991)

* Brandt P van den, Petri H, Dorant E, Goldbohm RA, Crommert S van de. A comparison of questionnaire information and pharmacy data on drug usage. Pharm Weekbl Sci Ed 13: $91-96$ (1991) 


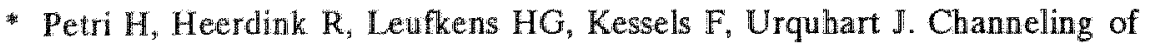
antidepressant drugs to patients with cardiovascular disease. Post Market Surveill 5: $159-167(1991)$

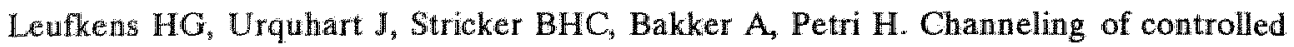
release formulation of ketoprofen (Oscorel) in patients with history of gastrointestinal problems. J Epidemiol Comm Health. (in press)

\section{Reports, Conference Proceedings}

Petri H, Kamakura T. Logistic regression models for markers of drug effects in medication histories. Technical Report No 132. Division of Biostatistics, Stanford University, 1989

Petri H, Sturmans F. Data linkage and intervention: a perspective. In: Progress in clinical pharmacy, proceedings of the 18 th European Symposium on Clinical Pharmacy. pp 63-71 (1990)

Petri H, Vander Stichele R, Boffin N. Geneesmiddelengebruik en voorschrijfgedrag [Drug utilization and prescribing behaviour]. Brussel: IFEB/IPhEB (1991)

Petri H. Vander Stichele R, Boffin N. Usage de medicaments et mode de prescription [Drug utilization and prescribing behaviour]. Bruxelles: IPhEB/IFEB (1991)

\section{Abstracts and other publications}

Mooy J, Boehm R, Petri H, Van Kemenade J, Van Baak M, Rahn K-H. The effects of verapramil and of propranolol on exercise tolerance in hypertensive patients.

Hochdruck 5: 46-47 (1985)

Petri H, De Vet HCW, Urquhart J, Naus J. The assessment of an adverse drug reaction by means of prescription sequence analysis. Pharm Weekbl Sci Ed 9: 142 (1987)

Petri H. Leufkens HGM, Van Hessen P, De Vet HCW, Urquhart J. Does flunarizine cause depression? A study by means of prescription sequence analysis. I Clin Res Drug Devel 2: 193-194 (1988)

Petri H, Sturmans F. Data linkage and intervention: a perspective. Pharm Weekbl Sci Ed 11 Suppl I: 5 (1989)

Petri H. Extrapiramidale bewegingsstoornissen na gebruik van flunarizine? [extrapyramidal motor dysfunction after use of flunarizine?] (letter) Ned Tijdschr Geneesk 133: 131 (1989)

Petri H, Urquhart $J$. Channeling of aerosol beta agonists and the interpretation of a concomitant adverse reaction. J Clin Res Drug Dev 3: 224 (1989)

Petri H, in: Phaf CWR en van Waardhuizen JP (red). Antimicrobiële farmacotherapie. deel II Bezinning op routine. (comments) Beecham Farma. ISBN 90-71428-06-0 (1990) 
Petri H, Leufkens HGM, Van Hessen $P$, Urquhart J. Prescription sequence analysis to assess adverse drug reactions. Pharm Weekbl Sci Ed 12, Suppl A: 5 (1990)

Petri $H$, Herings $R M C$, Urquhart J. Channeling of fenoterol and terbutaline to patients with a marker of severe asthma. Pharm Weekb] Sci Ed 12, Suppl F: 6 (1990)

Petri H. Heerdink ER, Leufkens HGM. Channeling of antidepressant drugs to patients with a marker of cardiovascular disease. I Clin Res Pharmacoepidemiol 5: 155 (1991)

Petri H, Leufkens HGM. Geneesmiddelengebruiksstudies en farmaco-epidemiologie [Studies on drug utilization and pharmaco-epidemiology] (report on symposium) Pharm Weekbl 126: 65 (1991)

Petri H, Heerdink R, Leufkens HG, Kessels F, Urquhart J. Differences in channeling of antidepressants drugs to persons with a cardiovascular condition. Pharm Weekbl Sci Ed 13, Suppl K:6 (1991) 

Graag wil ik verschillende mensen bedanken die, direkt of indirekt, betrokken waren bij het werk dat geleid heeft tot dit proefschrift.

Van mijn beide promotores heeft prof. Ferd Sturmans ervoor gezorgd dat het projekt indertijd van de grond kon komen; zijm belangstelling en steun hebben ook verder bijgedragen aan de voortgang van het werk. It was a great pleasure to work with prof. John Urquhart. Our discussions have broadened my view on many subjects. The engaging way how he organizes his activities have also been been very stimulating to me.

Fons Kessels was een onmisbare adviseur bij de analyse van de verzamelde gegevens. Fons, je was ook een goede overbuuman op de afdeling en ik ben blij dat je én van mijn paranimfen bent.

Jack Naus was al vanaf het begin van het onderzoek de middelaar bij het verzamelen van gegevens uit apotheken en daarmee een steunpilaar van het onderzoek.

Met prof. Albert Bakker, Bert Leufkens, Ron Herings en Rob Heerdink van Utrechtse faculteit farmacie heb ik in een aantal projekten prettig samengewerkt.

Binnen de vakgroep heeft een goede samenwerking met Paulien van Hessen en Piet van den Brandt geleid tot twee artikelen die in dit proefschnift te lezen zijn. In de begintijd van het projekt heeft Riekie de Vet ook een bijdrage aan het werk geleverd.

Reinhilde Silkens en Ed Gronenschild hebben ervoor gezorgd dat de gegevens door de computer verwerkt konden worden.

Thum Aarts was regelmatig een ad hoc leraar tekstverwerking; ook is de uiteindelijke vormgeving van dit boekje vooral door hem verzorgd.

Verder dank ik al degenen die op de één of andere manier aan de totstandkoming van dit proefschrift hebben bijgedragen. 

Hans Petri is geboren op 5 september 1954 te Leiden. De eerste schooljaren waren te Dakar (Senegal). Het VWO-diploma werd te Zutphen behaald in 1974. In hetzelfde jaar ving hij aan met de studie psychologie aan de Universiteit van Amsterdam (propaedeuse 1975). Aan de Rijksuniversiteit Limburg (RL) studeerde hij vanaf 1976 geneeskunde. Het artsexamen is afgelegd in 1982. Hij doorliep in 1983-1984 de huisartsopleiding en in 1985-1986 de door de RL ingestelde huisartsonderzoekeropleiding; in dat kader deed hij bij prof. K.H. Rahn onderzoek op het terrein van de klinische farmacologie. Tussendoor was er een periode van warneming in de huisartspraktijk en bij een bedrijfsgeneeskundige dienst. Vanaf 1986 is hij als toegevoegd onderzoeker werkzaam bij de vakgroep Epidemiologie van de RL; bij prof. J. Urquhart en prof. F. Sturmans is het onderzoek gedaan dat geleid heeft tot dit proefschrift. Tevens is hij als consulent verbonden aan het Instituut voor Farmacoepidemiologie van België (Brussel). 